Argonne

\title{
Verification of Historical System Transient Simulations for the RHF Research Reactor
}

Nuclear Engineering Division 


\begin{abstract}
About Argonne National Laboratory
Argonne is managed by UChicago Argonne, LLC

U.S. Department of Energy under contract DE-AC02-06CH11357. The

Laboratory's main facility is outside Chicago, at 9700 South Cass

Avenue, Argonne, Illinois 60439. For information about Argonne and its

pioneering science and technology programs, see www.anl.gov.
\end{abstract}

\title{
DOCUMENT AVAILABILITY
}

Online Access: U.S. Department of Energy (DOE) reports produced after 1991 and a growing number of pre-1991 documents are available free via DOE's SciTech

Connect (http://www.osti.gov/scitech/)

Reports not in digital format may be purchased by the public from the National Technical Information Service (NTIS):

U.S. Department of Commerce National

Technical Information Service 5301

Shawnee Rd

Alexandra, VA 22312

www.ntis.gov

Phone: (800) 553-NTIS (6847) or (703) 605-6000

Fax: (703) 605-6900

Email: orders@ntis.gov

\author{
Reports not in digital format are available to DOE and DOE contractors from the \\ Office of Scientific and Technical Information (OSTI): \\ U.S. Department of Energy \\ Office of Scientific and Technical Information \\ P.O. Box 62 \\ Oak Ridge, TN 37831-0062 \\ www.osti.gov \\ Phone: (865) 576-8401 \\ Fax: (865) 576-5728 \\ Email: reports@osti.gov
}

\footnotetext{
Disclaimer

This report was prepared as an account of work sponsored by an agency of the United States Government. Neither the United States Government nor any agency thereof, nor UChicago Argonne, LLC, nor any of their employees or officers, makes any warranty, express or implied, or assumes any legal liability or responsibility for the accuracy, completeness, or usefulness of any information, apparatus, product, or process disclosed, or represents that its use would not infringe privately owned rights. Reference herein to any specific commercial product, process, or service by trade name, trademark, manufacturer, or otherwise, does not necessarily constitute or imply its endorsement, recommendation, or favoring by the United States Government or any agency thereof. The views and opinions of document authors expressed herein do not necessarily state or reflect those of the United States Government or any agency thereof,
} Argonne National Laboratory, or UChicago Argonne, LLC. 
ANL/RTR/TM-15/5

\section{Verification of Historical System Transient Simulations for the RHF Research Reactor}

This work is sponsored by the

prepared by

J.R. Licht ${ }^{1}$, A. Bergeron ${ }^{1}$ and B. Dionne ${ }^{1}$

${ }^{1}$ Nuclear Engineering Division, Argonne National Laboratory, Argonne, IL 60439

and

F. Thomas ${ }^{2}$

${ }^{2}$ RHF Reactor Department, Institut Laue-Langevin (ILL)

September, 2017

U.S. Department of Energy, National Nuclear Safety Administration (NNSA),

Office of Material Management and Minimization (NA-23) Reactor Conversion Program 


\section{Table of Contents}

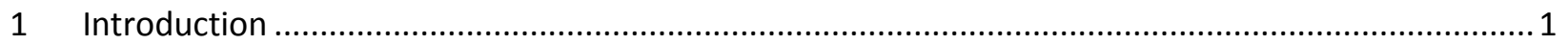

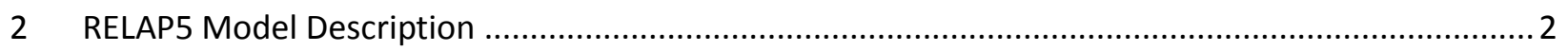

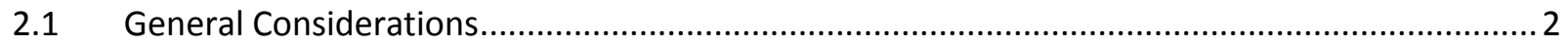

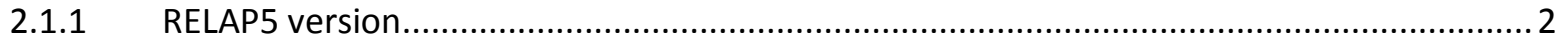

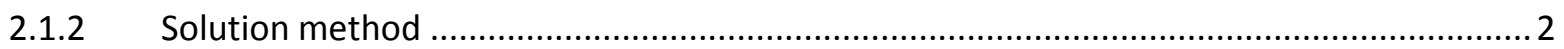

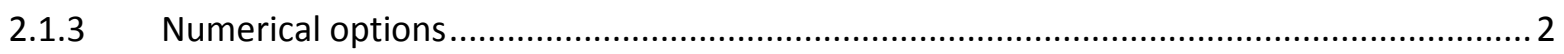

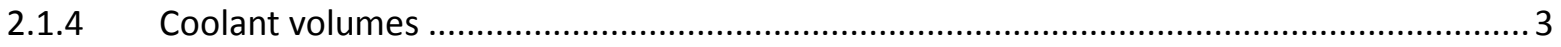

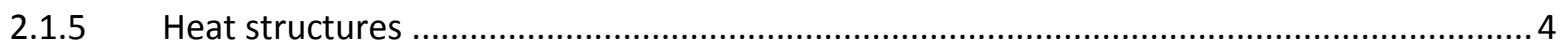

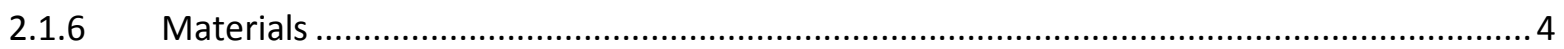

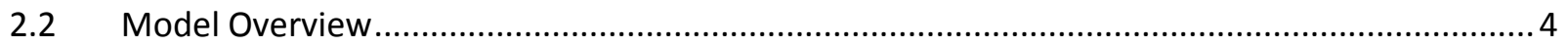

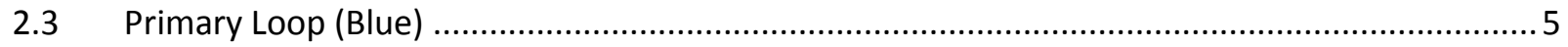

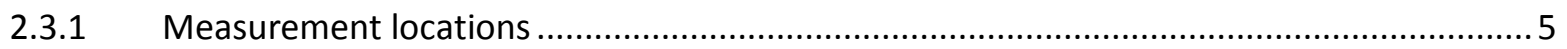

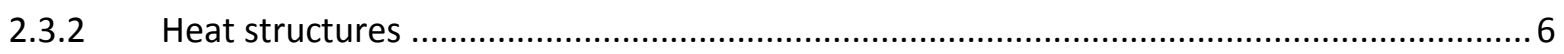

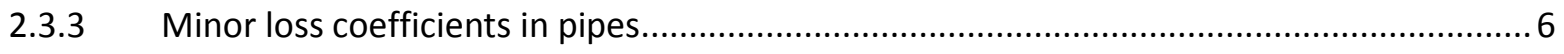

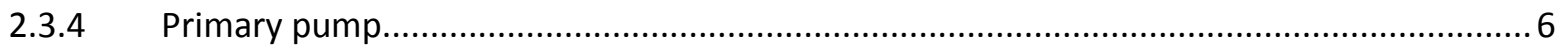

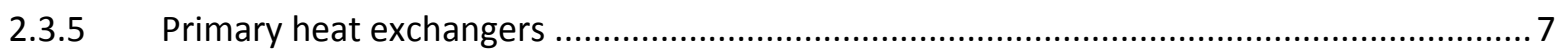

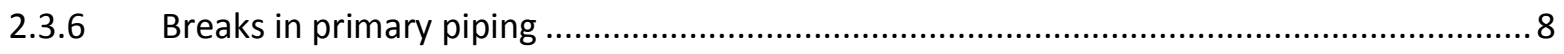

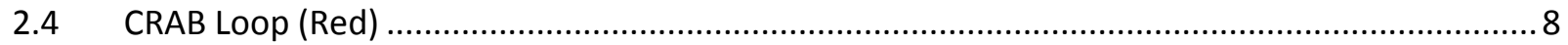

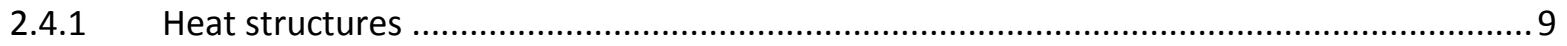

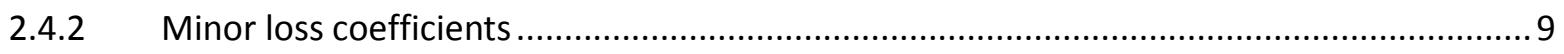

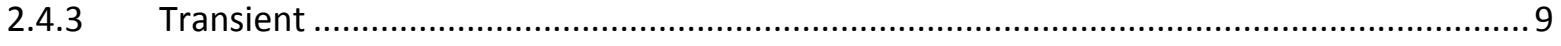

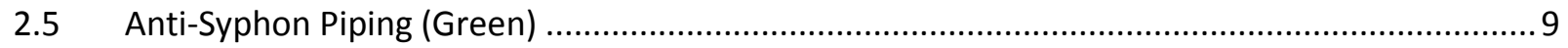

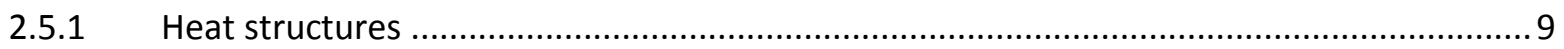

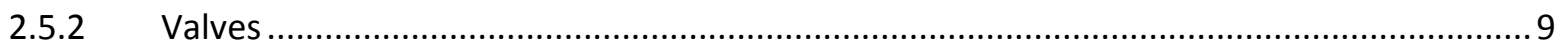

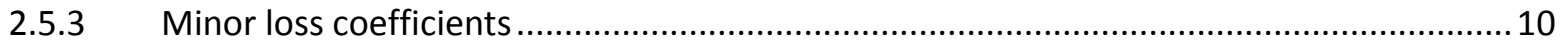

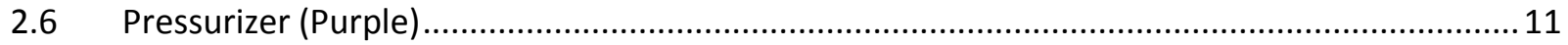

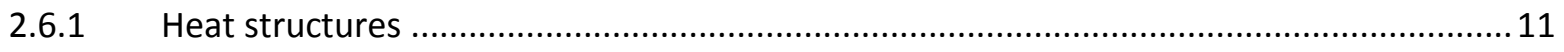

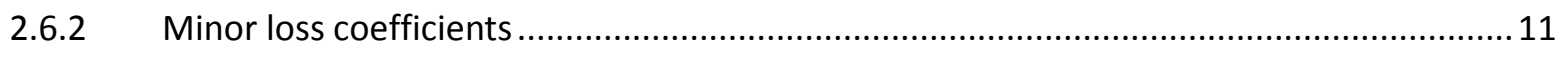

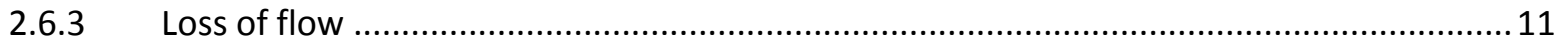

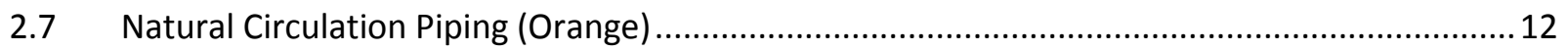

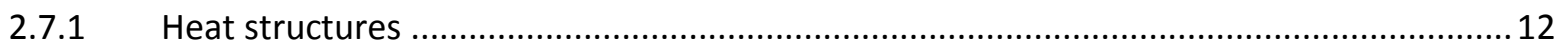




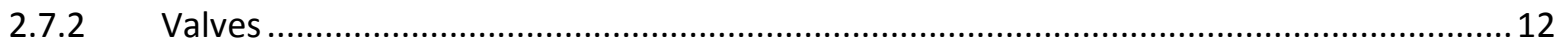

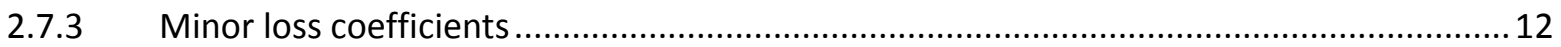

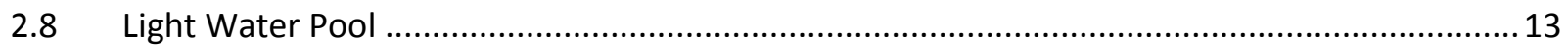

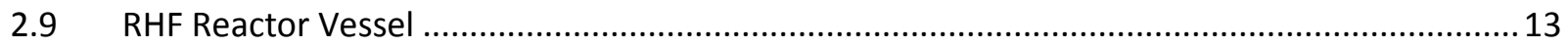

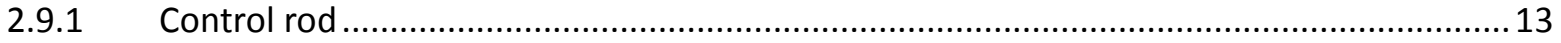

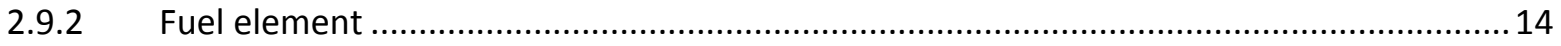

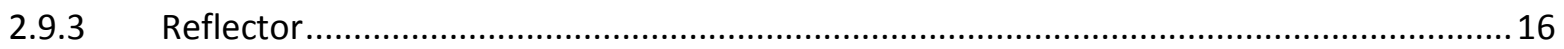

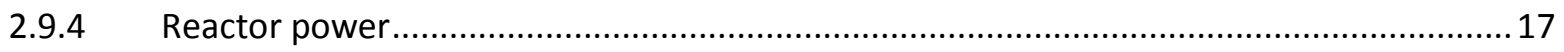

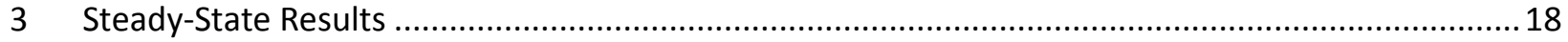

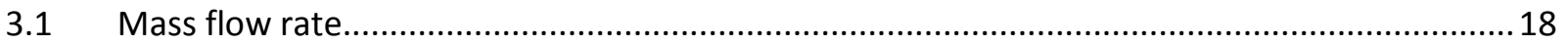

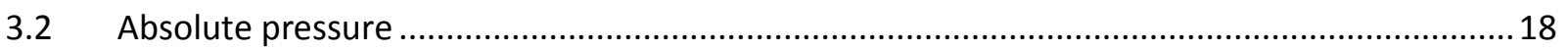

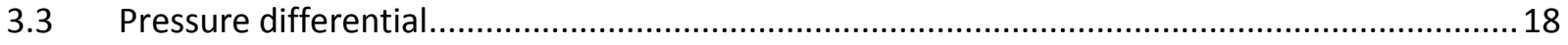

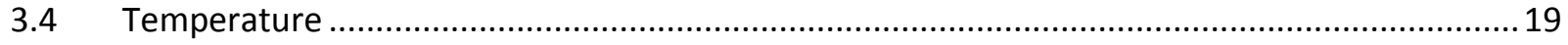

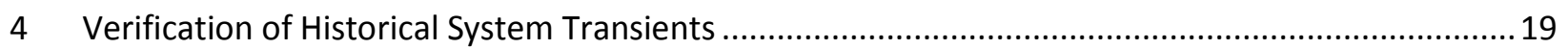

4.1 Procedure

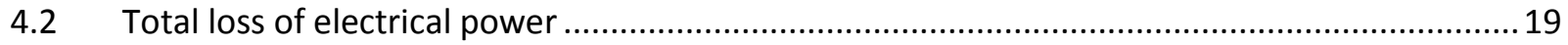

4.3 Total loss of electrical power with locked pump impellers ..................................................20

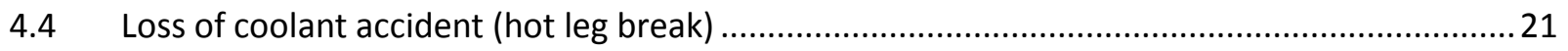

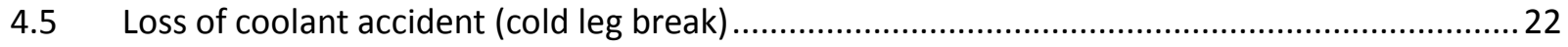

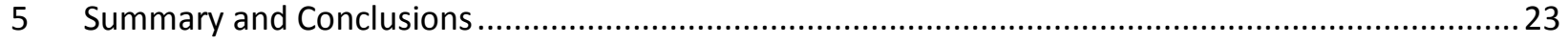

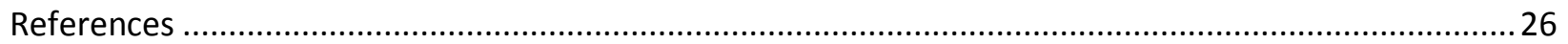

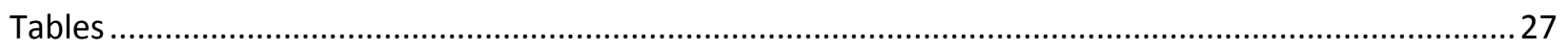

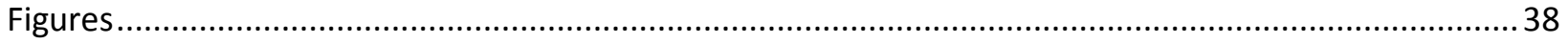

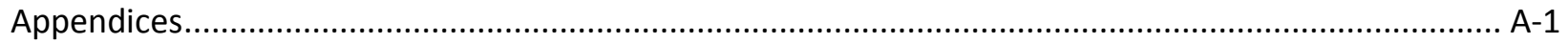

\section{Table of Tables}

Table 1 Material Properties used in RELAP5 model.............................................................................2 27

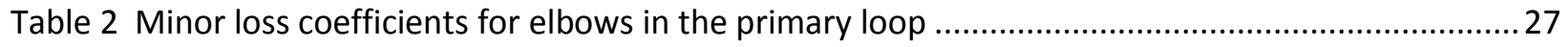

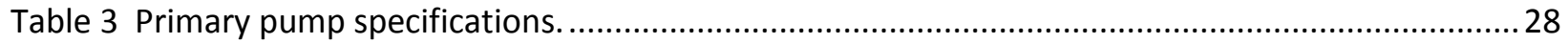

Table 4 Homologous curves implemented in RELAP5 model (normal operation). ..................................28 


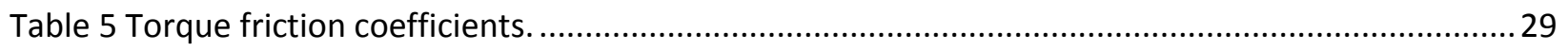

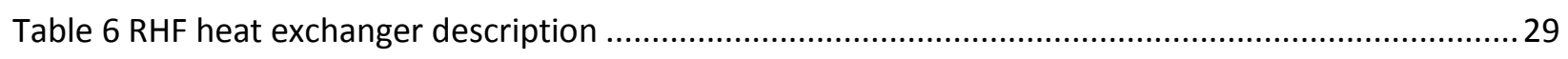

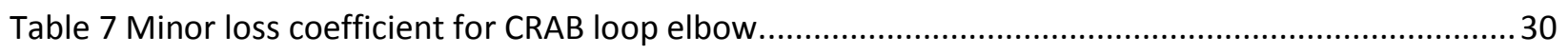

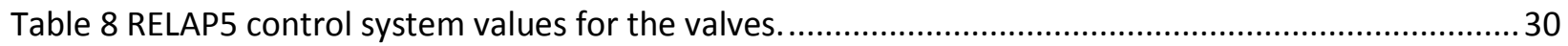

Table 9 normalized flow area as a function normalized valve position................................................... 30

Table 10 Target coast down pressure and the required pressure at RELAP5 boundary condition........... 31

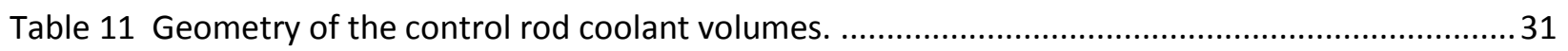

Table 12 Control rod flow distribution summary (From Table 27.8 of the SAR) ...................................32

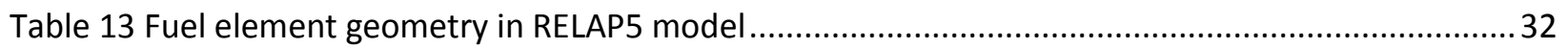

Table 14 ANL best estimate of coolant volume within heavy water tank.............................................. 33

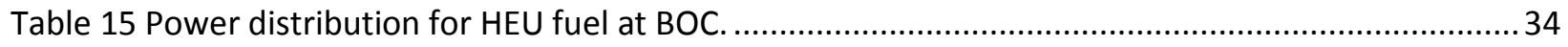

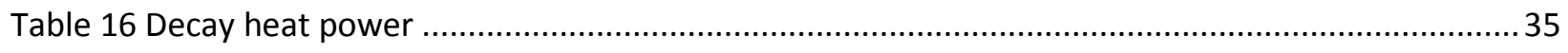

Table 17 RELAP5 steady-state simulation results compared to reference values....................................36

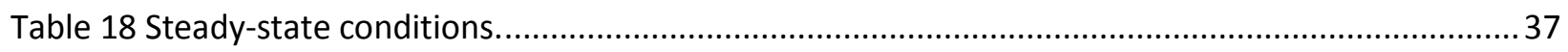




\section{Table of Figures}

Figure 1 Conceptual drawing of RHF with RELAP5 Volumes (volumes inside heavy water tank not shown)

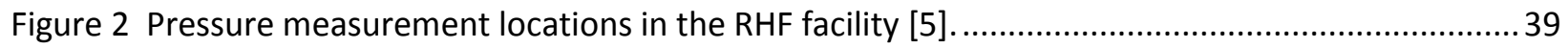

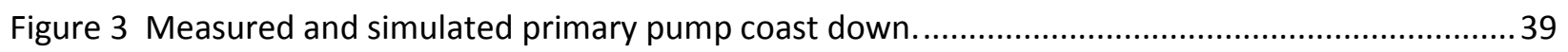

Figure 4 RHF primary heat exchanger (modified from drawing 4C-51-P1-001) ....................................40

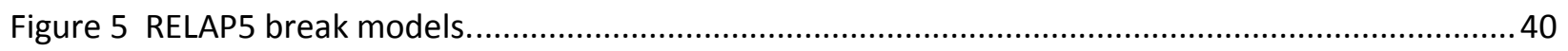

Figure 6 Target CRAB flow rate as determined from loss of flow tests.............................................. 41

Figure 7 Diagram of a check valve in a natural circulation line ......................................................... 41

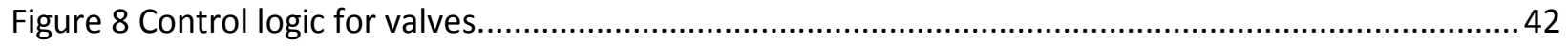

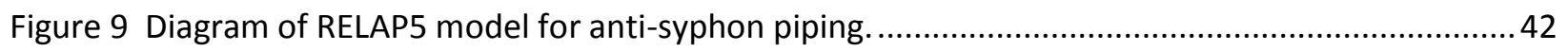

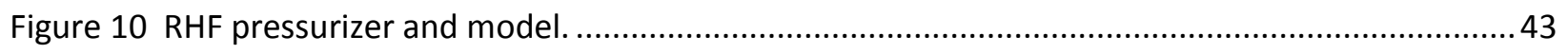

Figure 11 Comparison of target and RELAP5 simulated outlet pressure............................................. 43

Figure 12 RELAP5 description of the natural circulation lines connecting the chimney to the heavy water tank.

Figure 13 RELAP5 description of the natural circulation line connecting the CRAB loop to the heavy water tank.

Figure 14 Coolant volume discretization scheme and heat structure linkages in RELAP5 model. 45

Figure 15 Diagram of the conical head separating the flow between the control rod and fuel element regions .46

Figure 16 Discretization of the single and four channel fuel element model. .46

Figure 17 Conceptual drawing of RHF heavy water vessel (IR and OR = inner and outer radius, radial dimensions in $\mathrm{cm}$ ).

Figure 18 Comparison of axial (a) and radial (b) power density distribution in the HEU fuel element...... 48

Figure 19 Comparison of the decay heat power used in RELAP5 and CATHARE. .49

Figure 20 Normalized mass flow in the primary loop. RELAP5 174(1) .... .50

Figure 21 Normalized mass flow for single channel model. RELAP5 40(1)..... 50

Figure 22 Normalized mass flow for four channel model with helium pressurizer. RELAP5 40-43(1).......51

Figure 23 Normalized mass flow for four channel model with pressure BC. RELAP5 40-43(1)...............51

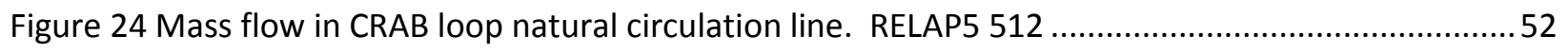

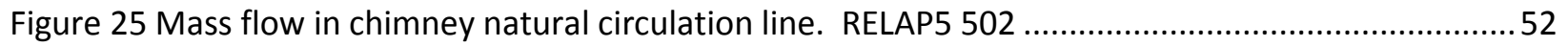

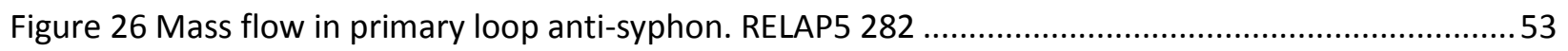




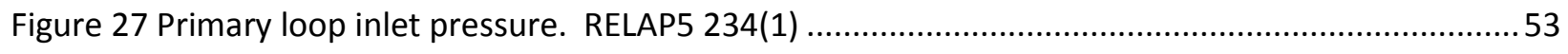

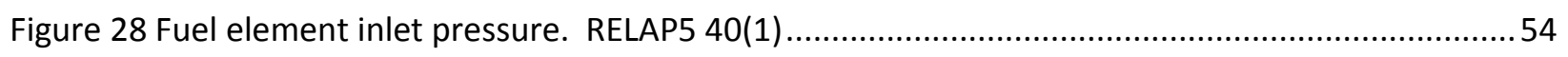

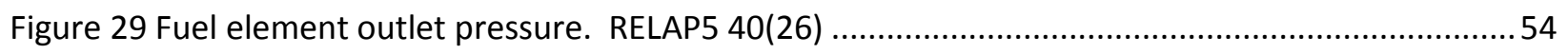

Figure 30 Peak transient fuel cladding temperature. RELAP5 41(3) .....................................................5

Figure 31 Fuel element coolant temperature. RELAP5 40(3) for single channel model and 41(3) for four

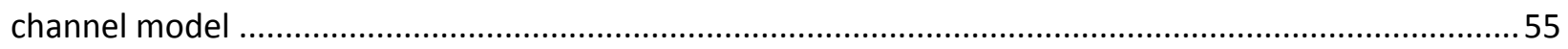

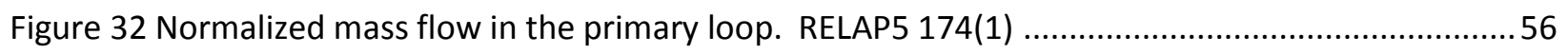

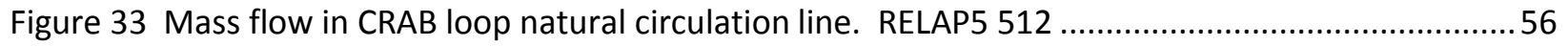

Figure 34 Mass flow in chimney natural circulation line. RELAP5 502 ...............................................57

Figure 35 Mass flow in primary loop anti-syphon. RELAP5 282 ......................................................57

Figure 36 Normalized mass flow for single channel model. RELAP5 40(1) ..........................................5

Figure 37 Normalized mass flow for four channel model with helium pressurizer. RELAP5 40-43(1) ......58

Figure 38 Normalized mass flow for four channel model with pressure BC. RELAP5 40-43(1)..............59

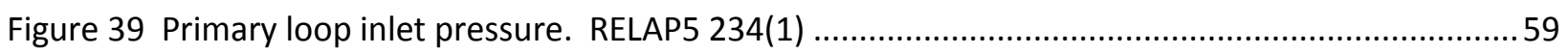

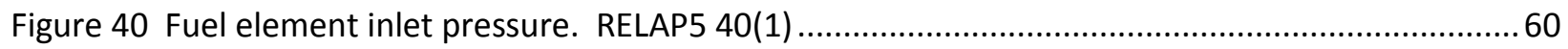

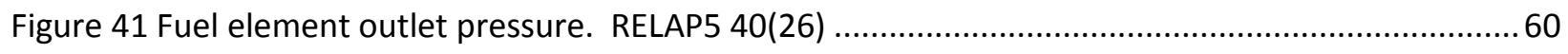

Figure 42 Peak transient fuel cladding temperature. RELAP5 41(3) ................................................... 61

Figure 43 Fuel element coolant temperature. RELAP5 40(3) for single channel model and 41(3) for four

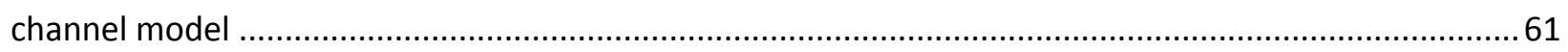

Figure 44 Normalized system mass due to pressurizer gas, break model and core model. Reference mass:

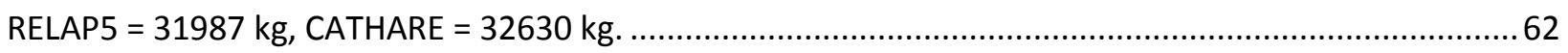

Figure 45 Mass flow through hot leg break due to pressurizer gas and break model. RELAP5 junction 828

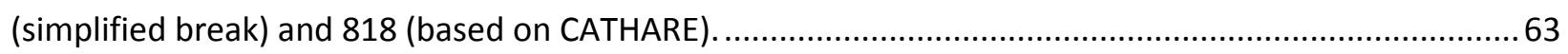

Figure 46 Mass flow through hot leg break due to core model. RELAP5 junction 828 (simplified break) and

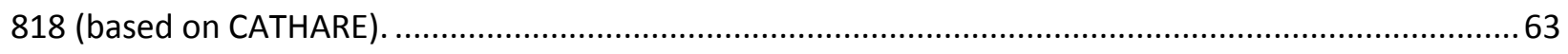

Figure 47 Exit pressure in primary loop due to pressurizer gas and break model. RELAP5 148(3) ..........64

Figure 48 Exit pressure in primary loop due to core model. RELAP5 148(3) .....................................64

Figure 49 Flow rate in CRAB loop natural circulation line due to pressurizer gas and break model. RELAP5

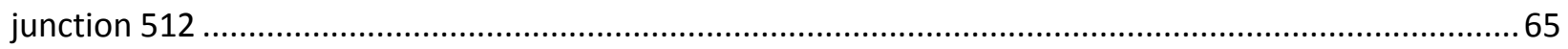

Figure 50 Flow rate in CRAB loop natural circulation line due to core model. RELAP5 junction 512.......65

Figure 51 Flow rate in CRAB loop primary loop anti-syphon due to pressurizer gas and break model.

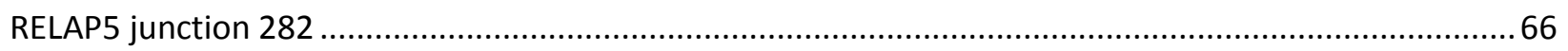


Figure 52 Flow rate in CRAB loop primary loop anti-syphon due to core model. RELAP5 junction 282 .. 66 Figure 53 Normalized flow rate in core for single channel model due to pressurizer gas and break model. RELAP5 40(1)

Figure 54 Normalized flow rate in core for four channel model. RELAP5 40(1) ...................................68

Figure 55 Fuel cladding temperature due to pressurizer gas and break model. RELAP5 41(3) ..............69

Figure 56 Fuel cladding temperature due to core model. RELAP5 40(3) ............................................69

Figure 57 Normalized system mass due to pressurizer gas, break model and core model. Reference mass: RELAP5 $=31987 \mathrm{~kg}$, CATHARE $=32630 \mathrm{~kg}$.

Figure 58 Mass flow through hot leg break due to pressurizer gas and break model. RELAP5 junction 828 (simplified break) and 818 (based on CATHARE).

Figure 59 Mass flow through hot leg break due to core model. RELAP5 junction 828 (simplified break) and 818 (based on CATHARE).

Figure 60 Exit pressure in primary loop due to pressurizer gas and break model. RELAP5 148(3) .......... 72

Figure 61 Exit pressure in primary loop due to core model. RELAP5 148(3) ....................................... 72

Figure 62 Flow rate in CRAB loop natural circulation line due to pressurizer gas and break model. RELAP5

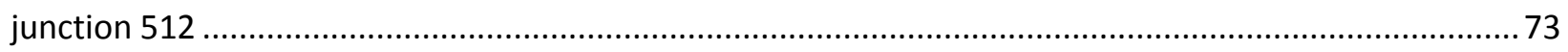

Figure 63 Flow rate in CRAB loop natural circulation line due to core model. RELAP5 junction $512 \ldots . . .73$

Figure 64 Flow rate in CRAB loop primary loop anti-syphon due to pressurizer gas and break model. RELAP5 junction 282 .

Figure 65 Flow rate in CRAB loop primary loop anti-syphon due to core model. RELAP5 junction 282 .. 74

Figure 66 Normalized flow rate in core for single channel model due to pressurizer gas and break model. RELAP5 40(1) 75

Figure 67 Normalized flow rate in core for four channel model. RELAP5 40(1) .....................................76

Figure 68 Fuel cladding temperature due to pressurizer gas and break model. RELAP5 41(3) ...............77

Figure 69 Fuel cladding temperature due to core model. RELAP5 40(3). .77 


\section{Introduction}

The RELAP5/Mod 3.3 [1] reactor transient analysis code was used to perform a verification of the RHF reactor system transients previously simulated with the CATHARE Code. The verification included comparisons of temperature, pressure, flows, etc. where direct code comparisons could be made. This work is a precursor to the simulations that will be performed with the RELAP5 code to evaluate the impact of converting the RHF reactor from Highly Enriched Uranium (HEU) to Low Enriched Uranium (LEU) fuel.

Simulations were performed for the following scenarios:

$>$ steady-state reactor operation [2],

$>$ total loss of electrical power accident [3],

$>$ total loss of electrical power with locked primary pump impellers accident [3], and

$>$ Hot and cold leg loss of coolant accident (LOCA) [4]:

- A break in the hot leg of $114 \mathrm{~mm}$ in diameter located $3.7 \mathrm{~m}$ upstream of the primary pumps.

- A break in the cold leg of $140 \mathrm{~mm}$ in diameter located downstream of the pumps (16.8 meters before the core inlet).

The second section of this document describes the RELAP5 model. Two models for the coolant discretization within the fuel element were developed to bound the thermal hydraulic behavior. Briefly, the fuel plates and channels were consolidated into an equivalent single plate and channel. The fuel plate was discretized into 5 longitudinal stripes to adequately describe the heat flux variation. Three of these stripes are considered 'hot stripes' of which one contains the peak heat flux depending on burnup and fuel type. The $4^{\text {th }}$ stripe contains the remainder of the fuelled section and the $5^{\text {th }}$ stripe represents the unheated edges. The first model, designated as the "single channel model", thermally linked each of the 5 stripes to a single hydraulic channel. This model is considered to be slightly non conservative since it assumes perfect coolant mixing at each axial node of the fuel plate. The second model, designated as the "four channel model", splits the single hydraulic channel into 4 channels. Three of these channels are geometrically similar and thermally linked to the 3 'hot-stripes'. The $4^{\text {th }}$ channel is thermally connected to the remaining plate stripes. The four channel model is considered to be conservative since it does not take into account coolant mixing between the four hydraulic channels.

Additionally, different versions of these core models were created to evaluate the impact of model improvements relative to that used in the CATHARE analyses. This included:

using a helium cover gas in the pressurizer as opposed to a steam surrogate, and

$>$ simplifying the break model used in the LOCA simulations.

To verify the RELAP5 models, steady-state simulations were performed and compared to reference reactor data for $100 \%$ of rated power and a coolant inlet temperature of $26.5^{\circ} \mathrm{C}$ (Section 3 ). Then, following the methods used for the CATHARE analyses, simulations of reactor transients were performed for $107 \%$ of rated power with a coolant inlet temperature of $33^{\circ} \mathrm{C}$. Section 4 provides an overview of the RELAP5 simulation results in comparison to that obtained with the CATHARE code. 


\section{RELAP5 Model Description}

\subsection{General Considerations}

\subsubsection{RELAP5 version}

The model described in this document was developed for RELAP5/Mod 3.3 [1]. Throughout the remainder of this document, RELAP5/Mod 3.3 will be referred to as RELAP5.

\subsubsection{Solution method}

The options selected for running the RELAP5 simulations summed to control option 7, which means the following options have been implemented:

- The hydrodynamics advancement setting was selected; it uses a mass error analysis to control the time step between the minimum and maximum time step (set to $1.1 \mathrm{e}-12 \mathrm{~s}$ and $0.1 \mathrm{~s}$, respectively).

- The heat conduction/transfer time step was set to be the same as the hydrodynamic time step.

- The heat conduction/transfer and hydrodynamics were coupled implicitly (to avoid calculation failure, the explicit method was used to achieve steady-state conditions before switching to the implicit method).

\subsubsection{Numerical options}

In some instances, RELAP5 simulations were terminated prematurely due to calculation failure. The RELAP5 code contains options that can be activated in order to overcome calculation failures by changing numerical or modeling methods. The following is a list and brief description of the options that were utilized in some of the RELAP5 simulations to overcome calculation failures ${ }^{1}$ :

Option 5: Smooth the heat transfer coefficient using an exponential type smoothing function.

Option 8: Adjust (minimize) the time step to limit the magnitude of change in void fraction.

Option 10: Adjust (minimize) the time step to limit the magnitude of change in pressure.

Option 18: Adds the sharp interface and reverse void profile logic from Mod2.5.

Option 20: Implement a smooth bubbly-slug transition region.

Option 22: Deactivates Simplex root finding method. The Simplex root finding method converges the solution for the steam partial pressure and internal energy when the Newton method starts oscillating about the true solution.

\footnotetext{
${ }^{1}$ As an example, a combination of options might be selected at the beginning of a transient to progress the calculation for a certain time before code failure. At that instance, a different combination of options might be selected at the restart to advance the code further or until completion. It should be noted that some of the options can impact results depending on when in the simulation they are implemented. Based on the many simulations that were run for this work, it is believed that the combination of options and the timing for their implementation allowed the calculations to run to completion without having a significant effect on the results.
} 
Option 24: Activates the original subcooled boiling model. The default SRL model is better at low pressure.

Option 51: Disables water packing for all volumes.

Option 52: Disables the choked flow model for any junctions in which the choked flow model was activated.

Option 62: Implement a new correlation to the Chen $\mathrm{F}$ factor in subroutine PREDNB to minimize oscillations.

Option 65: Modify the nucleate boiling heat flux that generates vapor when the bulk liquid is subcooled to minimize the "on/off" behavior associated with low-pressure/low-flow conditions.

Option 79: Add scaling factor to diagonal of the Jacobian squared matrix ten times if necessary. This helps is some cases when non-condensables are present.

\subsubsection{Coolant volumes}

Coolant volumes within the model were largely based on the piping system extracted from the RHF CATHARE model [2][3][4], component descriptions provided in the SAR [5] and vessel dimension provided in Ref. [6]. Default parameters for coolant volumes are given here:

The volume control flags tlpvbfe for pipe and snglvol components were by default set to 0000000 :

- $\mathrm{t}=0$ : no thermal front tracking

- I=0: no mixture level tracking

- $\mathrm{p}=0$ : water packing scheme used

- $\quad \mathrm{v}=0$ : vertical stratification model used

- $b=0$ : pipe interphase friction model used

- $f=0$ : wall friction along $x$-axis calculated

- $\quad \mathrm{e}=0$ : non-equilibrium model used

The junction control flags efvcahs for pipe and sngljun component were by default set to 0001000 :

- $\quad \mathrm{e}=0$ : modified PV term not used

- $\mathrm{f}=0$ : CCFL model not applied

- $\quad \mathrm{v}=0$ : option not available

- $\quad c=1$ : choking model not applied

- $a=0$ : smooth area change

- $\mathrm{h}=0$ : non-homogeneous model applied

- $s=0$ : momentum flux both to and from volume

The hydraulic diameter and area for tube geometries were by default set to 0 at all junctions (internally calculated). For all other geometries only the area was set to 0 (internally set to the smallest value of the 
neighboring volumes). The hydraulic diameter was manually set to the smallest of the neighboring cell values.

Wall roughness for all surfaces was by default set to a small value $(1.0 \mathrm{e}-6 \mathrm{~m})$. This value is not expected to significantly affect RELAP5 simulation results.

\subsubsection{Heat structures}

Heat structures were included for almost all pipes in the model and for a majority of the reactor vessel and its internals. Heat structures throughout the model were discretized into 3 radial regions (4 nodes). The following default parameters were set for the heat structure components without heat generation:

- the 9 word format was selected

- convection boundary = 101 (default convection correlations)

- $\quad$ heat transfer hydraulic diameter $=0$ (i.e. same as volume hydraulic diameter)

- the forward and reverse heated length $=100$ (i.e. neglect entrance effects)

- forward and reverse loss coefficients $=0$ (not required for current geometry)

- local boiling factor $=1.0$ (no heat generation)

Exceptions to the above default parameters are discussed in the applicable sections below.

\subsubsection{Materials}

Table 1 lists the RELAP5 model materials and their temperature independent properties. Properties for the HEU fuel (materials 1 ) were obtained from Ref. [7]. The beginning-of-cycle (BOC) fuel properties were used for this work. The properties for the cladding material, AlFeNi, were obtained from Ref. [2]. Materials 6, 7 and 8 were obtained from available online sources [8], [9] and [10], respectively.

\subsection{Model Overview}

Figure 1 shows a color-coded conceptual drawing of the RHF reactor as modeled in RELAP5. The reactor vessel, located at the bottom of a light water pool (volume 5), consists of a chimney (Volumes 14 to 24) and heavy water tank. Heavy water coolant flows downward through the chimney and splits to separately cool the annular fuel element and centrally located control rod.

The control rod coolant flows into the CRAB loop while the fuel element coolant flows through the reflector tank and into the primary loop. As indicated in Figure 1, a portion of the CRAB loop has not been included in the RELAP5 model; instead it has been approximated with inlet and outlet mass flow boundary conditions (490 through 493).

The primary loop is defined by volumes 120 through 256. Reactor flow in the primary loop is controlled by the speed of the primary pumps (168 and 169). The coolant inlet temperature is controlled through the temperature and heat transfer coefficient boundary condition applied to the secondary side of the primary heat exchangers (194). 
The pressure control system consists of an expansion vase (364-366), cover gas (380) and pressurization pumps. The pressurization pumps are not included in the RELAP5 model. For steady-state simulations, the pressurization is controlled with a time dependent pressure boundary (370) and the relatively small flow rate generated by the pressurization pumps was neglected. For transient simulations, the pressure can be controlled by the time dependent volume (370) or by the cover gas (380), depending on which valve (371 or 365 ) in the model is open.

To prevent accidental draining of the core in an accident scenario, the RHF reactor includes anti-syphon lines for the primary (276 to 288 ) and CRAB loop (472 to 488). The anti-syphon line for the CRAB loop operates continuously, in contrast to the anti-syphon line for the primary loop which contains a passively controlled valve that remains closed during normal operation.

Natural circulation lines (500 to 504 and 510 to 514) are available to promote cooling of the fuel element and control rod during an accident, but also contain passively controlled valves that remain closed during normal operation.

A hot and cold break in primary piping where included for LOCA simulations (800's). The cold leg break was located at volume 223 and the hot leg break was located at volume 159.

The remainder of Section 2 describes the modeling details for RHF.

\subsection{Primary Loop (Blue)}

The primary loop, as defined here, begins with a single pipe extending out of the top of the heavy water tank. This pipe contains a 180 degree bend that directs coolant below the reactor. This configuration is meant to prevent complete draining of the heavy water tank following a pipe break. Once below the reactor, the coolant is sent to the two primary pumps followed by two heat exchangers, both of which operate in parallel. The parallel piping for each of these has been consolidated into a single pipe with equivalent flow area and hydraulic diameter. Following the heat exchangers, the primary coolant mixes with the output of the CRAB loop and returns to the chimney above the heavy water tank.

\subsubsection{Measurement locations}

Reactor data for the primary loop was obtained from measurements made in room A13 of the RHF facility [5]. According to plant diagrams, these measurement locations are located just above the pipe elbows directly below the reactor ( $5.5 \mathrm{~m}$ below the bottom of the fuel element). This is consistent with a pressure head of 0.6025 bar utilized by the RHF engineers to calculate the core exit pressure and equates to measurements being made at a plant elevation of $\sim 205.8 \mathrm{~m}$ (Figure 2). This is also consistent with a document describing the CATHARE model [2]. It states the reactor inlet pressure measurement location at $6.123 \mathrm{~m}$ downstream from the start of the pipe labeled BF1. The reactor outlet pressure measurement location is described as $9.596 \mathrm{~m}$ downstream from the start of the pipe labeled BC2. Discussion with RHF engineers indicates that the inlet and outlet flow, temperature and pressure measurements in the primary 
loop are made in approximately the same location $( \pm 0.5 \mathrm{~m})$. These measurement locations for the inlet and outlet measurements are equivalent to RELAP5 volume $148(3)$ and volume $234(1)^{2}$, respectively.

\subsubsection{Heat structures}

All of the piping material was designated as AlFeNi except for the primary loop piping spanning volumes 148 through 214, which was stainless steel 316. Piping located within the light water pool (as indicated in Figure 1) was thermally connected to RELAP5 volume 5 (pool modeled as an infinite energy sink). Piping located outside the pool utilized a constant temperature $\left(30^{\circ} \mathrm{C}\right)$ and heat transfer coefficient $\left(10 \mathrm{~W} / \mathrm{m}^{2}-\mathrm{K}\right)$ boundary condition to approximate the surrounding atmospheric conditions.

\subsubsection{Minor loss coefficients in pipes}

Minor loss coefficients were calculated for the elbows in the primary loop with formulas given by Idel'chik [11] (Table 2).

A minor loss coefficient was also applied to the $180^{\circ}$ bend downstream of the heavy water tank and was determined from Ref. [11] to be 0.312 . This value was equally distributed across junctions $122,126,138$, and 142.

A minor loss coefficient was implemented at the junction of the primary loop and the chimney. This is a complicated geometry consisting of a horizontal, asymmetrically expanding pipe connected to a vertical chimney. The chimney wall contains several large, square openings that allow coolant to pass through the wall. The loss coefficient for this junction was determined by utilizing pressure loss information given in Figure 23.18 of the SAR [5]. The figure indicates a pressure loss of 0.3 bar for a velocity of $5 \mathrm{~m} / \mathrm{s}$ in the chimney (area of $0.141 \mathrm{~m}$ ). This junction is represented by volume 18(2) of the RELAP5 model (area = $0.238 \mathrm{~m}^{2}$ ) and its loss coefficient was determined to be 3.09. This minor loss coefficient value was applied to both the forward and reverse directions.

\subsubsection{Primary pump}

The RHF primary pump specifications provided in Table 24.6 of the SAR [5] are summarized here in Table 3. Both primary pumps have been explicitly modeled in RELAP5. The model of the pump flow area was based on the inlet and outlet piping diameters $(0.3 \mathrm{~m})$. The pump length $(1.44 \mathrm{~m})$ was chosen to match the volume $\left(0.102 \mathrm{~m}^{3}\right)$ given in the SAR specifications.

For the pump model, no two-phase operating options have been included as they are not required for the accident scenarios considered. The 'no-reverse' option has been selected and the reverse minor loss coefficient has been set to $9 \mathrm{e} 9$ to represent the check valves that prevent reverse flow through the pump.

The homologous curves were extracted from the CATHARE model and implemented in RELAP5 (Table 4). However, on closer inspection it seems that only the normal operating regime has been modeled while the others have been filled with temporary data. The homologous curves may need to be revisited if any of the accident scenarios require pump operation outside of normal conditions. The target flow rate of

\footnotetext{
${ }^{2}$ As a convention, the node number $\mathrm{N}$ of a pipe component number $\mathrm{CCC}$ will be referred to as $\mathrm{CCC}(\mathrm{N})$. 
$735.5 \mathrm{~kg} / \mathrm{s}$ was achieved by setting the pump velocity ratio to 0.948 . Alternatively, controllers can be used by maintaining the flow rate setting (in $\mathrm{m}^{3} / \mathrm{hr}$ ) based on the mass flow rate and coolant density at RELAP5 148(3).

In 1987 a pump coast down experiment was performed at RHF for cold conditions and included a measurement of the primary loop flow rate (Figure 3) [12]. This flow rate measurement was used as the basis for calibrating the pump coast down in the RELAP5 model. RHF engineers have suggested that the flow measurement is unreliable below about $10 \%$ of the nominal flow. Due to this uncertainty, two idealized coast-down curves were proposed to bound the expected flow rate. The first coast-down curve (lower bound) assumes that the slope in measured flow rate at $10 \%$ of the nominal flow remains constant until the flow rate reaches zero. The second coast-down curve (upper bound) assumes the slope in measured flow rate at the end of the data set remains constant until the flow rate reaches zero. Approximations to these idealized coast-down curves were achieved in RELAP5 by adjusting the torque friction coefficients for the pumps. Two sets of torque friction coefficients were specified to modify the time that flow approaches zero (Table 5). The coefficients are related to the torque friction by:

$$
\text { friction torque }=T F 0+T F 1 \cdot S+T F 2 \cdot S^{2}+T F 3 \cdot S^{3}
$$

where ' $\mathrm{S}$ ' is the ratio of current speed to rated speed.

Only the lower bound torque friction coefficients were used for the analyses described in this document since it is more conservative (as seen in Ref. [13]) and consistent with that used in the CATHARE model.

Figure 3 compares the RELAP5 calculated pump coast-down flow rate to the 1987 coast down data using these two sets of torque friction coefficients. The simulation results show that there is about a $200 \mathrm{~s}$ difference in the time that the flow rate approaches zero for the upper and lower bound cases. Also shown are the simulated coast-down results calculated with CATHARE (similar to the RELAP5 lower bound case). As discussed in Ref. [13], the brief increase in flow $30 \mathrm{~s}$ after pump trip was due to the opening of the natural circulation and anti-syphon valves which allows part of the flow to bypass the fuel element, effectively reducing the overall resistance of the primary loop.

\subsubsection{Primary heat exchangers}

The heat exchanger components modeled in RELAP5 were based on a design drawing (drawing number 4C-51-P1-001) supplied by the RHF team (Figure 4) and the information provided in the Table 24.4 in the SAR [5]. This information is summarized in Table 6. There are two heat exchangers that operate with the primary coolant $\left(\mathrm{D}_{2} \mathrm{O}\right)$ on the shell side and the DRAC river water $\left(\mathrm{H}_{2} \mathrm{O}\right)$ on the tube side. The $\mathrm{H}_{2} \mathrm{O}$ enters an inlet plenum which directs the water into 1040 tubes with an inner diameter (ID) of $17 \mathrm{~mm}$. These tubes are $6.02 \mathrm{~m}$ long. Water exits the tubes into a transition plenum and then returns down the remaining 1040 tubes into an outlet plenum. The $\mathrm{D}_{2} \mathrm{O}$ enter the shell side of the heat exchanger and travels along the outside of 1040 tubes, turns around, and flows along the outer diameter (OD) of the remaining 1040 tubes before exiting the heat exchanger. Based on a shell ID of $1.25 \mathrm{~m}$, the total $\mathrm{D}_{2} \mathrm{O}$ volume was calculated to be $3.43 \mathrm{~m}^{3}$. This is similar to the manufacturer's specified volume of $3.4 \mathrm{~m}^{3}$. 
To simplify the RELAP5 model, the shell side of each heat exchanger has been lumped into a single component with equivalent thermal-hydraulic characteristics. The tube side of the heat exchanger was modeled with a temperature and heat transfer coefficient boundary condition. The heat transfer coefficient was specified as $4000 \mathrm{~W} / \mathrm{m}^{2}-\mathrm{K}$ and the temperature on the secondary side was set to control the core inlet temperature. The heat transfer coefficient was conservatively assumed to be $0 \mathrm{~W} / \mathrm{m}^{2}-\mathrm{K}$ at the beginning of the simulated accident.

The inlet and outlet of the heat exchangers was modeled with junctions 193 and 200, respectively. The abrupt area change model was implemented at these junctions. Pipes 190 and 201 were considered to be a consolidation of parallel pipes, thus the hydraulic diameter was specified as $0.3 \mathrm{~m}$ with a flow area equivalent to two pipes. The heat exchanger specified pressure drop was 1.16 bar at a nominal flow rate of $1090 \mathrm{~m}^{3} / \mathrm{h}$ (Table 24.4 of the SAR [5]). In the RELAP5 model, this pressure drop was evaluated between volumes 190(2) and 201(1). A total loss factor of 158.8 was required to achieve the target pressure drop. This loss coefficient is quite high but can be justified by the fact that the heat exchanger design includes internal baffles that create a torturous coolant path. This loss factor was distributed equally between the 19 junctions within pipe 194 (heat exchanger).

\subsubsection{Breaks in primary piping}

The RELAP5 model for the breaks in primary piping was based on the CATHARE model [4]. They were modeled at two locations:

- A break in the hot leg of $114 \mathrm{~mm}$ in diameter located $3.7 \mathrm{~m}$ upstream of the primary pumps (downstream end of RELAP5 volume 159).

- A break in the cold leg of $140 \mathrm{~mm}$ in diameter located downstream of the pumps (16.8 meters before the core inlet at downstream end of RELAP5 volume 223).

Two different models were developed to simulate the breaks (Figure 5). The first model was based on the geometry used in the CATHARE model. In the CATHARE model, the break was comprised of four components connected to a tee (volume 159 and 223 in RELAP5 model). The first component was the section of pipe describing the branch of the tee (810 and 815) connected to the primary loop. The second was a continuation of this pipe with an additional pipe containing 21 cells of decreasing length (812 and 817). The third component was the trip valve. The fourth component was time dependent boundary condition representing atmospheric conditions (814 and 819). The second model, or simplified model, simply used a trip valve (823 and 828 ) and time dependent boundary condition representing atmospheric conditions directly connected to the break location in the primary loop (159 and 223).

The valve type describing the break was selected to be the "trip" type which opens instantly at the specified time. The choked flow option was activated at the valve. A discharge coefficient of 1 was used, but values of $0.6,0.8$ and 0.9 were investigated. No significant differences in the simulations results were observed for the different discharge coefficient values. The time dependent volumes were modeled as warm, steam saturated air with a pressure of $1.0305 \mathrm{e} 5 \mathrm{~Pa}$ and temperature of $30^{\circ} \mathrm{C}$.

\subsection{CRAB Loop (Red)}


The CRAB loop, as defined here, begins at the pipe connection near the bottom of the heavy water tank at the exit of the control rod. Similar to the primary loop, the piping ascends above the heavy water tank prior to a 180 degree bend that redirects the coolant downward below the reactor vessel. The CRAB loop has only been partially modeled for the RELAP5 calculations (as indicated in Figure 1) since it does not significantly contribute to the accident scenarios that are being simulated (this is the same assumption used in CATHARE). This assumption is justified since the pump coast down data shows that the flow rate approaches $0 \mathrm{~kg} / \mathrm{s}$ in approximately 8 seconds; much faster than the primary pumps (approximately 200400 seconds). The section of the CRAB loop downstream from the anti-syphon line has been removed and replaced with an outlet mass flow boundary condition (BC 491 in the RELAP5 model). It represents the combined flow of the anti-syphon line and control rod $(24.9 \mathrm{~kg} / \mathrm{s})$. This coolant was reintroduced into the primary loop at volume 220 with an inlet mass flow $(24.9 \mathrm{~kg} / \mathrm{s})$ and temperature $\left(19.7^{\circ} \mathrm{C}\right)$ boundary condition.

\subsubsection{Heat structures}

All of the CRAB loop piping material was designated as AG3NET with a 4.5e-3 m wall thickness. The CRAB loop piping is located within the light water pool and was thermally connected to RELAP5 volume 5 (pool modeled as an infinite energy sink). Volume 470 (tee junction of CRAB loop, anti-syphon and outflow boundary condition) was the only volume not connected to a heat structure.

\subsubsection{Minor loss coefficients}

A single minor loss coefficient was included in the CRAB loop and was applied to the elbow designated by volume 456 (Table 7).

\subsubsection{Transient}

The decrease in flow through the CRAB loop boundary conditions was based on data from loss of flow tests performed in the RHF reactor. Figure 6 shows that the measured (RELAP5) flow rate decreases to $0 \mathrm{~kg} / \mathrm{s}$ in $\sim 8 \mathrm{~s}$. For comparison, the decrease in flow modeled by CATHARE was based on the assumption that the flow approaches $0 \mathrm{~kg} / \mathrm{s}$ in $\sim 3 \mathrm{~s}$.

\subsection{Anti-Syphon Piping (Green)}

There are two anti-syphon pipes to prevent a break in the CRAB or primary loop from syphoning coolant from the core (one connecting the CRAB loop to the primary inlet piping, the other connecting the primary outlet piping to the primary inlet piping). The anti-syphon pipe for the primary loop contains a valve that remains closed during normal operation. The anti-syphon for the CRAB loop operates continuously.

\subsubsection{Heat structures}

The anti-syphon piping material for the CRAB and primary loop were designated as AG3NET with a wall thickness of 2.0e-3 $\mathrm{m}$ and $0.01 \mathrm{~m}$, respectively. The anti-syphon pipes are located within the light water pool and were thermally connected to RELAP5 volume 5 (pool with infinite energy sink).

\subsubsection{Valves}

Verification of Historical System Transient Simulations for the RHF Research Reactor 
The anti-syphon line for the primary loop contains a check valve (282) actuated by a pressure differential between its downstream pressure and the CRAB outlet pressure (Figure 7).

The SAR (Section 233.11.2) [5] states that the RHF valves ( 2 for the natural circulation piping and 1 for the anti-syphon pipe) open with a $\sim 1$ bar pressure differential. A control system for each valve was implemented to compare the CRAB outlet pressure at RELAP5 volume 220 and the downstream valve pressure (Figure 8).

Table 8 shows the relative elevation and pressure correction applied to the control system to capture the 1 bar differential at the valves. It was found that reducing this pressure differential limit in RELAP5 by 0.15 bar resulted in valve opening times consistent with that measured in the 1987 loss of flow tests ${ }^{3}$. The opening rate for the valves were based on the loss of flow tests and are representative of the time difference between the first indication of valve movement and reaching fully open.

Table 9 shows the flow area as a function of valve position. The SAR states that the flow passage area is equivalent to a $70 \mathrm{~mm}$ diameter for valves 502 and 512 (natural circulation) and $100 \mathrm{~mm}$ diameter for valve 282 (anti-syphon). The flow areas were determined by calculating the fraction of circular cross sectional area open to coolant flow due to the relative position of the valve.

\subsubsection{Minor loss coefficients}

\section{Anti-syphon for CRAB Loop}

The anti-syphon pipe contains two elbows. The first is represented by volume 480 (Figure 9) and was treated as a smooth elbow with a radius to hydraulic diameter ratio of 22 . The loss coefficient was determined to be 0.74 from Table $6-2$ of Ref. [11] and was applied to the junction within volume 480 .

The second elbow was considered to be a smooth, sharp angled elbow and its loss coefficient was calculated to be 1.2 based on Table 6-1 of Ref. [11] (radius to hydraulic diameter ratio of $\sim 0.5$ ). The loss coefficient was applied to junction 486.

The anti-syphon line inlet connection is to RELAP5 volume 250. Based on the description in the CATHARE model this is a horizontal tee. The cross flow junction model was used by connecting to face 6 of branch 250. As described in Appendix A, the forward and reverse loss coefficients were 3.005 and 1.000, respectively. These were applied to junction 489.

No loss coefficient was specified for the connection of the anti-syphon line and the CRAB loop.

\section{Anti-Syphon for Primary Loop}

The anti-syphon pipe model for the primary loop (Figure 9) contains five minor loss coefficients. The connection of the anti-syphon pipe to the primary inlet pipe was modeled as a tee with a cross flow

\footnotetext{
3 This 0.15 bar adjustment required to match experimental data is likely related to the bias in pressure head correction. The RELAP5 reference pressure is at volume 220 but the actual location of the pressure tap was only known to be downstream of the CRAB loop pumps.
} 
junction to face 6 of pipe 248. As described in Appendix A, the forward and reverse loss coefficients were 8.461 and 5.847, respectively. A loss coefficient of 1.2 was applied to two sharp 90 degree angle elbows (junction 286 and 278) and valve 282. The tee connection to the primary outlet piping was modeled with a cross flow junction to face 6 of branch 132. As described in Appendix $A$, the forward and reverse loss coefficients were 3.762 and 5.315 , respectively.

\subsection{Pressurizer (Purple)}

The RHF pressurizer connects to the top of the 180 degree bend in the primary loop piping downstream from the reactor core. The reactor pressure is controlled by two pressurization pumps operated in parallel $\left(\sim 18 \mathrm{~m}^{3} / \mathrm{hr}\right.$ ). These pumps are identical to those used in the CRAB loop. The pumps obtain water from an expansion vase containing heavy water maintained at a facility elevation of $223.509 \pm 0.191 \mathrm{~m}$ (SAR 241.1.3.8 [5]). Under normal operation, the expansion vase water is replenished by small diameter piping connected to the top of the vessel chimney and reflector tank. A low pressure helium cover gas system maintains the expansion vase pressure at slightly above atmospheric pressure (1.06 bar).

The RELAP5 model of the pressurizer (Figure 10) is similar to that described above but does not include the pressurization pumps. Instead, the pressurizer pipe is connected directly to the heavy water inventory in the expansion vase (volume 364). There are two isolation valves attached to this volume. The isolation valve 371 is connected to a time dependent boundary condition used to replace the effect of the pressurization pumps and establish steady state pressure. This time dependent boundary condition was also used to control the reactor pressure during a transient in certain cases. Isolation valve 365 connects the heavy water inventory (364) to the upper portion of the expansion vase (366) and the helium cover gas volume (380). This is an artificial valve that remains closed during normal operation. The cover gas in the expansion vase is connected to helium gas supply. The supply volume $\left(40 \mathrm{~m}^{3}\right)$ was obtained from the CATAHRE model.

The height of the pressurizer system (length of the pressurizer pipe) was specified such that the top of the heavy water volume (364) was $11.7 \mathrm{~m}$ above the core mid-plane.

The pressurizer system was initialized to the hot leg temperature prior to the start of a transient. The helium cover gas pressure was initialized at a pressure of 1.06 bar. Some of the RELAP5 simulations used steam (quality of 1 at 1.06 bar) as a surrogate for the helium cover gas to compare with results obtained with the CATHARE model.

\subsubsection{Heat structures}

No heat structures were included in the pressurizer model.

\subsubsection{Minor loss coefficients}

The pressurizer connection to the primary loop utilized the cross flow junction model by connecting to face 6 of branch 134. As described in Appendix A, the forward and reverse loss coefficients were 6.083 and 8.12 , respectively.

\subsubsection{Loss of flow}


Following discussions with the RHF engineers, it was decided that the time dependent pressure for accident simulations could be based on the 1987 loss of flow data [12]. Thus, for certain transient simulations the pressurizer pressure was controlled by a time dependent volume (370). At RHF, the reported pressure values $\left(P_{\text {outlet }}\right)$ are given for the core outlet. These values have been obtained from the following equation:

$$
P_{\text {outlet }}[\text { bar }]=P_{\text {detector }}[\text { bar }]-0.6025+5 E(+8) \cdot Q^{2}
$$

where $Q$ is the flow rate in $\mathrm{m}^{3} / \mathrm{hr}, 0.6025$ is the static head of the heavy water and $P_{\text {detector }}$ is the measured pressure. For these analyses, the measured pressure was reduced by an additional 0.34 bar so that the target pressure for the simulations was 4.0 bar at nominal conditions. This target pressure is given in Table 10 as a function of time. Table 10 also shows the pressure that is required in the time dependent volume (370) to achieve the target pressure at RELAP5 volume 148(3). Figure 11 shows the RELAP5 simulation results compared to the target pressure at the primary loop outlet measurement location. The RELAP5 simulated pressure did not evolve smoothly as oscillations occurred up to $50 \mathrm{~s}$ beyond the trip. These oscillations are likely due to the approximation of the pressurizer as an imposed boundary condition but should not have a significant effect on simulation results for a loss of electrical power.

\subsection{Natural Circulation Piping (Orange)}

Two natural circulation pipes were modeled in RELAP5 (see Figure 1). One of these connects the chimney to the reflector region of the heavy water tank. This model is actually a consolidation of three parallel pipes and valves. The other natural circulation pipe is similar to the previous except that it only contains one pipe and valve and connects the reflector region of the heavy water tank to the CRAB loop.

\subsubsection{Heat structures}

The material for the natural circulation pipes was designated as AG3NET. These are located within the light water pool and are thermally connected to RELAP5 volume 5 (pool with infinite energy sink). The natural circulation piping connected to the chimney had a thickness of $0.01 \mathrm{~m}$. The natural circulation piping connected to the CRAB loop had a thickness of $0.0045 \mathrm{~m}$.

\subsubsection{Valves}

Each of the natural circulation pipes contains a valve as described in section 2.5.2.

\subsubsection{Minor loss coefficients}

The natural convection pipe connecting the chimney to the heavy water tank (Figure 12) contained three loss coefficients. A loss coefficient of 1.2 was added to valve 502 and was based on a sharp angle elbow $(r / D=0)$ correlation provided in Idel'chik diagram 6-7 [11]. The RELAP5 abrupt area model was applied to this valve as well as at the pipe connection at the heavy water tank. A tee was modeled at the connection to the chimney. The cross flow junction model was used by connecting to face 6 of pipe 24. As described in Appendix A, the forward and reverse loss coefficients were 22.94 and 19.923, respectively. 
The natural convection pipe connecting the CRAB loop to the heavy water tank (Figure 13) also contained three loss coefficients. A loss coefficient of 1.2 was added to valve 512 and was based on a sharp angle elbow $(r / D=0)$ correlation provided in Idel'chik diagram 6-7 [11]. The RELAP5 abrupt area model was applied to this valve as well as at the pipe connection at the heavy water tank. Connection to the CRAB loop was modeled as a symmetrical tee with cross junction connection to face 6 of branch 462 . The forward and reverse loss coefficients were 1.84 (Appendix A).

\subsection{Light Water Pool}

The light water pool was modeled as an infinite energy sink boundary condition with temperature and pressure of $30^{\circ} \mathrm{C}$ and $1.0305 \mathrm{e} 5 \mathrm{~Pa}$. Figure 1 conceptually indicates which pipes are located within the pool.

\subsection{RHF Reactor Vessel}

Figure 14 shows a conceptual drawing of the reactor vessel, or heavy water tank, and its internal components. The primary loop piping connects to a central chimney extending from the top of the heavy water tank. Coolant flows down the chimney and enters the heavy water tank at volume 28 of the model. Volumes 28 and 30 are a continuation of the chimney volumes penetrating the heavy water tank. Coolant splits between the primary loop (through the fuel element) and CRAB loop (through the control rod). A small amount of coolant bypasses the fuel element and enters the reflector region directly.

The RELAP5 model discretization of the fluid within the reactor vessel consists of the fuel element, control rod and reflector regions. Figure 14 also illustrates the heat structures of the reactor vessel and their links to the coolant volumes. Lines connecting coolant volumes indicate a thermal connection through a structure. Lines arcing from a structure and pointing to the coolant indicate heat generation within the coolant volume and the structure which is used to define its magnitude. (In RELAP5, the magnitude of heat generation within the coolant is specified through an adjacent heat structure). A table describing the detailed power generation within the RHF core and vessel were obtained from MCNP calculations for HEU fuel at BOC conditions. This heat generation (indicated by a star in Figure 14) was modeled within the control rod tubes, fuel plates, vessel walls and coolant as detailed in the following sections.

\subsubsection{Control rod}

The entry into the control rod region (volume 36) corresponds to the inside of a "conical head" (Figure 15). The flow area of $0.0354 \mathrm{~m}^{2}$ for volume 36 was based on the volume of a conical frustum of equivalent upper and lower diameters. Volume 58 represents the coolant above the control rod and its length depends on the control rod tip axial position. The control rod consists of four vertical, annular cylinders at the end of a traversing system that moves the control rod up and down depending on neutronic requirements. In the reference RELAP5 model the top of the control rod is placed at the core mid-plane ${ }^{4}$.

\footnotetext{
${ }^{4}$ The control rod position has been fixed for the current stage of RELAP5 model development and thermal-hydraulic analyses.
} 
Table 11 describes the geometry of the various coolant volumes within the control rod. The coolant paths within the control rod converge into volume 64 , representing the region below the control rod. The length of this region is related to the length of volume 58 above the control rod since the overall length of the control rod region remains fixed for all control rod position. The junction between volumes 62 and 64 was modeled based on a drawing (drawing number 3-54-P1-1003-8) that indicates there are three coolant holes with a diameter of $0.011 \mathrm{~m}$. The lower end of volume 64 is connected to volume 66 which connects to the CRAB loop piping. It should be noted that the control rod has a complex design and its representation in RELAP5 is mostly based on the CATHARE model, which in itself is rather complex. Because of this, volumes and junctions connected to volume 64 are quite simplified relative to design drawings.

\subsubsection{Minor loss coefficients}

Section 273.5 of the SAR [5] provides data that allows for the calibration of the flow distribution within the control rod. A summary of this data is given in Table 12 for a total flow $50 \mathrm{~m}^{3} / \mathrm{h}$; where the pressure drop was stated as 0.12 bar (assumed to be between RELAP5 volumes 58 and 64). Loss factors were applied at the indicated RELAP5 junctions (Table 12) to reproduce the target conditions. The abrupt area change model was applied to the junction of volumes 62 and 64.

It was not possible to achieve the 0.12 bar pressure drop and achieve the target flow rates. This indicates that the control rod description in the RELAP5 model, obtained from the CATHARE model, is not quite accurate. Of note is that Table 27.8 of the SAR suggests that the coolant flowing through the short control rod channels exits back into the center of the control rod as opposed to merging with the coolant from the tall control rod tubes which exit into an outer annulus. Implementing this change into the RELAP5 model would reduce the overall pressure drop; however, more detailed control rod dimensions would be required before this could be implemented. The flow rate distribution and pressure drop stated in Table 12 was considered sufficient at this time.

In addition to these losses, the abrupt area change model was applied to junction 450 (connects the bottom of the control rod volumes to the CRAB loop outlet piping).

\subsubsection{Heat Structures}

Heat structures within the control rod were limited to, as indicated in Figure 14, the tube separating the control rod coolant from the fuel element and the four control rod tubes. Heat generation was applied to the control rod tubes (heat structures 700, 720, 740 and 760), the coolant volume between them (volumes 70, 72, 74 and 76) and the coolant above and within the control rod (volumes 58 and 60). The heat generation within these coolant volumes was assumed to be uniformly distributed. In the current model no thermal connections where made in the vessel below the control rod tubes.

\subsubsection{Fuel element}

The RHF reactor contains a single fuel element consisting of 280 involute curved fuel plates welded to two concentric aluminum tubes. These concentric tubes separate the coolant within the fuel element from the control rod and reflector regions. The fuel plate thickness is $1.27 \mathrm{~mm}$ with a fuel meat thickness of 
$0.51 \mathrm{~mm}$ and the coolant gap between the plates is $1.8 \mathrm{~mm}$. In the RELAP5 model, the fuel plates and coolant channels are consolidated into an equivalent single coolant channel and fuel plate.

The involute plate was discretized into 5 longitudinal stripes to adequately describe the heat flux variation in the width of the fuel (Figure 16). Two 'hot stripes' were defined at the outer edge of the fuel (heat structures 410 and 420) and another at the inner edge (heat structure 430). The remainder of the heated fuel plate was lumped into heat structure 400 . The non-heated portion of the fuel plate was designated as heat structure 401 . This discretization was based on the radial variation in the power profile. Briefly, heat structure 410 is considered to contain the peak cladding temperature for BOC conditions. Heat structure 420 and 430 are place holders for cases in which the peak clad temperature is suspected to occur inside of heat structure 410 or at the inner edge of the fuel (e.g. EOC conditions).

Two models for the coolant discretization within the fuel element were developed to bound the thermal hydraulic behavior. The first model, designated as the "single channel model", thermally linked each of the 5 longitudinal stripes to a single hydraulic channel. This model is considered to be slightly nonconservative since it assumes perfect coolant mixing at each axial node of the fuel element. The second model, designated as the "four channel model", splits the single hydraulic channel into 4 channels. Three of these channels are geometrically similar and thermally linked to the 3 'hot stripes'. The 4 th channel is thermally connected to the remaining fuel plate stripes. The four-channel model is considered to be conservative since it does not take into account coolant mixing between hydraulic channels (within the fuel element). For comparisons of RELAP5 simulation results with CATHARE, it is worth noting that the CATHARE model utilized single and three channel discretization schemes, of which both neglected the unheated edges of the fuel plate. The channel sizes were, starting from the outer edge of the fuel plate, $6.1 \mathrm{~mm}(1 / 11), 12.2 \mathrm{~mm}(2 / 11)$ and $48.8 \mathrm{~mm}(8 / 11)$.

Table 13 provides the critical parameters for each of the heat structures. It should be noted that the $3.0 \mathrm{~mm}$ arc length for the heat structures 410,420 and 430 was based on the considerations used in determining the discretization of the MCNP analysis. The coolant flow area and heat structure surface areas were determined by calculating the involute length bounded by the coolant with a gap size of $1.8 \mathrm{~mm}$ and channel height of $903 \mathrm{~mm}$. The involute equations in Cartesian coordinates are:

$$
\begin{gathered}
x=a(\cos t+t \sin t) ; \mathrm{X} \text {-coordinate } \\
y=a(\sin t-t \cos t) ; \mathrm{Y} \text {-coordinate } \\
r=\sqrt{x^{2}+y^{2}} ; \text { Radius } \\
l=\frac{1}{2} a t^{2} ; \text { Arc length }
\end{gathered}
$$

where ' $a$ ' was defined as $0.1368 \mathrm{~m}$.

The hydraulic diameter for the fuel element coolant volume (40) and its internal junctions were specified as $3.517 \mathrm{e}-3 \mathrm{~m}$. 
RELAP5 also allows the modification of the channels shape factor; a parameter that allows the user to adjust the laminar friction factor due to the non-circular shape of the channel:

$$
f R e=24 \cdot\left(1-1.3553 x+1.9467 x^{2}-1.7012 x^{3}+0.9564 x^{4}-0.2537 x^{5}\right)
$$

where ' $x$ ' is the channel width to length ratio. For a gap width of 0.0018 and an arc length of $0.0759 \mathrm{~m}$, the shape factor input into the RELAP5 model was 0.688 (shape factor $=16 / f R e$ ).

For the reference simulations, the axial discretization of the coolant volume was 24 equal spaced volumes within the heated region ( $0.8 \mathrm{~m}$ long) of the fuel element and an additional volume at the top and bottom of the unheated length ( $0.052 \mathrm{~m}$ and $0.051 \mathrm{~m}$ long, respectively for HEU).

\subsubsection{Minor loss coefficients}

The only loss coefficients in the fuel element region implemented in the RELAP5 model are from the application of the abrupt area change model to the junctions at the inlet and outlet of the fuel element.

\subsubsection{Heat structures}

The heat structures defining the fuel element were assumed to be rectangular plates with a thickness of $1.27 \mathrm{~mm}$ and length equal to the involute length. A heat structure was created for each of the 'hot stripes' as well as for the remaining heated and unheated section of the fuel element. In the thickness direction, the fuel element structures contained 10 nodes with 3 radial regions in each of the sections: left cladding, fuel (or center clad) and right cladding. The 12 word RELAP5 format was used to include specifying a natural convection length equal to the height of the fuel; a value used in the natural convection heat transfer correlation (Churchill and Chu, as described in [1]) at the plate surface. The axial discretization of the heat structures was the same as the coolant. A detailed table of power density as a function of radius and axial position was produced from MCNP calculations and the information was consolidated by summing the power distribution within each of the heat structure axial nodes (discussed further in Section 2.9.4).

\subsubsection{Reflector}

The reflector region consists of RELAP5 volumes 100-118 and each of these was discretized axially to match above, at and below the fuel element region. The CATHARE model uses a heavy water volume of $11.2 \mathrm{~m}^{3}$. However, there are a number of structures (beam tubes and sources) within the reflector region (for experimental purposes) which have not been accounted for. A detailed hand calculation (Table 14) accounting for these structures results in a reflector volume of $10.7 \mathrm{~m}^{3}$. For simplicity, it was assumed that all of the beam tube and source volumes were located at the same elevation as the fuel element. At this location, the cross sectional area of the reflector was reduced from $4.69 \mathrm{~m}^{2}$ to $4.15 \mathrm{~m}^{2}$, which reduces the reflector volume from $11.2 \mathrm{~m}^{3}$ to $10.7 \mathrm{~m}^{3}$.

\subsubsection{Minor loss coefficients}

Entry into the reflector region is complicated by the flow turnaround and grid plates. This junction (96) was modeled with a flow area and hydraulic diameter characteristic of the grid plate (drawing Re 3C 53 GS P13 015): 
- $24+4 \times 48$ holes of $1.4 \mathrm{~cm}$ diameter $=332.5 \mathrm{~cm}^{2}$

- 48 gap $15.65 \mathrm{~cm}$ long, $0.7 \mathrm{~cm}$ width and $2 \times 48$ half disk of radius $0.35 \mathrm{~cm}=544.3 \mathrm{~cm}^{2}$

- 48 gap $15.65 \mathrm{~cm}$ long, $0.77 \mathrm{~cm}$ width and $2 \times 48$ half disk of radius $0.385 \mathrm{~cm}=600.8 \mathrm{~cm}^{2}$

Total flow area through the grid was specified as $0.14786 \mathrm{~m}^{2}$. Using the flow area and wetted perimeter, the hydraulic diameter was calculated to be $0.01334 \mathrm{~m}$. The abrupt area change model was applied to this junction. Based on the pressure losses determined from computational fluid dynamic simulations shown in Ref. [14], a forward and reverse loss coefficient of 22.7 was applied to the junction representing the grid plates.

The core bypass, or leakage, is stated to be $42 \mathrm{~m}^{3} / \mathrm{h}$; with $85 \mathrm{~m}^{3} / \mathrm{h}$ flowing through the control rod and $2365 \mathrm{~m}^{3} / \mathrm{h}$ through the fuel. This leakage is modeled with a junction connecting the outlet of branch 34 with the outlet of branch 110. To achieve the target flow rate for a hydraulic diameter and flow area of $0.053 \mathrm{~m}$ and $2.21 \times 10^{-3} \mathrm{~m}^{2}$, respectively, the required loss coefficient at junction 1 of volume 34 was calculated to be 58.85. This value was applied to both the forward and reverse loss coefficient. The hydraulic diameter and flow area of the core bypass were obtained from CATHARE and no other reference was found to confirm the basis for these values.

An abrupt area change model was also applied to the primary outlet piping connection at the top of the reflector region (tank).

\subsubsection{Heat structures}

Heat structures associated with the reflector volume includes the portion of chimney pipe that penetrates into the top of the heavy water vessel, the outer cylinder of the fuel element, and the grid plate (structures 280, 402 and 900, respectively) as well as the heavy water tank bottom, side and top (structures 1001, 1061 and 1181, respectively). The dimensions used in determining these heat structures (and coolant volumes) are shown in Figure 17; the values were based on that provided in Ref. [6]. Heat generation within the reactor vessel was applied to the side of the heavy water tank (structure 1061) and within the coolant. The heat generation for these was assumed to be uniformly distributed and limited to the same elevation as the fuel.

\subsubsection{Reactor power}

Detailed axial and radial power distributions for HEU fuel at BOC (fresh core, no Xenon, "full power" conditions as described in Ref. [15], control rod $24.92 \mathrm{~cm}$ withdrawn) are given in Table 15 . The methodology used to normalize MCNP tallie into power distribution is described in Ref. [15]. The power distribution given in the tables includes the four stripes for the fuel element, the control rod tubes and its coolant volumes and the reactor vessel and its coolant volumes. For the columns in Table 15 with a power fraction highlighted in red background color, the power fractions don't sum to 1.0 because in RELAP5 the total power generated in the coolant is determined by the multiplying the power fraction by the power specified in the neighboring heat structure.

Comparisons of the power distribution used in RELAP5 and CATHARE models are shown in Figure 18 with respect to that calculated with the MCNP code. The range of axial power distribution for each of the 
RELAP5 heat structures $(400,410,420$, and 430$)$ agrees well with that used in the CATHARE model. The same is true for the radial distribution which is shown as vertical lines representing the range of power density for a given stripe.

Table 16 shows the decay heat power curve that has been implemented in the RELAP5 model. The values were obtained from ANSI/ANS-5.1-2005 [16] for thermal fission of ${ }^{235} \mathrm{U}$ at $200 \mathrm{MeV} /$ fission, 24 hours of prior operation, and includes neutron capture by fission products. The decay heat power curve has been applied to the steady state power values for each heat structure and does not take into account the redistribution of energy following a reactor scram. Figure 19 shows that the decay heat power is initially higher than that used in CATHARE but the values are quite similar after $100 \mathrm{~s}$. The CATHARE decay curve takes into account the distribution of gamma energy following a scram.

\section{Steady-State Results}

Table 17 presents the RELAP5 steady-state simulation results in comparison to reference values for a rated power of $100 \%$ and an inlet temperature $\sim 26.5^{\circ} \mathrm{C}$. The reference values were obtained from Ref. [2] and are the same values that were used to evaluate the adequacy of the CATHARE model.

\subsection{Mass flow rate}

The mass flow rate of the RELAP5 model can be set to any flow rate depending on the applied pump speed. For the steady-state simulations this was chosen to match the reference flow rate of $2407 \mathrm{~m}^{3} / \mathrm{hr}$. Similarly, the CRAB loop was chosen to produce a mass flow rate of $24.9 \mathrm{~kg} / \mathrm{s}$. The only flow rates that are governed by the system hydraulics that are not specified are the flow split between the anti-syphon and core inlet and the distribution of the core inlet between the fuel element and the fuel bypass. Good agreement is found for the flow distribution between the fuel element and fuel bypass. The percent difference in flow between the simulated and reference value for the anti-syphon is large; however, it is unclear how this reference value was obtained since there is no flow measurement in this piping. Regardless, the magnitude is quite small compared to other flow rates and this difference will not have a significant effect on simulation results.

\subsection{Absolute pressure}

The primary outlet pressure located at volume 148(3) was specified in the RELAP5 model to match the reference value of 4.0 bar. Good agreement is also found for the pressure at the pump inlet and outlet. The primary inlet pressure is also similar to the reference value (within $2 \%$ ).

\subsection{Pressure differential}

The pressure drop across the heat exchanger for nominal conditions is within $7 \%$ of the reference value. The pressure drop across the fuel plate is lower than the reference value. However, further comparisons can be made for the core region by comparing the inlet and outlet core pressure to CFD simulations in Ref. [14]. The pressure losses in the core are relatively simple to determine as they only consist of frictional losses for the coolant between the fuel plates and the inlet and outlet abrupt area change losses. Utilizing a flow rate of $2407 \mathrm{~m}^{3} / \mathrm{h}\left(2365 \mathrm{~m}^{3} / \mathrm{h}\right.$ through the fuel), the calculated pressure drop in the fuel 
element was 7.8 bar for the RELAP5 models. This value is close to the CFD value 7.71 bar determined at a slightly lower flow rate of $2336 \mathrm{~m}^{3} / \mathrm{hr}$.

\subsection{Temperature}

The primary inlet temperature of $26.6^{\circ} \mathrm{C}$ was indirectly achieved by setting the heat exchanger secondary side temperature boundary condition. The temperature values obtained at either side of the heat exchanger, the primary outlet and control rod outlet are all very similar to the reference values.

\section{Verification of Historical System Transients}

\subsection{Procedure}

Steady-state simulations using the single and four channel core models were performed with RELAP5 for a core inlet temperature of $33^{\circ} \mathrm{C}$ and a rated power of $107 \%$. These results are presented in Table 18 .

These steady-state results were used as initial conditions for the transient simulations. The steady-state solution was continued for $5 \mathrm{~s}$ to ensure a consistent transition. At time equals "zero", it is considered that the power to the primary, CRAB and pressurization pumps is lost. The secondary side of the heat exchanger was also terminated by reducing the heat transfer coefficient boundary condition to $0 \mathrm{~W} / \mathrm{m}^{2} \mathrm{~K}$. The reactor power was tripped at $1.5 \mathrm{~s}$ for loss of electrical power simulations and at $0.0 \mathrm{~s}$ for LOCA simulations. The simulations were run for $495 \mathrm{~s}$ with the simulation results printed according to:

Total Loss of Electrical Power
Every 0.1s for time $=0$ to $10 \mathrm{~s}$
Every $2.0 \mathrm{~s}$ for time $=10$ to $95 \mathrm{~s}$
Every $1.0 \mathrm{~s}$ for time $=95$ to $195 \mathrm{~s}$
Every $2.0 \mathrm{~s}$ for time $=195$ to $495 \mathrm{~s}$

With Locked Pump Impellers

Every $0.1 \mathrm{~s}$ for time $=0$ to $30 \mathrm{~s}$

Every $2.0 \mathrm{~s}$ for time $=30$ to $130 \mathrm{~s}$

Every $1.0 \mathrm{~s}$ for time $=130$ to $495 \mathrm{~s}$
Loss of Coolant Accident Every $0.1 \mathrm{~s}$ for time $=0$ to $2 \mathrm{~s}$

Every $1.0 \mathrm{~s}$ for time $=2$ to $195 \mathrm{~s}$

Every 3.0s for time $=195$ to $495 \mathrm{~s}$

The results in the following sections are not a comprehensive description of all the relevant transient parameters; it provides an overview of the parameters (e.g. temperature, pressure and flow) that could be directly compared to the CATHARE results.

\subsection{Total loss of electrical power}

Four sets of simulations were performed for the total loss of electrical power accidents with RELAP5. These included simulations for both the single and four channel models for each of the pressurizer models. That is, the helium cover gas model and the time dependent pressure boundary condition (BC) model. These are compared with the CATHARE simulation results extracted from figures in Ref. [3].

Figure 20 shows a comparison of the coast down measured within the primary loop. There is relatively good agreement between the RELAP5 and CATHARE simulation results. A temporary increase in flow occurs at about $25 \mathrm{~s}$ due to the opening of the anti-syphon and natural circulation valves. As described in [13], the difference in magnitude is due to the minor loss coefficients included in the tees of the RELAP5 model. Both models approach zero flow rate at about the same time (170 s). The 4-channel core model approaches zero about $15 \mathrm{~s}$ before the 2-channel core model. (At zero power conditions there is no 
difference in cost down between core models, the $15 \mathrm{~s}$ effect is due to the heating of the core). There is no significant impact in the coast down due to the type of pressurizer model used in the RELAP5 simulations.

Figure 21 to Figure 23 show that the timing of the flow inversion in the core occurs at nearly the same time for both codes regardless of the core or pressurizer model. Both codes show some oscillations occur during flow reversal. The long term flow through the core is similar for both codes.

Figure 24 to Figure 26 compare the RELAP5 and CATHARE predicted flows through the valves of the natural circulation and anti-syphon lines. The peak flow in the CRAB loop natural circulation line is similar ( 15 $\mathrm{kg} / \mathrm{s}$ ) for both codes. The long term flow predicted by the RELAP5 model is near zero while CATAHRE model predicts $-1 \mathrm{~kg} / \mathrm{s}$ (flow is reversed in control rod). This difference could be due the model in RELAP5 being based on the current design whereas the CATHARE model was based on an older design.

The peak flow in the chimney natural circulation line is less than half of that predicted by the CATHARE model $(31 \mathrm{~kg} / \mathrm{s}$ versus $76 \mathrm{~kg} / \mathrm{s}$ ). However, the opposite trend occur for the long term flow, that is, the RELAP5 flow rate is $\sim 2.5 \mathrm{~kg} / \mathrm{s}$ whereas the CATHARE flow rate is $<1 \mathrm{~kg} / \mathrm{s}$.

The peak flow in the anti-syphon line is $34 \mathrm{~kg} / \mathrm{s}$ compared to the CATHARE value of $59 \mathrm{~kg} / \mathrm{s}$. The long term flows are similar for both models.

Figure 27 provides a comparison of the primary loop inlet pressure. RELAP5 simulations bound the CATHARE inlet pressure. The time dependent pressure BC predicts a long term pressure slightly below the CATHARE value while the helium cover gas $B C$ pressure is slightly higher. For reference, the inlet and outlet fuel element pressures are shown in Figure 28 and Figure 29, although there is no CATHARE data to compare with.

Figure 30 and Figure 31 show the clad and coolant temperature $8 \mathrm{~cm}$ below the top of the fuelled portion of the fuel element (node 3 in the RELAP5 model). Good agreement is found for the steady-state temperatures. The cladding temperature is $83^{\circ} \mathrm{C}$ and the coolant temperature $37^{\circ} \mathrm{C}$. Between the start of the transient and the peak clad temperature both the coolant and clad temperature are larger than the CATHARE values by as much as $20^{\circ} \mathrm{C}$. This effect could be caused by how the termination of the heat exchangers is modeled. The peak cladding temperature predicted by CATHARE was $130^{\circ} \mathrm{C}$. The average RELAP5 simulation results are similar to this value but undergo large oscillations $\left( \pm 20^{\circ} \mathrm{C}\right)$ for about $50 \mathrm{~s}$ following the initial spike. The long term cladding temperature remains constant between $120^{\circ} \mathrm{C}$ and $130^{\circ} \mathrm{C}$ for the different RELAP5 models, similar to the CATHARE result $\left(\sim 120^{\circ} \mathrm{C}\right)$.

\subsection{Total loss of electrical power with locked pump impellers}

The same sets of figures from the previous section are shown in Figure 32 through Figure 43 but for a total loss of electrical power with locked pump impellers. For these simulations the RELAP5 flow rate was forced to zero at about the same time as the CATHARE model ( 20s). The agreement between the RELAP5 and CATHARE model results is quite similar to the previous section. It is worth noting that the RELAP5 results are much more oscillatory in the early part of this transient (0-150s), although the mean values tend to agree with the CATHARE results. The peak cladding temperature predicted using CATHARE was 
$145^{\circ} \mathrm{C}\left(165^{\circ} \mathrm{C}\right.$ for the RELAP5 simulations). The average RELAP5 simulation results are similar to this value but undergo large oscillations $\left( \pm 30^{\circ} \mathrm{C}\right)$ for about $100 \mathrm{~s}$ following the initial spike. The long term cladding temperature remains constant between $120^{\circ} \mathrm{C}$ and $130^{\circ} \mathrm{C}$ for the different RELAP5 models, similar to the CATHARE result $\left(\sim 130^{\circ} \mathrm{C}\right)$.

\subsection{Loss of coolant accident (hot leg break)}

Four sets of RELAP5 simulations were performed for the LOCAs. The first simulation was done following the methods used for the CATHARE simulations (a steam cover gas and break model geometry used in CATHARE). The next simulation shows the impact of switching from the break model used in CATHARE to that recommended in the RELAP5 user manual [1]. The third simulation was performed with the cover gas switched from steam to helium. The last simulation is the same as the third except that it uses the four channel core model instead of the single channel core model. Results from these simulations are compared with the CATHARE simulation result extracted from figures in Ref. [4].

Figure 44 compares all of the RELAP5 and CATHARE model results for the normalized system mass for a loss of coolant through a hot leg break. The system mass was normalized because the initial mass is slightly different for each of the models. The two RELAP5 models with steam cover gas and different break models produce similar results out to about $180 \mathrm{~s}$, at which point the results of the simplified break model deviate with a modest decrease in system mass. This shows there is not a significant effect on system mass due to the break model in the hot leg. The normalized system mass calculated with RELAP5 for a steam cover gas is also similar to that obtained with the CATHARE code, except in the region of $70 \mathrm{~s}$ to $250 \mathrm{~s}$. As can be seen in Figure 45, this is due to the CATHARE code predicting a spike in mass flow rate through the hot leg break from $70 \mathrm{~s}$ to $90 \mathrm{~s}$. The RELAP5 results for a helium cover gas indicate that the choice of cover gas has a significant effect on the system mass. For this model, the system pressure is sufficient to continually drive fluid out the break until about $75 \mathrm{~s}$ (i.e. location of the sudden change in mass). This time indicates the onset of significant void occurring at the break junction. At this time the hot leg of the primary system is mostly stagnated steam. For a steam cover gas, a significant amount of water remains in the hot leg. This difference is due to the fact that the steam cover gas condenses to water and reduces the system pressure that drives the coolant through the break. For a helium cover gas, $4300 \mathrm{~kg}$ of water is ejected through the break. If a steam cover gas is used instead of helium, as was done for the CATHARE model, the ejected mass is only $2900 \mathrm{~kg}$.

The exit pressure in the primary loop is initially 4 bar for all models at the instant the transient is initiated before quickly dropping to about 1 bar (Figure 47 and Figure 48). The models with a steam cover gas remain at a relatively steady pressure of 0.7 bar with the exception of the RELAP5 model which uses the simplified break model. In this case, there is a sudden drop in pressure at about $200 \mathrm{~s}$ to 0.5 bar. This is coincident with the sudden loss in system mass from Figure 45 . The reason for this drop in pressure is not clear. For the helium cover gas model the pressure immediately fall to near 1 bar, similar to the steam cover gas case. However, the pressure briefly remains near 1 bar before increasing to 1.5 bar during the time of $6 \mathrm{~s}$ to $36 \mathrm{~s}$. This time coincides with the break being in choked flow. After $36 \mathrm{~s}$, the flow is no longer choked and the pressure then drops down to 1 bar at about the time the break transitions from liquid flow to gas flow (75 s). 
Figure 49 and Figure 50 show that both codes and the different REALAP5 models produce similar flow rates in the CRAB loop natural circulation line for the first $70 \mathrm{~s}$ of the transient with a peak flow of almost $15 \mathrm{~kg} / \mathrm{s}$. Following this, the CATHARE code results show a zero flow rate. The RELAP5 results are also near zero but are very chaotic.

Figure 51 and Figure 52 show the flow rate through the primary loop anti-syphon. The peak flow from the CATHARE results is $72 \mathrm{~kg} / \mathrm{s}$ while the REALP5 results are $33 \mathrm{~kg} / \mathrm{s}$. Again, the CATHARE flow is near zero. The RELAP5 results are chaotic for the steam cover gas model but not for the helium cover gas model. The flow is nearly zero because there is no coolant at this level of the reactor.

Figure 53 and Figure 54 show the core flow rate approaches zero about the same time for all RELAP5 models and the CATHARE model. The CATHARE results show that steady-state long term flow is slightly negative while the REALP5 results are quite oscillatory and no steady value can be readily identified.

The steady-state peak cladding temperature is in good agreement for all models (Figure 55 and Figure 56). For the transient, the helium and steam cover gas cases bound CATHARE with peak temperatures of $120^{\circ} \mathrm{C}$ and $90^{\circ} \mathrm{C}$, respectively. The one and four channel core models produce similar results except that two data points for the four channel core model reach $\sim 133^{\circ} \mathrm{C}$.

\subsection{Loss of coolant accident (cold leg break)}

Similar sets of figures are shown for a LOCA with cold leg break. The normalized system mass is shown in Figure 57. All of the models show a similar mass loss for the first $25 \mathrm{~s}$ followed by a decrease in the mass loss rate. After $100 \mathrm{~s}$, the system mass in the CATHARE model remains relatively constant. The RELAP5 model that is similar to the CATHARE model shows that the system slowly decreases with time. Switching to the simplified break model produces different results. In particular, the break goes briefly into choked flow at $25 \mathrm{~s}$ and limits the mass loss relative to the other calculations (which do not go into choked flow). The long term system mass continually decreases at a rate faster than was calculated for the break geometry used in the CATHARE model. The reason for this is not clear, especially since the difference in rate of change for the long term system mass occurs when the flow through the break is nearly zero. The only significant difference from switching the model to a helium cover gas is that the break does not go into choked flow. The reason that the system mass appears essentially insensitive to the cover gas in the cold leg break is that discharge through the break is primarily liquid, whereas for the hot leg break the cover gas impacted whether or not the discharge was gas or liquid.

Figure 58 and Figure 59 show the mass flow rate through the cold leg break. Despite the difference in system mass shown in previous figures, the results look quite similar as the flow rate appears to go to zero in about 75s. Both models show a similar magnitude of oscillation when the flow is near zero.

Figure 60 and Figure 61 show the exit pressure in the primary loop beginning near 4 bar and immediately decreasing to about 0.1 bar. The models with a steam cover gas reach a near steady pressure of 0.5 bar while the helium cover gas models reach a pressure of 1 bar. This difference is related to the condensation of steam when used as a cover gas. 
Figure 62 through Figure 65 show the flow rate through the CRAB loop natural circulation line and the primary loop anti-syphon. The results are similar for all models with the flow rate remaining essentially zero beyond $100 \mathrm{~s}$. Again, the peak magnitude in the primary loop anti-syphon is about half of that calculated in the CATHARE code.

Figure 66 and Figure 67 show a close up of the normalized flow rate through the core. All of the models show the flow approaching zero at about $20 \mathrm{~s}$ and remaining there for the duration of the simulation.

Finally, Figure 68 and Figure 69 show the cladding temperature for a cold break LOCA. The results are quite similar to that obtained for the hot leg break. That is, for the transient, the helium and steam cover gas cases bound CATHARE but with peak temperatures of $120^{\circ} \mathrm{C}$ and $100^{\circ} \mathrm{C}$, respectively. The one and four channel core models produce similar results except that one data point for the four channel core model reaches $\sim 180^{\circ} \mathrm{C}$.

\section{Summary and Conclusions}

The purpose of this document is to provide a verification of the historical system transients of the RHF reactor that have previously been simulated with the CATHARE code. This verification was performed with models developed for the RELAP5 reactor transient analysis code to provide comparisons of temperature, pressure, flows, etc. where direct code comparisons could be made. The reactor scenarios selected for verification included:

$>$ steady-state reactor operation,

$>$ total loss of electrical power accident,

$>$ total loss of electrical power with locked primary pump impellers accident, and

$>$ hot and cold leg LOCAs:

- A break in the hot leg of $114 \mathrm{~mm}$ in diameter located $3.7 \mathrm{~m}$ upstream of the primary pumps.

- A break in the cold leg of $140 \mathrm{~mm}$ in diameter located downstream of the pumps (16.8 meters before the core inlet).

Simulations of the steady-state reactor operation were performed for conditions of $100 \%$ power with an inlet temperature of $26.5^{\circ} \mathrm{C}$ and exit pressure of 4 bar. At these conditions the models were found to be in excellent agreement with known temperatures, pressures and flow rates.

For transient analyses, the steady state conditions where changed to $107 \%$ power with an inlet temperature of $33^{\circ} \mathrm{C}$ to be consistent with historical transient analyses performed with the CATHARE code.

Four sets of simulations were performed for both of the total loss of electrical power accidents using the RELAP5 code. These included simulations for both the single and four channel models for each of the pressurizer models. That is, the helium cover gas model and the time dependent pressure BC model. It was found that the pressurizer model did not have a large effect on the results of the transient. The main difference was the helium cover gas model produced a pressure value 0.7 bar higher than the time 
dependent pressure $B C$ model. This higher pressure results in a higher saturation temperature by about $9^{\circ} \mathrm{C}$. Since the heat transfer at the fuel cladding surface goes into the nucleate boiling regime, the peak cladding temperature is similar to the saturation temperature and the models produce peak cladding temperature differences similar to this $9^{\circ} \mathrm{C}$ magnitude.

For the total loss of electrical power accident, the peak cladding temperature predicted using the CATHARE code was $130^{\circ} \mathrm{C}$. The average RELAP5 simulation results are similar to this value but undergo large oscillations $\left( \pm 20^{\circ} \mathrm{C}\right)$ for about $50 \mathrm{~s}$ following the flow reversal. The long term cladding temperature remains constant between $120^{\circ} \mathrm{C}$ and $130^{\circ} \mathrm{C}$ for the different RELAP5 models, similar to the CATHARE result $\left(\sim 120^{\circ} \mathrm{C}\right)$.

For a total loss of electrical power with locked impellers, the peak cladding temperature predicted using CATHARE was $145^{\circ} \mathrm{C}\left(165^{\circ} \mathrm{C}\right.$ for the RELAP5 simulations). The cladding temperatures predicted by RELAP5 are similar to CATHARE but undergo large oscillations $\left( \pm 30^{\circ} \mathrm{C}\right)$ for about $100 \mathrm{~s}$ following the flow reversal. The long term cladding temperature remains constant between $120^{\circ} \mathrm{C}$ and $130^{\circ} \mathrm{C}$ for the different RELAP5 models, similar to the CATHARE result $\left(\sim 130^{\circ} \mathrm{C}\right)$. The single and four channel core models were found to have similar peak cladding temperatures (within $5^{\circ} \mathrm{C}$ ) that were also in agreement with the CATHARE simulation results.

A difference between the RELAP5 and CATHARE simulation results was the magnitude of the natural circulation flow in the three different natural circulation pipes. This difference was mainly due to the minor loss coefficients specified at the tee junctions in the RELAP5 model. While data directly measuring the natural circulation flow was not available, comparison of the measured flow diverted from the primary piping following the opening of the natural circulation valves supported the use of the minor loss coefficients and the magnitude of natural circulation flows calculated by RELAP5.

Four sets of simulations were performed for the hot and cold leg LOCAs using the RELAP5 code. The first simulation was done following the methods used for the CATHARE simulations (a steam cover gas and the break model geometry used in CATHARE). The second simulation was the same as the first but utilized a simplified break model. The third simulation was the same as the second but the cover gas was changed from steam to helium. The last simulation was the same as the third but utilized the four channel core model instead of the single channel core model. These simulations showed that the choice of cover gas has an impact on the long term pressure following a LOCA. For models that used steam as a cover gas, condensation of the steam resulted in a system pressure lower than what was calculated for helium. For the hot leg LOCA this had a noticeable impact on the amount of coolant discharged through the break since the type of cover gas impacted whether or not vapor reached the break. This was not true for the cold leg break as the break discharge was liquid regardless of the cover gas.

Comparisons of the results from the break geometry used in the CATHARE simulations and the simplified break model shows that the break geometry can impact the results of the cold break LOCA. The reason for this was not clear as the difference occurred primarily when the flow rate through the break was near zero. 
For the hot leg LOCA, the helium and steam cover gas cases bound CATHARE results with peak temperatures of $120^{\circ} \mathrm{C}$ and $90^{\circ} \mathrm{C}$, respectively. The one and four channel core models produce similar results except that two data points for the four channel core model reach $\sim 133^{\circ} \mathrm{C}$. Similar results were obtained for the cold leg LOCA; that is, the helium and steam cover gas cases bound CATHARE with peak temperatures of $120^{\circ} \mathrm{C}$ and $100^{\circ} \mathrm{C}$, respectively. The one and four channel core models produce similar results except that one data point for the four channel core model reaches $\sim 180^{\circ} \mathrm{C}$.

It was also found that using a non-condensable gas in the models for LOCA simulations created difficulties in running the RELAP5/MOD3.3 code to completion. Some of the options available in the RELAP5 code to modify or improve the numerical scheme or model options were utilized to successfully overcome calculation failures in most cases. Based on numerous preliminary calculations, the numerical options did not appear to have any significant impact on the main outcomes of the simulation results (when used appropriately). 


\section{References}

[1] RELAP5/MOD3.3 Code Manual, Nuclear Safety Analysis Division, July 2003, Information Systems Laboratories, Inc., Rockville, Maryland, and Idaho Falls, Idaho.

[2] E. Pelle, "Note De Realization Du Jeu De Données Et Validation Du Transitoire Stabilise," CSSI/3111/AB03B023/NRT/V12E/2.0, February 2004.

[3] E. Pelle, "Note De Realization Des Transitoires Accidentels 《< Hors Brèche >," CSSI/3111/AB03B023/NRT/HBRE/2.0, March 2004.

[4] E. Pelle, "Note De Realization Des Transitoires Accidentels 《< Brèche >>," CSSI/3111/AB03B023/NRT/BRE/2.0, June 2004.

[5] "Réacteur à Haut Flux", INB n67, Rapport de Sureté, 2004.

[6] Y. Calzavara, S. Fuard, A. Bergeron, Evaluation of measurements performed on the French High Flux Reactor (RHF), NEA/NSC/DOC(2006).

[7] B. Dionne, A. Bergeron, J.R. Licht, Y.S. Kim, and G.L. Hofman, "Thermal properties for the thermalhydraulics analyses of the BR2 maximum nominal heat flux", ANL/RERTR/TM-11-20 Rev 1, January, 2015.

[8] MatWeb website, http://www.matweb.com/search/DataSheet.aspx?MatGUID=5edc39d3 b0fd 44efa9fdd90d049c3737\&ckck=1

[9] MatWeb website, http://www.matweb.com/search/DataSheet.aspx?MatGUID=5f6bec9d37a84 a77bcf295bf3653ac58

[10] hpalloy website, http://www.hpalloy.com/alloys/descriptions/NICKEL201.html

[11] I.E. Idel'chik, Handbook of hydraulic resistance, 1966.

[12] "Etude du refroidissement de l'élément combustible et de la barre de pilotage du Réacteur à Haut Flux, à la suite de la perte totale des alimentations électriques," SPECIFICATION TECHNIQUE Re 3C 53 S 3001 Ind. A.

[13] J. Licht, A. Bergeron, B. Dionne and F. Thomas, "RHF RELAP5 Model and Preliminary Loss-ofOffsite-Power Simulation Results for LEU Conversion," ANL/GTRI/TM-14/7, August 2014.

[14] F. Thomas, Y. Calzavara and H. Guyon (ILL); A. Tentner and A. Bergeron (ANL), "Thermohydraulique d'une lame RHF," Rapport RHF n 414, February 29, 2012.

[15] Y. Calzavara et al. "Etude Neutronique du RHF," RHF report 447, 2012.

[16] American Nuclear Society, ANSI/ANS-5.1-2005, Decay Heat Power in Light Water Reactors, April $1^{\text {st }}, 2005$. 


\section{Tables}

Table 1 Material Properties used in RELAP5 model.

\begin{tabular}{|c|c|c|c|c|c|c|}
\hline $\begin{array}{c}\text { RELAP5 } \\
\text { Material } \\
\#\end{array}$ & Material & Applies to: & Density & $\begin{array}{c}\text { Specific } \\
\text { Heat }\end{array}$ & $\begin{array}{c}\text { Heat } \\
\text { Capacity }\end{array}$ & $\begin{array}{c}\text { Thermal } \\
\text { Conductivity }\end{array}$ \\
\cline { 4 - 7 } & & {$\left[\mathrm{kg} / \mathrm{m}^{3}\right]$} & {$[\mathrm{J} / \mathrm{kg}-\mathrm{K}]$} & {$\left[\mathrm{J} / \mathrm{m}^{3}-\mathrm{K}\right]$} & {$[\mathrm{W} / \mathrm{m}-\mathrm{K}]$} \\
\hline 1 & UAl $\mathrm{x}-\mathrm{Al}$ & HEU fuel @ BOC & 3580 & 646 & $2.3124 \mathrm{E} 6$ & 80.5 \\
\hline 5 & AlFeNi & $\begin{array}{c}\text { Cladding / } \\
\text { piping/ control } \\
\text { rod }\end{array}$ & 2702 & 903 & $2.4399 \mathrm{e} 6$ & 130 \\
\hline 6 & INOX316 & Piping & 7990 & 500 & $3.9950 \mathrm{e} 6$ & 16.2 \\
\hline 7 & D2O & Chimney & 1100 & 4200 & $4.6200 \mathrm{e} 6$ & 0.63 \\
\hline 8 & Ni201 & Control Rod & 8900 & 440 & $3.9160 \mathrm{e} 6$ & 70 \\
\hline
\end{tabular}

Table 2 Minor loss coefficients for elbows in the primary loop

\begin{tabular}{|l|c|c|c|c|c|}
\hline \multirow{2}{*}{ Description } & $\begin{array}{c}\text { Idel'chik } \\
\text { Diagram }\end{array}$ & $\begin{array}{c}\text { Approximate } \\
\text { radius }(\mathrm{m})\end{array}$ & $\begin{array}{c}\text { Diameter } \\
(\mathrm{m})\end{array}$ & $\begin{array}{c}\text { Loss } \\
\text { Coefficient }\end{array}$ & $\begin{array}{c}\text { Application } \\
\text { Point in } \\
\text { RELAP5 }\end{array}$ \\
\hline \multirow{2}{*}{$\begin{array}{l}\text { Smooth elbow with } \\
\mathrm{R} / \mathrm{D}>1.5 \text { and } 0<\theta \leq 180\end{array}$} & \multirow{2}{*}{$6-2$} & 1.252 & 0.394 & 0.218 & $152(3)$ \\
\cline { 3 - 6 } & & 1.252 & 0.394 & 0.218 & $230(3)$ \\
\cline { 3 - 6 } $\begin{array}{l}\text { Sharp bends with } \\
0.5<R / D<1.5 \text { and } 0<\theta \leq 180\end{array}$ & \multirow{2}{*}{$6-1$} & 1.066 & 0.400 & 0.212 & $242(2)$ \\
\cline { 3 - 6 } & & 0.509 & 0.440 & 0.232 & $178(1)$ \\
\cline { 3 - 6 } & & 0.531 & 0.440 & 0.243 & $186(1)$ \\
\hline
\end{tabular}


Table 3 Primary pump specifications.

\begin{tabular}{|c|c|c|c|}
\hline & $\begin{array}{l}\text { SAR (Values } \\
\text { given for } \\
\text { each pump) }\end{array}$ & $\begin{array}{c}\text { CATHARE } \\
\text { (Consolidation of } \\
2 \text { pumps) }\end{array}$ & $\begin{array}{l}\text { RELAP5 (Values applied } \\
\text { to each pump) }\end{array}$ \\
\hline \multicolumn{4}{|l|}{ Geometry } \\
\hline Pipe inlet diameter & $0.3 \mathrm{~m}$ & $0.444 \mathrm{~m}$ & $0.3 \mathrm{~m}$ \\
\hline Pipe outlet diameter & $0.3 \mathrm{~m}$ & $0.444 \mathrm{~m}$ & $0.3 \mathrm{~m}$ \\
\hline Coolant volume & $0.102 \mathrm{~m}^{3}$ & $0.204 \mathrm{~m}^{3}$ & $0.102 \mathrm{~m}^{3}$ \\
\hline Length & & $1.32 \mathrm{~m}$ & $1.44 \mathrm{~m}$ \\
\hline Flow area & & $0.15483 \mathrm{~m}^{2}$ & $0.070686 \mathrm{~m}^{2}$ \\
\hline \multicolumn{4}{|c|}{ Characteristics } \\
\hline Speed (100\%) & 2960 rpm & $2970 \mathrm{rpm}$ & $309.97 \mathrm{rev} / \mathrm{s}(2960 \mathrm{rpm})$ \\
\hline Flow (100\%) & $1090 \mathrm{~m}^{3} / \mathrm{h}$ & $2407 \mathrm{~m}^{3} / \mathrm{h}$ & $1090 \mathrm{~m}^{3} / \mathrm{h}$ \\
\hline Head (100\%) & $129 \mathrm{~m}$ & $\sim 127 \mathrm{~m}$ & $129 \mathrm{~m}$ \\
\hline Pump Power (torque) & $600 \mathrm{~kW}$ & $3200 \mathrm{~N}-\mathrm{m}$ & $1935.6 \mathrm{~N}-\mathrm{m}$ \\
\hline Rated Density & & & $1100 \mathrm{~kg} / \mathrm{m}^{3}$ \\
\hline Inertia & 205 kg-m ${ }^{2}$ & 430 kg-m ${ }^{2}$ & $205 \mathrm{~kg}-\mathrm{m}^{2}$ \\
\hline Homologous Curves & & Yes & Based on CATHARE \\
\hline $\begin{array}{l}\text { Torque Friction } \\
\text {-Coefficient } 1 \\
\text {-Coefficient } 2 \\
\text {-Coefficient } 3 \\
\text {-Coefficient } 4\end{array}$ & & $\begin{array}{c}4.65 \\
0.26 \\
0.0 \\
0.0 \\
\end{array}$ & $\begin{array}{l}\text { Determined from loss } \\
\text { of flow tests }\end{array}$ \\
\hline
\end{tabular}

Table 4 Homologous curves implemented in RELAP5 model (normal operation) ${ }^{5}$.

\begin{tabular}{|c|c|c|c|c|c|}
\hline $\mathrm{v} / \alpha$ & $\mathrm{h} / \alpha^{2}$ & $\beta / \alpha^{2}$ & $\alpha / \mathrm{v}$ & $\mathrm{h} / \mathrm{v}^{2}$ & $\beta / \mathrm{v}^{2}$ \\
\hline 0 & 1.208 & 0.559 & 0 & -0.5 & -0.45 \\
\hline 0.1 & 1.198 & 0.588 & 0.1 & -0.42 & -0.3 \\
\hline 0.2 & 1.193 & 0.628 & 0.2 & -0.3 & -0.2 \\
\hline 0.3 & 1.178 & 0.663 & 0.3 & -0.01 & -0.1 \\
\hline 0.4 & 1.168 & 0.706 & 0.4 & 0.008 & 0.1 \\
\hline 0.5 & 1.158 & 0.745 & 0.5 & 0.1 & 0.3 \\
\hline 0.6 & 1.14 & 0.800 & 0.6 & 0.139 & 0.438 \\
\hline 0.7 & 1.133 & 0.853 & 0.7 & 0.358 & 0.567 \\
\hline 0.8 & 1.098 & 0.902 & 0.8 & 0.541 & 0.702 \\
\hline 0.9 & 1.046 & 0.951 & 0.9 & 0.754 & 0.858 \\
\hline 1 & 1 & 1 & 1 & 1 & 1 \\
\hline
\end{tabular}

${ }^{5} \alpha=$ rotational ratio; $v=$ volumetric flow ratio; $h=$ head ratio; and $\beta=$ torque ratio.

Verification of Historical System Transient Simulations for the RHF Research Reactor 
Table 5 Torque friction coefficients.

\begin{tabular}{|c|c|c|c|c|}
\hline & TF0 & TF1 & TF2 & TF3 \\
\hline Lower Bound & 10 & 700 & 3300 & 0 \\
\hline Upper Bound & -30 & 740 & 3310 & 0 \\
\hline
\end{tabular}

Table 6 RHF heat exchanger description

\begin{tabular}{|c|c|c|c|}
\hline Parameter & Value & Units & Comments \\
\hline Number of heat exchangers & 2 & & Modeled as 1 equivalent heat exchanger in RELAP5 \\
\hline \multicolumn{4}{|c|}{ HX Drawing (drawing 4C-51-P1-001) Specifications } \\
\hline Number of tubes & 2080 & & \multirow{5}{*}{ Information from SAR [5] } \\
\hline Tube outer diameter & 0.02 & $\mathrm{~m}$ & \\
\hline Tube wall thickness & 0.0015 & $\mathrm{~m}$ & \\
\hline HX tube length & 6.02 & $\mathrm{~m}$ & \\
\hline Shell inner diameter & 1.25 & $\mathrm{~m}$ & \\
\hline \multicolumn{4}{|l|}{ Calculated Parameters } \\
\hline Tube wetted perimeter & 65.35 & $\mathrm{~m}$ & \multirow{9}{*}{ These numbers represent half of the heat exchanger } \\
\hline Shell wetted perimeter & 3.21 & $\mathrm{~m}$ & \\
\hline Total wetted perimeter & 68.56 & $\mathrm{~m}$ & \\
\hline Tube area & 0.33 & $\mathrm{~m}^{2}$ & \\
\hline Shell area & 0.61 & $\mathrm{~m}^{2}$ & \\
\hline Total area & 0.29 & $\mathrm{~m}^{2}$ & \\
\hline Tube volume & 1.97 & $\mathrm{~m}^{3}$ & \\
\hline Shell volume & 3.69 & $\mathrm{~m}^{3}$ & \\
\hline Total volume & 1.73 & $\mathrm{~m}^{3}$ & \\
\hline Total volume $(x 2)$ & 3.45 & $\mathrm{~m}^{3}$ & Total volume within heat exchanger \\
\hline Actual & 3.40 & $\mathrm{~m}^{3}$ & Information from SAR [5] \\
\hline \multicolumn{4}{|l|}{ RELAP5 VOLUME (194) } \\
\hline Divisions & 20 & & \\
\hline Total length & 12.04 & $\mathrm{~m}$ & \multirow{2}{*}{$\begin{array}{l}\text { Equivalent heat exchanger utilizes length from } 1 \text { heat } \\
\text { exchanger }\end{array}$} \\
\hline Unit length & 0.602 & $\mathrm{~m}$ & \\
\hline Area & 0.57 & $\mathrm{~m}^{2}$ & Based on 2 heat exchangers \\
\hline Hydraulic diameter & 0.017 & $\mathrm{~m}$ & $4 \times$ flow area / wetted perimeter of cross section \\
\hline \multicolumn{4}{|c|}{ RELAP5 HEAT STRUCTURE (1941) } \\
\hline Divisions & 20 & & \\
\hline Left boundary & 0.0085 & $\mathrm{~m}$ & Inner radius of a tube \\
\hline Right boundary & 0.01 & $\mathrm{~m}$ & Outer radius of a tube \\
\hline Cylinder height / division & 1252.16 & $\mathrm{~m}$ & Accounts for all tubes in both heat exchangers \\
\hline
\end{tabular}


Table 7 Minor loss coefficient for CRAB loop elbow.

\begin{tabular}{|l|c|c|c|c|c|}
\hline Description & $\begin{array}{c}\text { Idel'chik } \\
\text { Diagram }\end{array}$ & $\begin{array}{c}\text { Approximate } \\
\text { radius }(\mathrm{m})\end{array}$ & $\begin{array}{c}\text { diameter } \\
(\mathrm{m})\end{array}$ & $\begin{array}{c}\text { Loss } \\
\text { Coefficient }\end{array}$ & $\begin{array}{c}\text { Application } \\
\text { point in RELAP5 }\end{array}$ \\
\hline $\begin{array}{l}\text { Smooth elbow with } \\
\mathrm{R} / \mathrm{D}>1.5 \text { and } 0<\mathrm{t} \leq 180\end{array}$ & $6-2$ & 0.24 & 0.08 & 0.216 & $\begin{array}{c}\text { Split between } \\
\text { junctions } 454 \\
\text { and 458 }\end{array}$ \\
\hline
\end{tabular}

Table 8 RELAP5 control system values for the valves.

\begin{tabular}{|c|c|c|c|c|c|c|}
\hline RELAP5 & Description & $\begin{array}{c}\text { Relative } \\
\text { elevation } \\
(\mathrm{m})\end{array}$ & $\begin{array}{c}\text { Pressure head } \\
\text { correction (bar) }\end{array}$ & $\begin{array}{c}\text { RELAP5 opening } \\
\text { pressure } \\
\text { differential (bar) }\end{array}$ & $\begin{array}{c}\text { Calibrated } \\
\text { pressure } \\
\text { differential (bar) }\end{array}$ & $\begin{array}{c}\text { Opening } \\
\text { rate } \\
{\left[\mathrm{s}^{-1}\right]}\end{array}$ \\
\hline 282 & $\begin{array}{c}\text { Anti-syphon } \\
\text { (Primary loop) }\end{array}$ & 11.12 & 1.200 & 2.200 & 2.050 & 0.176 \\
\hline 502 & $\begin{array}{c}\text { Natural circulation } \\
\text { (chimney) }\end{array}$ & 9.60 & 1.036 & 2.036 & 1.886 & 0.320 \\
\hline 512 & $\begin{array}{c}\text { Natural circulation } \\
\text { (CRAB loop) }\end{array}$ & 10.39 & 1.121 & 2.121 & 1.971 & 0.248 \\
\hline
\end{tabular}

Table 9 normalized flow area as a function normalized valve position.

\begin{tabular}{|c|c|c|c|}
\hline \multirow{2}{*}{$\begin{array}{l}\text { Normalized } \\
\text { position }\end{array}$} & \multicolumn{2}{|c|}{ Flow Area $\left[\mathrm{m}^{2}\right]$} & \multirow{2}{*}{$\begin{array}{c}\text { Normalized } \\
\text { flow area }\end{array}$} \\
\hline & 502,512 & 282 & \\
\hline 0 & 0.000000 & 0.000000 & 0.0 \\
\hline 0.1 & 0.000200 & 0.000409 & 0.052 \\
\hline 0.2 & 0.000548 & 0.001118 & 0.142 \\
\hline 0.3 & 0.000971 & 0.001982 & 0.252 \\
\hline 0.4 & 0.001438 & 0.002934 & 0.374 \\
\hline 0.5 & 0.001924 & 0.003927 & 0.5 \\
\hline 0.6 & 0.002411 & 0.004920 & 0.626 \\
\hline 0.7 & 0.002877 & 0.005872 & 0.748 \\
\hline 0.8 & 0.003301 & 0.006736 & 0.858 \\
\hline 0.9 & 0.003648 & 0.007445 & 0.948 \\
\hline 1 & 0.003848 & 0.007854 & 1.0 \\
\hline
\end{tabular}


Table 10 Target coast down pressure and the required pressure at RELAP5 boundary condition.

\begin{tabular}{|c|c|c|c|c|c|}
\hline $\begin{array}{c}\text { Time after trip } \\
(\mathrm{sec})\end{array}$ & $\begin{array}{c}\text { Target } \\
\text { pressure (bar) }\end{array}$ & $\begin{array}{c}\text { Pressure } \\
\text { specified at } \\
\text { volume 370 } \\
\text { (bar) }\end{array}$ & $\begin{array}{c}\text { Time after trip } \\
(\mathrm{sec})\end{array}$ & $\begin{array}{c}\text { Target } \\
\text { pressure (bars) }\end{array}$ & $\begin{array}{c}\text { Pressure } \\
\text { specified at } \\
\text { volume 370 } \\
\text { (bar) }\end{array}$ \\
\hline 0.00 & 4 & 2.21 & 4.08 & 3.49 & 1.8 \\
\hline 0.16 & 4.1 & 2.41 & 4.24 & 3.46 & 1.77 \\
\hline 0.39 & 4.25 & 2.56 & 4.94 & 3.32 & 1.63 \\
\hline 0.71 & 4.3 & 2.61 & 5.24 & 3.26 & 1.57 \\
\hline 0.85 & 4.32 & 2.63 & 6.10 & 3.14 & 1.45 \\
\hline 1.18 & 4.26 & 2.57 & 7.31 & 2.97 & 1.28 \\
\hline 1.41 & 4.22 & 2.53 & 7.72 & 2.91 & 1.22 \\
\hline 1.65 & 4.17 & 2.48 & 8.93 & 2.75 & 1.06 \\
\hline 1.77 & 4.15 & 2.46 & 9.11 & 2.72 & 1.03 \\
\hline 1.89 & 4.11 & 2.42 & 10.54 & 2.53 & 0.84 \\
\hline 2.24 & 3.98 & 2.29 & 12.12 & 2.43 & 0.74 \\
\hline 2.36 & 3.95 & 2.26 & 12.85 & 2.38 & 0.69 \\
\hline 2.83 & 3.83 & 2.14 & 13.27 & 2.36 & 0.67 \\
\hline 2.93 & 3.81 & 2.12 & 14.00 & 2.33 & 0.39 \\
\hline 3.07 & 3.77 & 2.08 & 15.00 & 2.3 & 0.36 \\
\hline 3.54 & 3.64 & 1.95 & $15.00+$ & 2.3 & 0.36 \\
\hline
\end{tabular}

Table 11 Geometry of the control rod coolant volumes.

\begin{tabular}{|c|c|c|c|c|c|}
\hline $\begin{array}{c}\text { RELAP5 } \\
\text { Volume }\end{array}$ & Geometry & $\begin{array}{c}\text { Inner } \\
\text { Radius }[\mathrm{m}]\end{array}$ & $\begin{array}{c}\text { Outer } \\
\text { Radius }[\mathrm{m}]\end{array}$ & $\begin{array}{c}\text { Flow Area } \\
{\left[\mathrm{m}^{2}\right]}\end{array}$ & $\begin{array}{c}\text { Length } \\
(\mathrm{m})\end{array}$ \\
\hline 60 & Cylinder & - & 0.1074 & $3.6238 \mathrm{e}-2$ & 0.598 \\
\hline 62 & Cylinder & - & 0.0901 & $2.5503 \mathrm{e}-2$ & 1.377 \\
\hline 70 & Annulus & 0.0942 & 0.0978 & $2.1715 \mathrm{e}-3$ & 0.357 \\
\hline 72 & Annulus & 0.1038 & 0.1074 & $2.3886 \mathrm{e}-3$ & 0.357 \\
\hline 74 & Annulus & 0.1114 & 0.1184 & $5.5036 \mathrm{e}-3$ & 0.955 \\
\hline 76 & Annulus & 0.1244 & 0.1304 & $4.8029 \mathrm{e}-3$ & 0.955 \\
\hline 78 & Annulus & 0.0942 & 0.1304 & $6.6607 \mathrm{e}-3$ & 0.920 \\
\hline 80 & Annulus & 0.1220 & 0.1304 & $1.4700 \mathrm{e}-2$ & 0.101 \\
\hline
\end{tabular}


Table 12 Control rod flow distribution summary (From Table 27.8 of the SAR)

\begin{tabular}{|c|c|c|c|c|c|c|}
\hline $\begin{array}{c}\text { Channel } \\
\text { [RELAP5 junction] }\end{array}$ & $\begin{array}{c}\text { Inner } \\
\text { Diameter } \\
(\mathrm{mm})\end{array}$ & $\begin{array}{l}\text { Outer } \\
\text { Diameter } \\
(\mathrm{mm})\end{array}$ & $\begin{array}{c}\text { SAR } \\
\text { Table } 27.8 \\
\text { flow rate } \\
\text { (kg/s) }\end{array}$ & $\begin{array}{l}\text { RELAP5 flow } \\
\text { rate without } \\
\text { loss factor } \\
(\mathrm{kg} / \mathrm{s})\end{array}$ & $\begin{array}{l}\text { RELAP5 flow } \\
\text { rate with loss } \\
\text { factor } \\
(\mathrm{kg} / \mathrm{s})\end{array}$ & $\begin{array}{l}\text { Required } \\
\text { loss } \\
\text { factor }\end{array}$ \\
\hline Total & & & 15.28 & 15.28 & 15.28 & \\
\hline $\begin{array}{c}\text { Between fuel } \\
\text { element and tall } \\
\text { Ni tube } \\
{[58(4)]}\end{array}$ & 124.4 & 130.4 & 5.98 & 4.42 & 5.98 & 20.13 \\
\hline $\begin{array}{c}\text { Between tall } \mathrm{Ni} \\
\text { and tall Al tube } \\
{[58(3)]}\end{array}$ & 111.4 & 118.4 & 5.10 & 5.19 & 5.10 & 32.12 \\
\hline $\begin{array}{c}\text { Between tall Al } \\
\text { and short Ni tube } \\
{[60(3)]}\end{array}$ & 103.8 & 107.4 & 1.72 & 2.71 & 1.72 & 65.14 \\
\hline $\begin{array}{c}\text { Between short } \mathrm{Ni} \\
\text { and short Al tube } \\
{[60(2)]}\end{array}$ & 94.2 & 97.8 & 1.35 & 2.46 & 1.34 & 87.94 \\
\hline $\begin{array}{c}\text { Center of control } \\
\text { rod } \\
{[60(1)]}\end{array}$ & 0 & 90.1 & 1.12 & 0.51 & 1.13 & 0 \\
\hline Pressure drop & & & $12 \mathrm{kPa}$ & $6 \mathrm{kPa}$ & $18 \mathrm{kPa}$ & \\
\hline
\end{tabular}

Table 13 Fuel element geometry in RELAP5 model

\begin{tabular}{|c|c|c|c|c|c|c|}
\hline $\begin{array}{c}\text { Heat } \\
\text { structure }\end{array}$ & $\begin{array}{c}\text { Inner/Outer } \\
\text { Radius }[\mathrm{mm}]\end{array}$ & $\begin{array}{c}\text { Plate Arc } \\
\text { Length }[\mathrm{mm}]\end{array}$ & $\begin{array}{c}\text { Total Flow } \\
\text { Area }\left[\mathrm{m}^{2}\right]\end{array}$ & $\begin{array}{c}\text { Total } \\
\text { Volume }\left[\mathrm{m}^{3}\right]\end{array}$ & $\begin{array}{c}\text { Hydraulic } \\
\text { Diameter }[\mathrm{m}]\end{array}$ & $\begin{array}{c}\text { Total Surface } \\
\text { Area }\left[\mathrm{m}^{2}\right]\end{array}$ \\
\hline \multirow{2}{*}{401} & $136.9 / 139.8$ & 2.9 & $1.462 \mathrm{e}-3$ & $1.320 \mathrm{e}-3$ & & \multirow{2}{*}{4.450} \\
\cline { 2 - 5 } & $194.7 / 198.8$ & 5.9 & $2.974 \mathrm{e}-3$ & $2.685 \mathrm{e}-3$ & & \\
\hline 400 & $142.7 / 190.4$ & 58.1 & $29.282 \mathrm{e}-3$ & $26.442 \mathrm{e}-3$ & & 29.38 \\
\hline 410 & $192.6 / 194.7$ & 3.0 & $1.512 \mathrm{e}-3$ & $1.365 \mathrm{e}-3$ & \multirow{2}{*}{0.003517} & 1.517 \\
\hline 420 & $190.4 / 192.6$ & 3.0 & $1.512 \mathrm{e}-3$ & $1.365 \mathrm{e}-3$ & & 1.517 \\
\hline 430 & $139.8 / 142.7$ & 3.0 & $1.512 \mathrm{e}-3$ & $1.365 \mathrm{e}-3$ & & 1.517 \\
\hline Total & $136.9 / 198.8$ & 75.9 & 0.03825 & 0.03454 & & 38.381 \\
\hline
\end{tabular}


Table 14 ANL best estimate of coolant volume within heavy water tank.

\begin{tabular}{|c|c|}
\hline Component & $\begin{array}{c}\text { ANL best estimate } \\
\text { volume }\left(\mathrm{m}^{3}\right)\end{array}$ \\
\hline Heavy water tank, cylindrical section (empty) & 10.436 \\
\hline Heavy water tank, conical section (empty) & 1.189 \\
\hline Total & 11.625 \\
\hline Central chimney (within tank) & 0.148 \\
\hline Fuel element & 0.137 \\
\hline Grids & 0.172 \\
\hline \multicolumn{2}{|l|}{ Beam tubes: } \\
\hline $\mathrm{H} 1$ & 0.022 \\
\hline $\mathrm{H} 2$ & 0.029 \\
\hline $\mathrm{H} 3$ & 0.026 \\
\hline $\mathrm{H} 4$ & 0.018 \\
\hline $\mathrm{H} 5$ & 0.045 \\
\hline $\mathrm{H} 6-\mathrm{H} 7$ & 0.021 \\
\hline $\mathrm{H} 8$ & 0.024 \\
\hline $\mathrm{H} 9$ & 0.033 \\
\hline $\mathrm{H} 10$ & 0.038 \\
\hline $\mathrm{H} 11$ & 0.034 \\
\hline $\mathrm{H} 12$ & 0.015 \\
\hline $\mathrm{H} 13$ & 0.030 \\
\hline V4 & 0.003 \\
\hline V7 & 0.003 \\
\hline \multicolumn{2}{|l|}{ Source: } \\
\hline Hot & 0.080 \\
\hline Cold & 0.035 \\
\hline Total & 10.712 \\
\hline
\end{tabular}


Table 15 Power distribution for HEU fuel at BOC.

\begin{tabular}{|c|c|c|c|c|c|c|c|c|c|c|c|c|c|c|c|c|c|}
\hline \multirow{2}{*}{\multicolumn{2}{|c|}{$\begin{array}{l}\text { HEU at BOC } \\
\text { Component }\end{array}$}} & \multicolumn{4}{|c|}{ Fuel } & \multicolumn{10}{|c|}{ Control Rod } & \multicolumn{2}{|c|}{ Reflector } \\
\hline & & Remainder & $\begin{array}{c}\text { Hot } \\
\text { Stripe \#1 }\end{array}$ & $\begin{array}{c}\text { Hot } \\
\text { Stripe \#2 }\end{array}$ & $\begin{array}{c}\text { Hot } \\
\text { Stripe \#3 }\end{array}$ & $\begin{array}{c}\text { Volume } \\
76\end{array}$ & $\begin{array}{l}\text { Long Ni } \\
\text { Rod }\end{array}$ & $\begin{array}{c}\text { Volume } \\
74\end{array}$ & $\begin{array}{l}\text { Long Al } \\
\text { rod }\end{array}$ & $\begin{array}{c}\text { Volume } \\
72\end{array}$ & $\begin{array}{l}\text { Short } \mathrm{Ni} \\
\text { rod }\end{array}$ & $\begin{array}{c}\text { Volume } \\
\quad 70\end{array}$ & $\begin{array}{l}\text { Short Al } \\
\text { rod }\end{array}$ & $\begin{array}{c}\text { Above } \\
\text { Control } \\
\text { Rod }\end{array}$ & $\begin{array}{l}\text { Within } \\
\text { Control } \\
\text { Rod }\end{array}$ & Reflector & $\begin{array}{c}\text { Vessel } \\
\text { Wall }\end{array}$ \\
\hline \multicolumn{2}{|c|}{ Heat Structure } & 400 & 410 & 420 & 430 & 760 & 760 & 740 & 740 & 720 & 720 & 700 & 700 & 360 & 740 & 402 & 1061 \\
\hline \multicolumn{2}{|c|}{ RELAP5 Table } & 9 & 10 & 11 & 12 & 13 & 13 & 14 & 14 & 15 & 15 & 16 & 16 & 17 & 14 & 18 & 19 \\
\hline \multicolumn{2}{|c|}{ Power (W) } & $4.26 \mathrm{E}+07$ & $4.35 E+06$ & $3.84 E+06$ & $2.26 E+06$ & $7.61 E+04$ & $4.73 E+05$ & $6.88 \mathrm{E}+04$ & $5.92 \mathrm{E}+04$ & $4.09 E+03$ & $6.62 E+04$ & $3.64 E+03$ & $8.32 E+03$ & $3.38 \mathrm{E}+04$ & $5.12 E+05$ & $3.69 E+06$ & $3.98 \mathrm{E}+05$ \\
\hline \multirow{26}{*}{$\begin{array}{l}\text { Power } \\
\text { Ratios } \\
\text { (Axial } \\
\text { Segment) }\end{array}$} & 1 & & & & & 0.1019 & 0.6337 & 0.7365 & 0.6337 & 0.0309 & 0.5000 & 0.2186 & 0.5000 & & 8.6453 & & \\
\hline & 2 & 0.0431 & 0.0380 & 0.0381 & 0.0561 & 0.0295 & 0.1832 & 0.2129 & 0.1832 & 0.0309 & 0.5000 & 0.1259 & 0.2880 & & & & \\
\hline & 3 & 0.0417 & 0.0382 & 0.0381 & 0.0540 & 0.0295 & 0.1832 & 0.2129 & 0.1832 & & & 0.0927 & 0.2120 & 0.0833 & & 0.0417 & \\
\hline & 4 & 0.0433 & 0.0400 & 0.0400 & 0.0538 & & & & & & & & & 0.0833 & & 0.0417 & 0.0417 \\
\hline & 5 & 0.0443 & 0.0412 & 0.0413 & 0.0537 & & & & & & & & & 0.0833 & & 0.0417 & 0.0417 \\
\hline & 6 & 0.0445 & 0.0427 & 0.0426 & 0.0498 & & & & & & & & & 0.0833 & & 0.0417 & 0.0417 \\
\hline & 7 & 0.0448 & 0.0448 & 0.0446 & 0.0442 & & & & & & & & & 0.0833 & & 0.0417 & 0.0417 \\
\hline & 8 & 0.0453 & 0.0454 & 0.0452 & 0.0442 & & & & & & & & & 0.0833 & & 0.0417 & 0.0417 \\
\hline & 9 & 0.0466 & 0.0471 & 0.0471 & 0.0444 & & & & & & & & & 0.0833 & & 0.0417 & 0.0417 \\
\hline & 10 & 0.0468 & 0.0472 & 0.0472 & 0.0445 & & & & & & & & & 0.0833 & & 0.0417 & 0.0417 \\
\hline & 11 & 0.0478 & 0.0483 & 0.0484 & 0.0456 & & & & & & & & & 0.0833 & & 0.0417 & 0.0417 \\
\hline & 12 & 0.0478 & 0.0483 & 0.0484 & 0.0456 & & & & & & & & & 0.0833 & & 0.0417 & 0.0417 \\
\hline & 14 & 0.0475 & 0.0480 & 0.0481 & 0.0451 & & & & & & & & & 0.0833 & & 0.0417 & 0.0417 \\
\hline & 15 & 0.0461 & 0.0466 & 0.0467 & 0.0436 & & & & & & & & & & & 0.0417 & 0.0417 \\
\hline & 16 & 0.0457 & 0.0462 & 0.0462 & 0.0432 & & & & & & & & & & & 0.0417 & 0.0417 \\
\hline & 17 & 0.0437 & 0.0442 & 0.0443 & 0.0410 & & & & & & & & & & & 0.0417 & 0.0417 \\
\hline & 18 & 0.0424 & 0.0430 & 0.0431 & 0.0396 & & & & & & & & & & & 0.0417 & 0.0417 \\
\hline & 19 & 0.0403 & 0.0411 & 0.0412 & 0.0376 & & & & & & & & & & & 0.0417 & 0.0417 \\
\hline & 20 & 0.0377 & 0.0388 & 0.0388 & 0.0351 & & & & & & & & & & & 0.0417 & 0.0417 \\
\hline & 21 & 0.0361 & 0.0373 & 0.0373 & 0.0333 & & & & & & & & & & & 0.0417 & 0.0417 \\
\hline & 22 & 0.0320 & 0.0337 & 0.0336 & 0.0287 & & & & & & & & & & & 0.0417 & 0.0417 \\
\hline & 23 & 0.0314 & 0.0332 & 0.0331 & 0.0280 & & & & & & & & & & & 0.0417 & 0.0417 \\
\hline & 24 & 0.0272 & 0.0299 & 0.0297 & 0.0230 & & & & & & & & & & & 0.0417 & 0.0417 \\
\hline & 25 & 0.0263 & 0.0286 & 0.0287 & 0.0207 & & & & & & & & & & & 0.0417 & 0.0417 \\
\hline & 26 & & & & & & & & & & & & & & & 0.0417 & 0.0417 \\
\hline & 27 & & & & & & & & & & & & & & & & 0.0417 \\
\hline
\end{tabular}


Table 16 Decay heat power

\begin{tabular}{|c|c|c|c|}
\hline $\begin{array}{c}\text { Time after trip } \\
\text { (s) }\end{array}$ & $\begin{array}{c}\text { Decay Heat } \\
\text { Power }\end{array}$ & $\begin{array}{c}\text { Time after trip } \\
\text { (s) }\end{array}$ & $\begin{array}{c}\text { Decay Heat } \\
\text { Power }\end{array}$ \\
\hline 1 & $5.79 \%$ & 120 & $2.54 \%$ \\
\hline 1.5 & $5.61 \%$ & 150 & $2.41 \%$ \\
\hline 2 & $5.45 \%$ & 180 & $2.30 \%$ \\
\hline 4 & $5.02 \%$ & 200 & $2.24 \%$ \\
\hline 6 & $4.73 \%$ & 300 & $2.03 \%$ \\
\hline 8 & $4.51 \%$ & 400 & $1.89 \%$ \\
\hline 10 & $4.34 \%$ & 600 & $1.69 \%$ \\
\hline 15 & $4.03 \%$ & 800 & $1.55 \%$ \\
\hline 20 & $3.81 \%$ & 900 & $1.50 \%$ \\
\hline 30 & $3.51 \%$ & 1000 & $1.45 \%$ \\
\hline 40 & $3.31 \%$ & 1500 & $1.25 \%$ \\
\hline 60 & $3.01 \%$ & 1800 & $1.16 \%$ \\
\hline 80 & $2.81 \%$ & 2000 & $1.11 \%$ \\
\hline 100 & $2.66 \%$ & 3600 & $0.85 \%$ \\
\hline
\end{tabular}


Table 17 RELAP5 steady-state simulation results compared to reference values.

\begin{tabular}{|l|c|c|c|c|}
\hline & $\begin{array}{c}\text { Reference } \\
{[2]}\end{array}$ & $\begin{array}{c}\text { RELAP5 } \\
1 \text { core model }\end{array}$ & $\begin{array}{c}\text { RELAP5 } \\
4 \text { core model }\end{array}$ & RELAP5 Location \\
\hline Mass Flow Rate & $\mathrm{kg} / \mathrm{s}\left(\mathrm{m}^{3} / \mathrm{h}\right)$ & $\mathrm{kg} / \mathrm{s}\left(\mathrm{m}^{3} / \mathrm{hr}\right)$ & $\mathrm{kg} / \mathrm{s}\left(\mathrm{m}^{3} / \mathrm{hr}\right)$ & Volume (node) \\
\hline Primary pump & $735.5(2407)$ & $734.2(2407)$ & $734.2(2407)$ & 174 \\
\hline CRAB loop & $24.9(81.5)$ & 24.9 & 24.9 & 490 \\
Anti-syphon & $1.2 \quad(4)$ & 0.82 & 0.82 & 480 \\
\hline Fuel & $722.6(2365)$ & 721.4 & $28.8 / 28.7 / 28.5 / 635$ & $41 / 42 / 43 / 40$ \\
\hline Fuel bypass & $12.8(42)$ & 12.7 & 12.8 & $34(1)$ \\
\hline Absolute Pressure & Bar & Bar & & Volume (node) \\
\hline Primary outlet (9.6m BC2) & 4 & 4.0 & 4.0 & $148(3)$ \\
\hline Pump inlet & 4.2 & 4.2 & 4.2 & $166(10)$ \\
\hline Pump outlet & 16 & 15.8 & 15.8 & $174(1)$ \\
\hline Primary inlet (6.1m BF1) & 13.7 & 13.9 & 13.9 & $234(1)$ \\
\hline Pressure differential & Bar & Bar & & Volume (node) \\
\hline$\Delta p$ pump & 12 & 11.6 & 11.6 & $174(1)-166(10)$ \\
\hline$\Delta p$ heat exchanger & 1.5 & 1.40 & 1.40 & $190(2)-201(1)$ \\
\hline$\Delta p$ fuel plate & 8 & 7.8 & 7.8 & $40(1)-40(6)$ \\
\hline Temperature & Bar & Bar & & Volume (node) \\
\hline Primary inlet (6.1m BF1) & 26.5 & 26.6 & 26.6 & $234(1)$ \\
\hline Heat exchanger outlet & 27.4 & 26.9 & 26.9 & $201(1)$ \\
\hline Heat exchanger inlet & 45.7 & 45.9 & 45.9 & $190(2)$ \\
\hline Primary outlet (9.6m BC2) & 44.9 & 45.1 & 45.1 & $148(3)$ \\
\hline Control rod outlet & 32.3 & 33.8 & 33.8 & 470 \\
\hline
\end{tabular}

${ }^{6}$ Assuming a coolant density of $1100 \mathrm{~kg} / \mathrm{m}^{3}$.

Verification of Historical System Transient Simulations for the RHF Research Reactor 
Table 18 Steady-state conditions.

\begin{tabular}{|l|c|c|c|}
\hline & $\begin{array}{c}\text { RELAP5 } \\
\text { core model }\end{array}$ & $\begin{array}{c}\text { RELAP5 } \\
\text { 4 core model }\end{array}$ & RELAP5 Location \\
\hline Power & MW (\%) & MW (\%) & \\
\hline Reactor & $62.5(107)$ & $62.5(107)$ & \\
\hline Fuel element & $56.8(107)$ & $56.8(107)$ & \\
\hline Mass Flow Rate & $\mathrm{kg} / \mathrm{s}\left(\mathrm{m}^{3} / \mathrm{hr}\right)$ & $\mathrm{kg} / \mathrm{s}\left(\mathrm{m}^{3} / \mathrm{hr}\right)$ & Volume (node) \\
\hline Primary pump & $731.9(2407)$ & $731.9(2407)$ & 174 \\
\hline CRAB loop & 24.9 & 24.9 & 490 \\
Anti-syphon & 0.82 & 0.82 & 480 \\
\hline Fuel & 719.2 & $28.7 / 28.6 / 28.5 / 633.5$ & $41 / 42 / 43 / 40$ \\
\hline Fuel bypass & 12.7 & 12.7 & $34(1)$ \\
\hline Absolute Pressure & Bar & & Volume (node) \\
\hline Primary outlet (9.6m BC2) & 4.0 & 4.0 & $148(3)$ \\
\hline Primary inlet (6.1m BF1) & 13.2 & 13.2 & $234(1)$ \\
\hline Temperature & Bar & & Volume (node) \\
\hline Primary inlet (6.1m BF1) & 32.8 & 32.8 & $234(1)$ \\
\hline Primary outlet (9.6m BC2) & 52.6 & 52.6 & $148(3)$ \\
\hline Peak fuel cladding & 100.4 & 106.6 & $41(14)$ \\
\hline
\end{tabular}




\section{Figures}

\section{Chapter 2 Figures}

Included in RELAP5 model
$\ldots . .$. Excluded
Vass Flow Boundary Condition \#

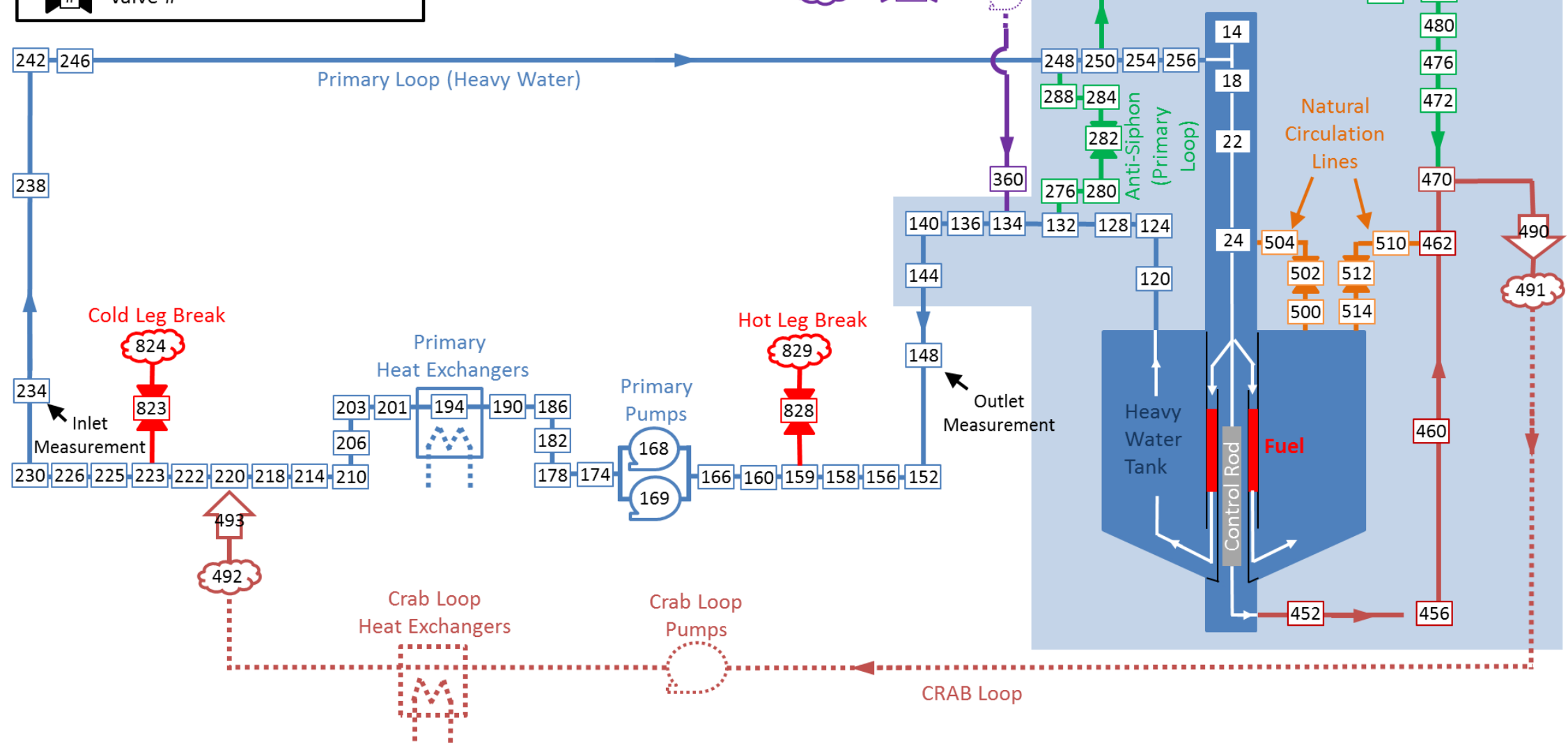

Figure 1 Conceptual drawing of RHF with RELAP5 Volumes (volumes inside heavy water tank not shown) 


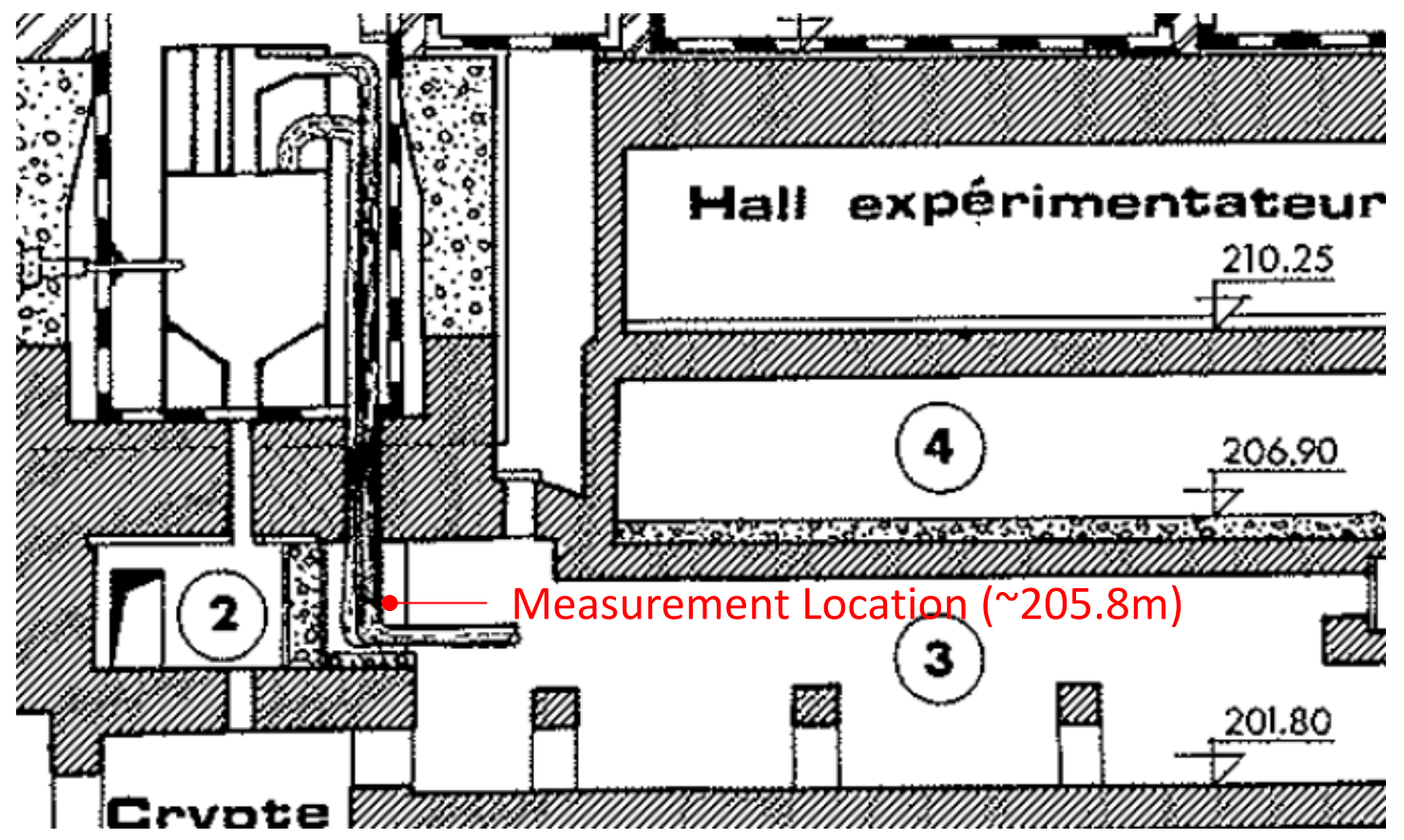

Figure 2 Pressure measurement locations in the RHF facility [5].

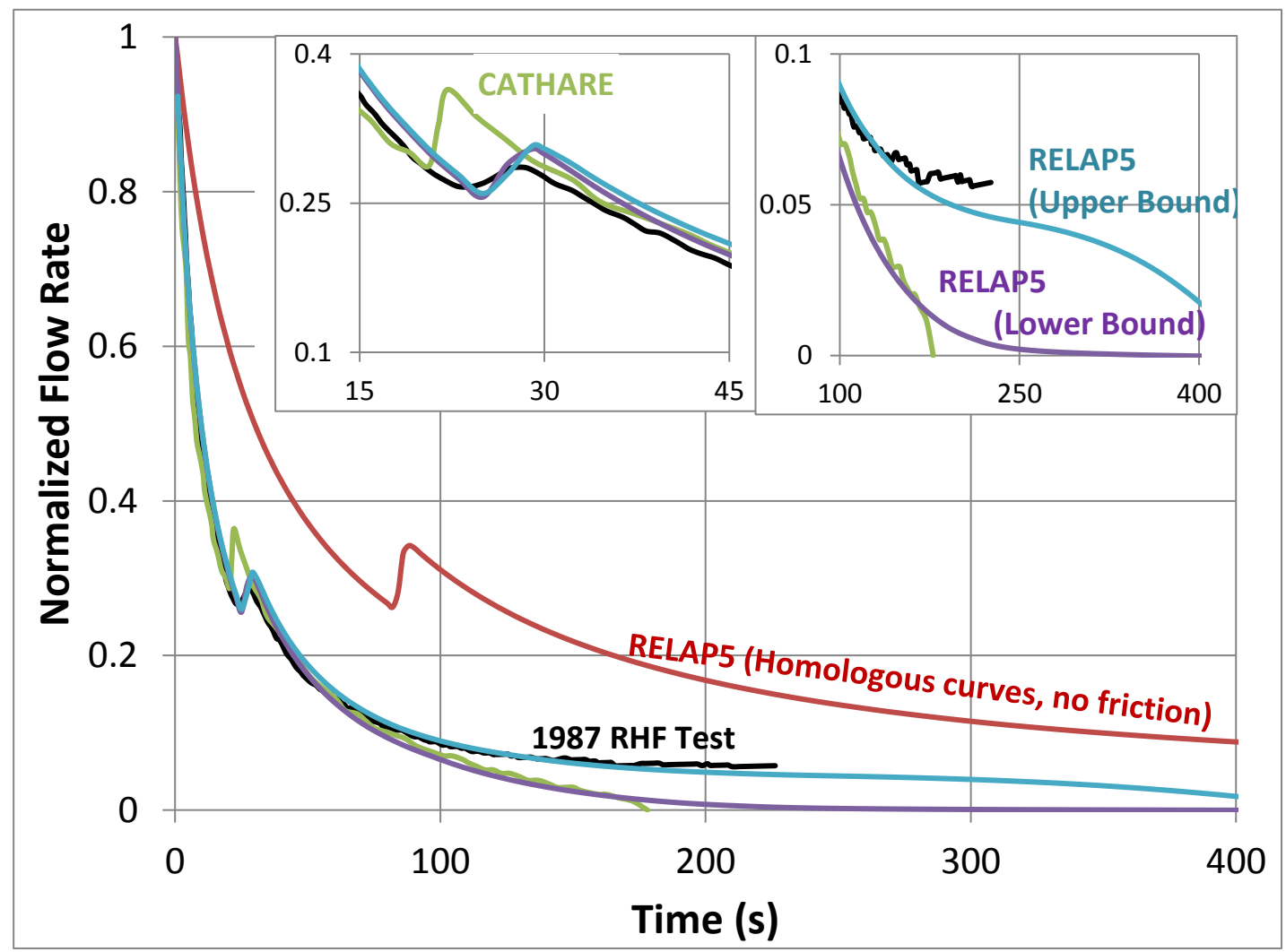

Figure 3 Measured and simulated primary pump coast down. 


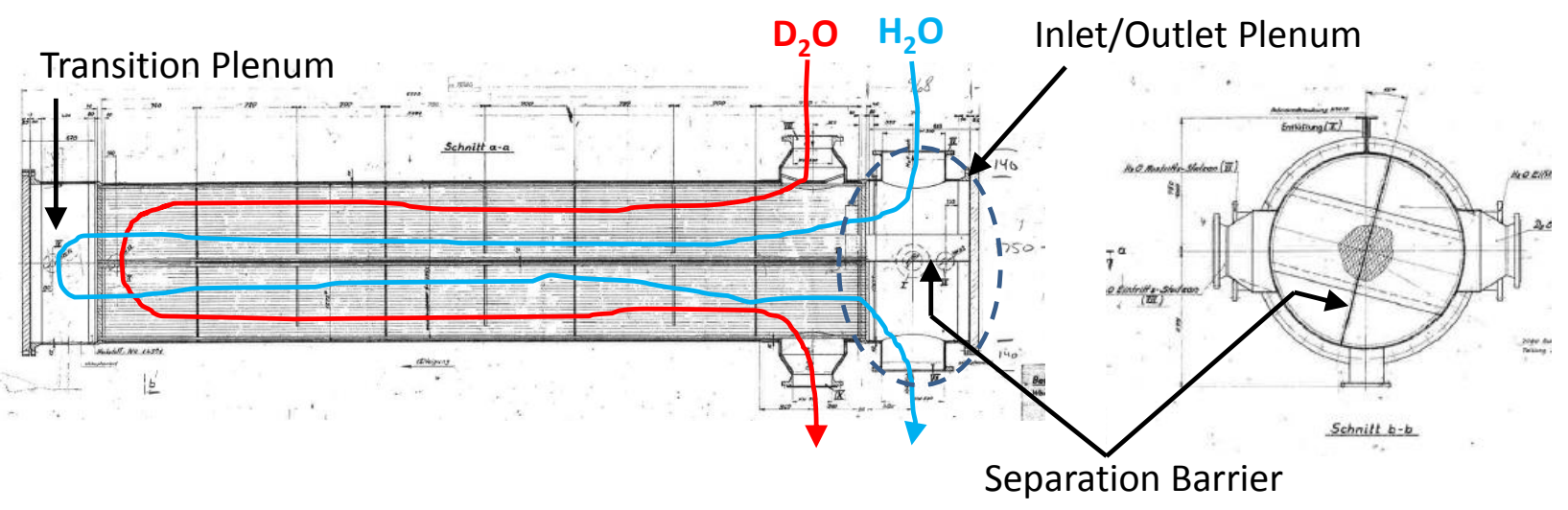

Figure 4 RHF primary heat exchanger (modified from drawing 4C-51-P1-001).

RELAP5 break model (based on CATHARE)

RELAP5 break model (Recommended)
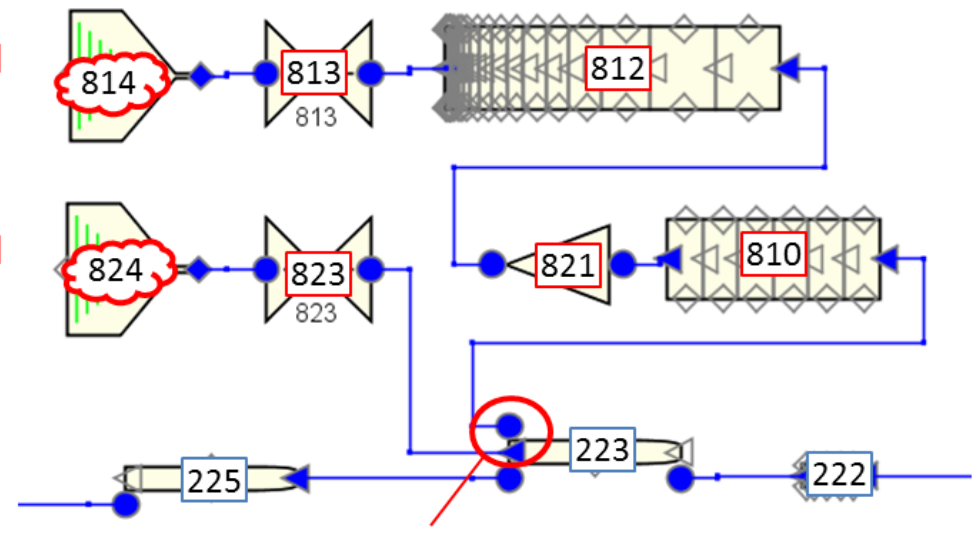

Cold Leg Break

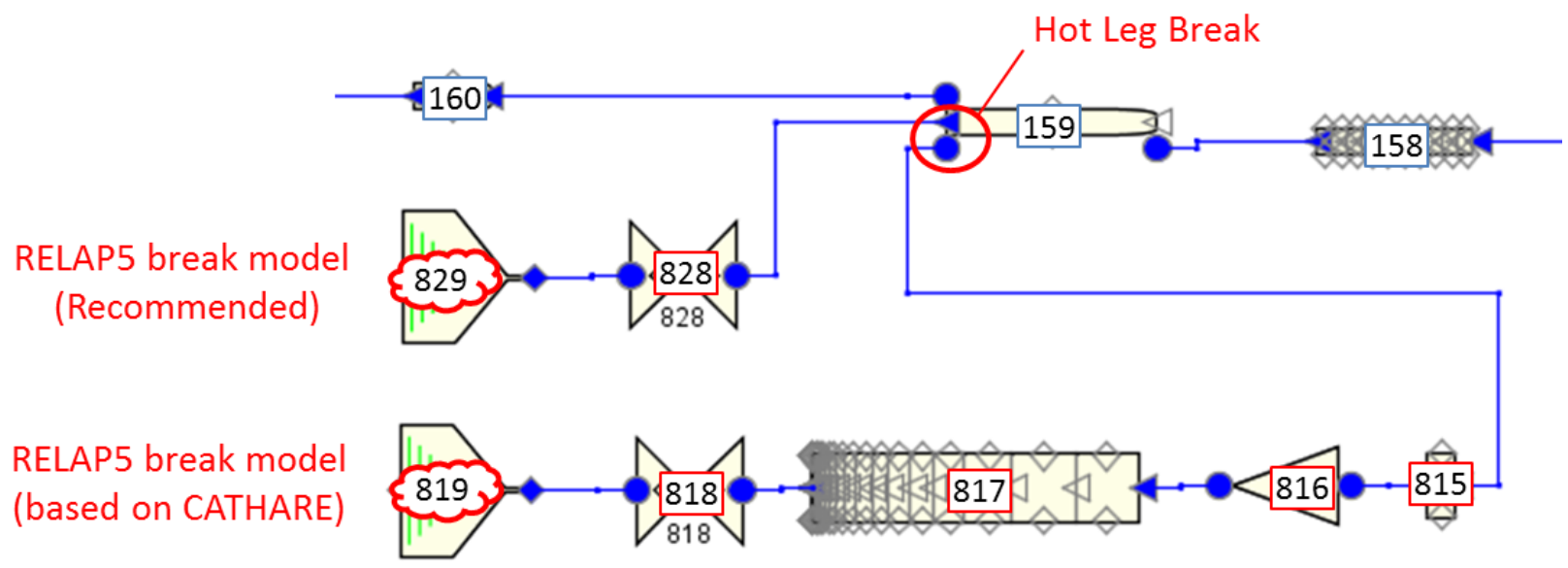

Figure 5 RELAP5 break models.

Verification of Historical System Transient Simulations for the RHF Research Reactor 


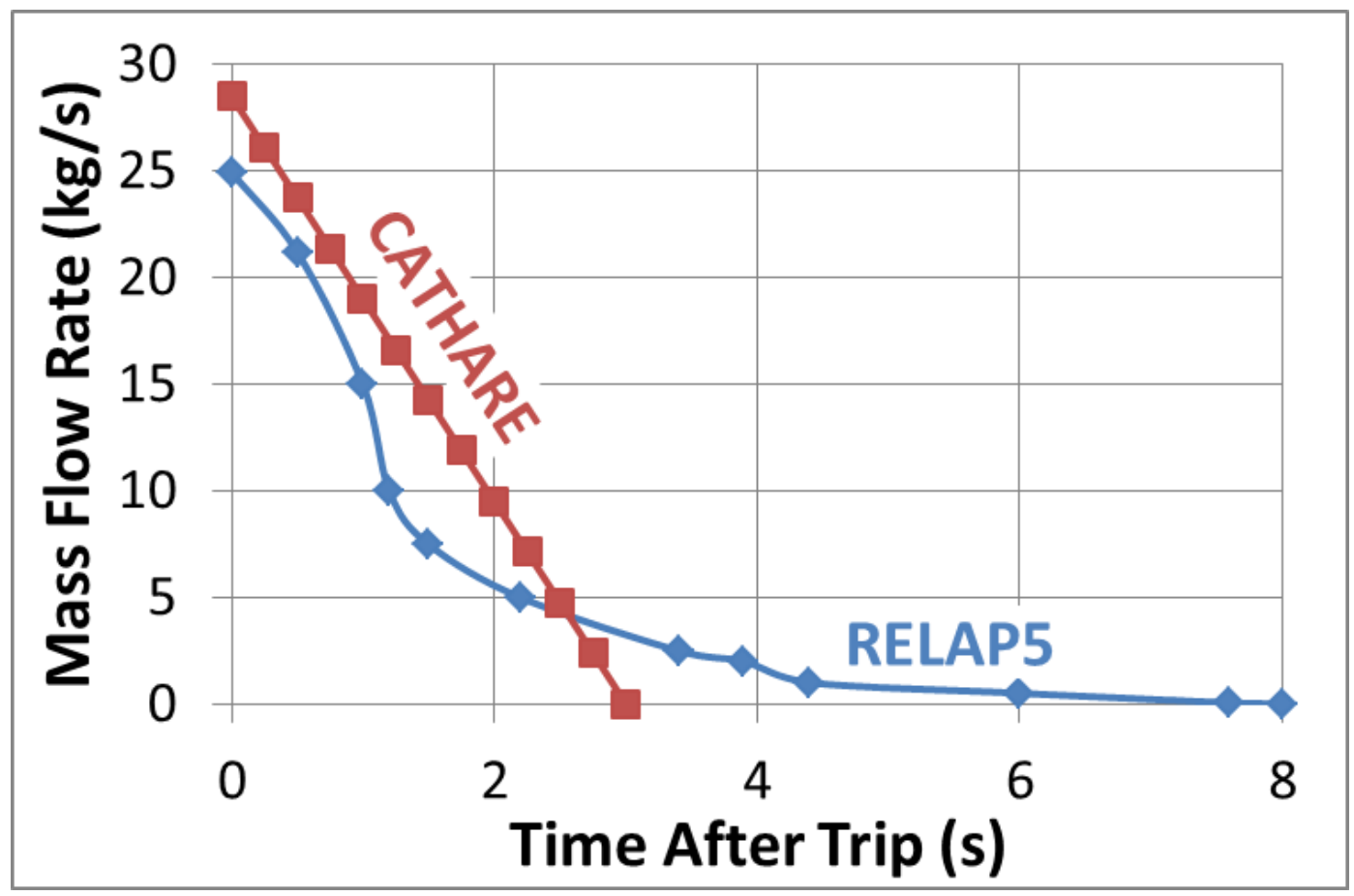

Figure 6 Target CRAB flow rate as determined from loss of flow tests.

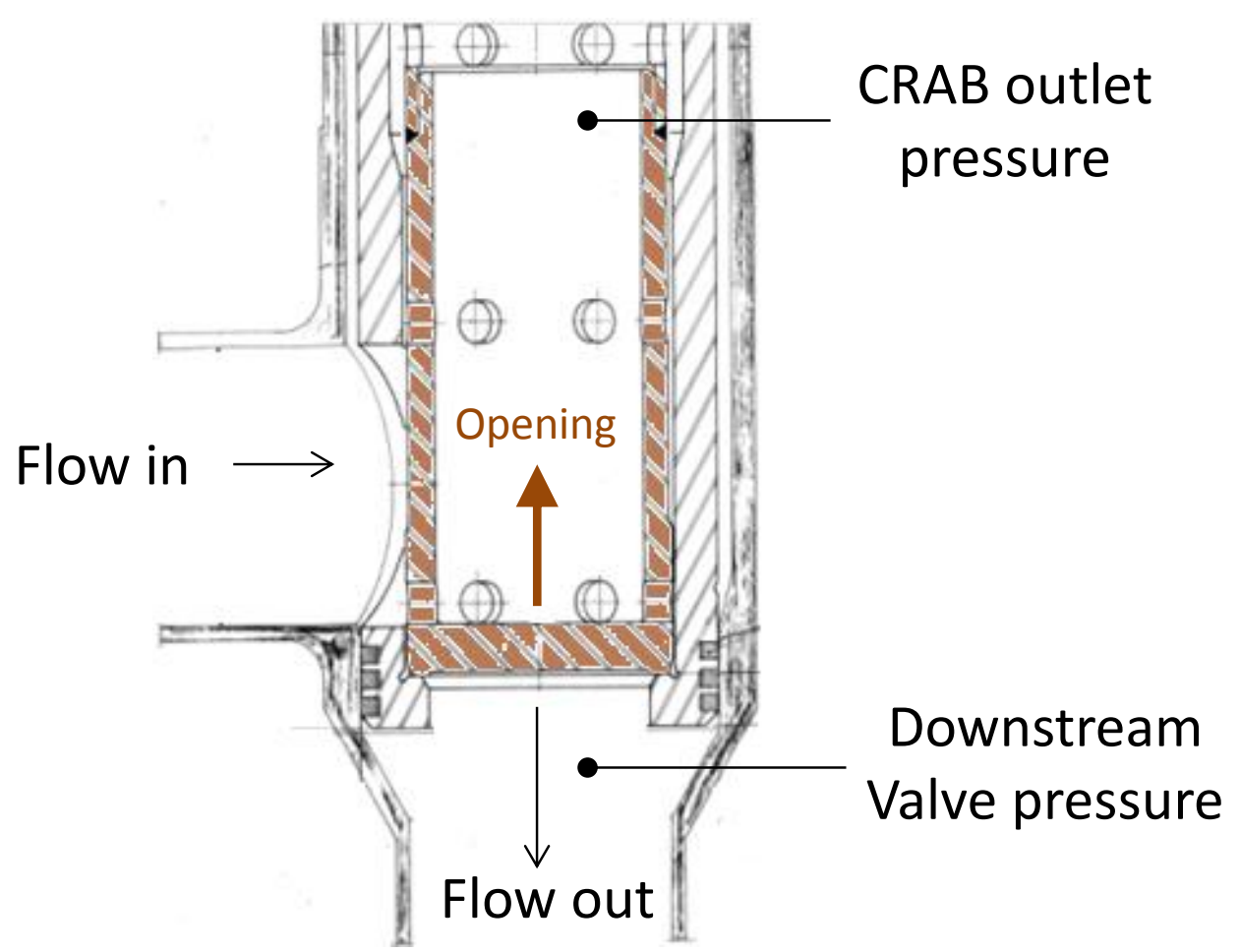

Figure 7 Diagram of a check valve in a natural circulation line 


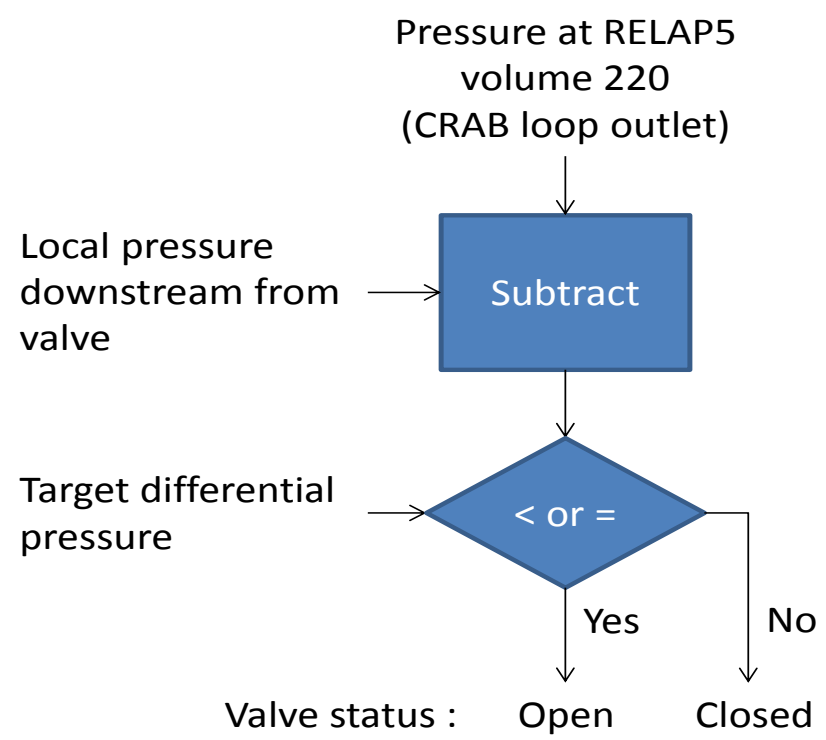

Figure 8 Control logic for valves.

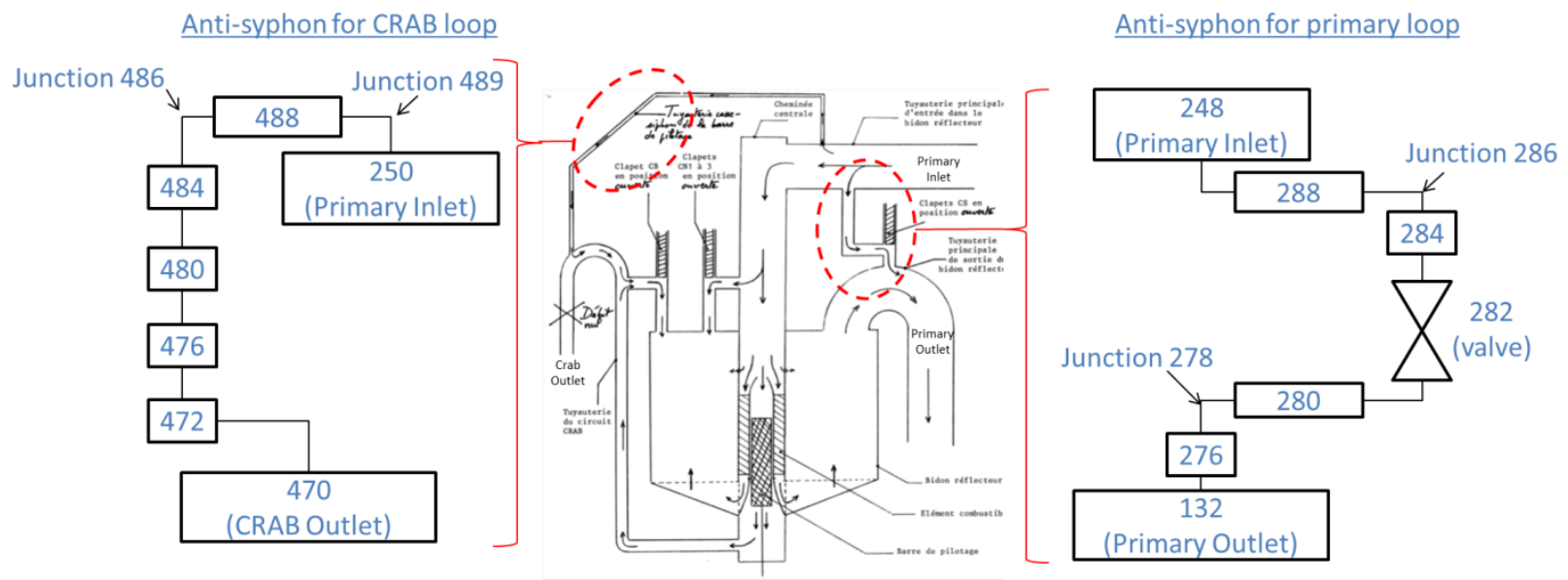

Figure 9 Diagram of RELAP5 model for anti-syphon piping. 


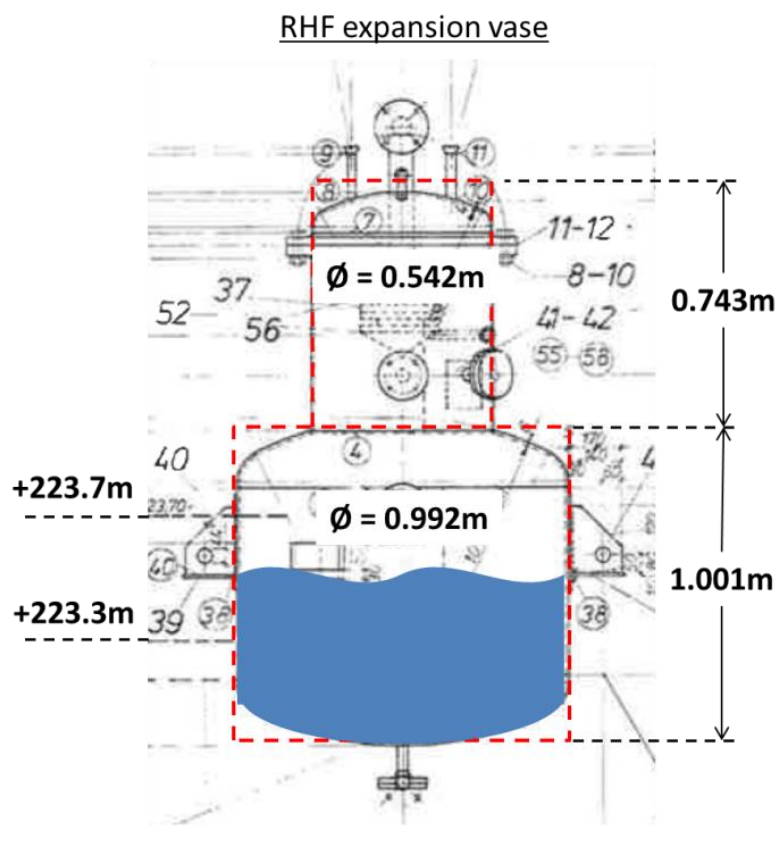

$\underline{\text { RELAP5 expansion vase }}$

Figure 10 RHF pressurizer and model.

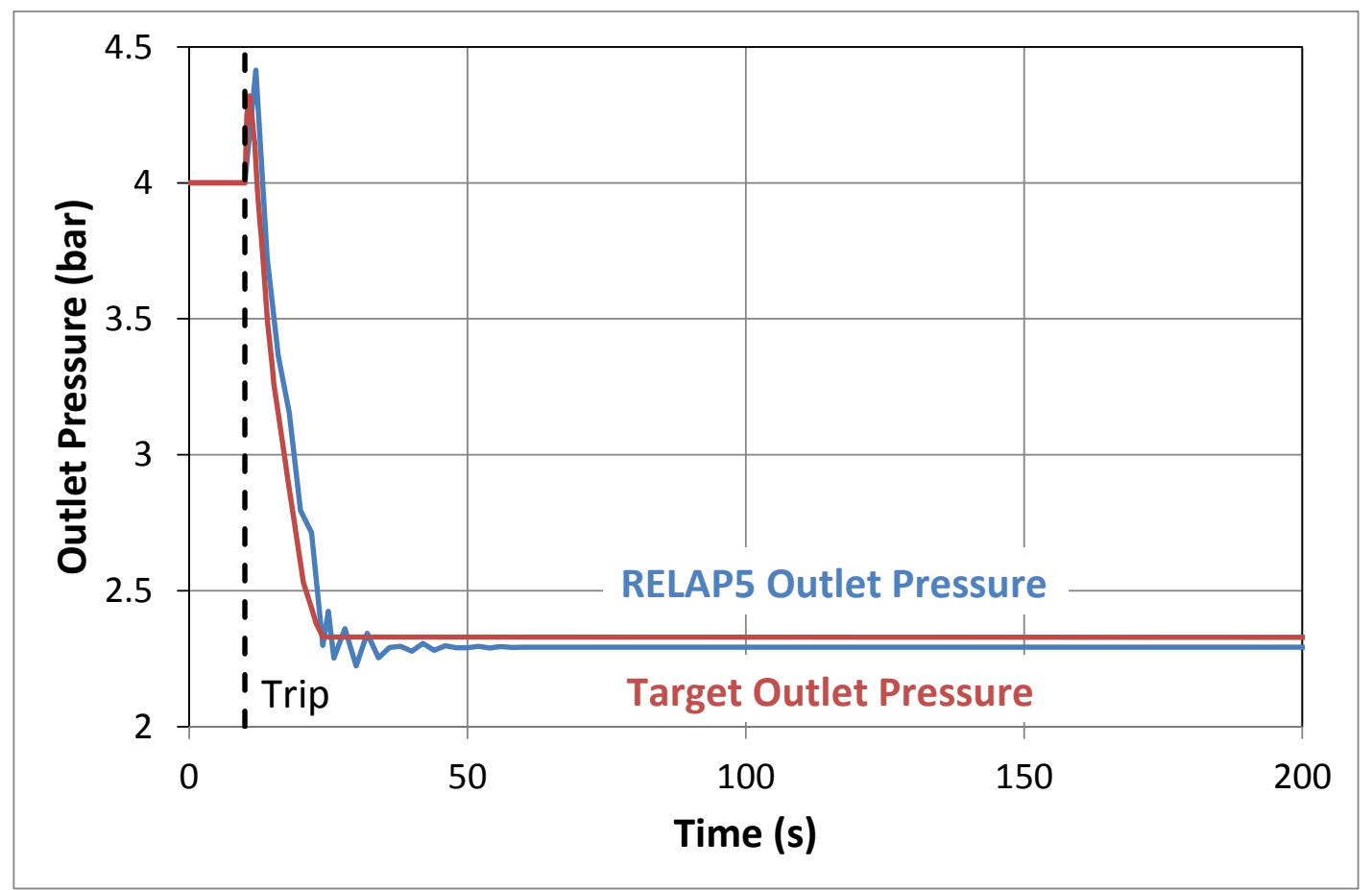

Figure 11 Comparison of target and RELAP5 simulated outlet pressure.

Verification of Historical System Transient Simulations for the RHF Research Reactor 


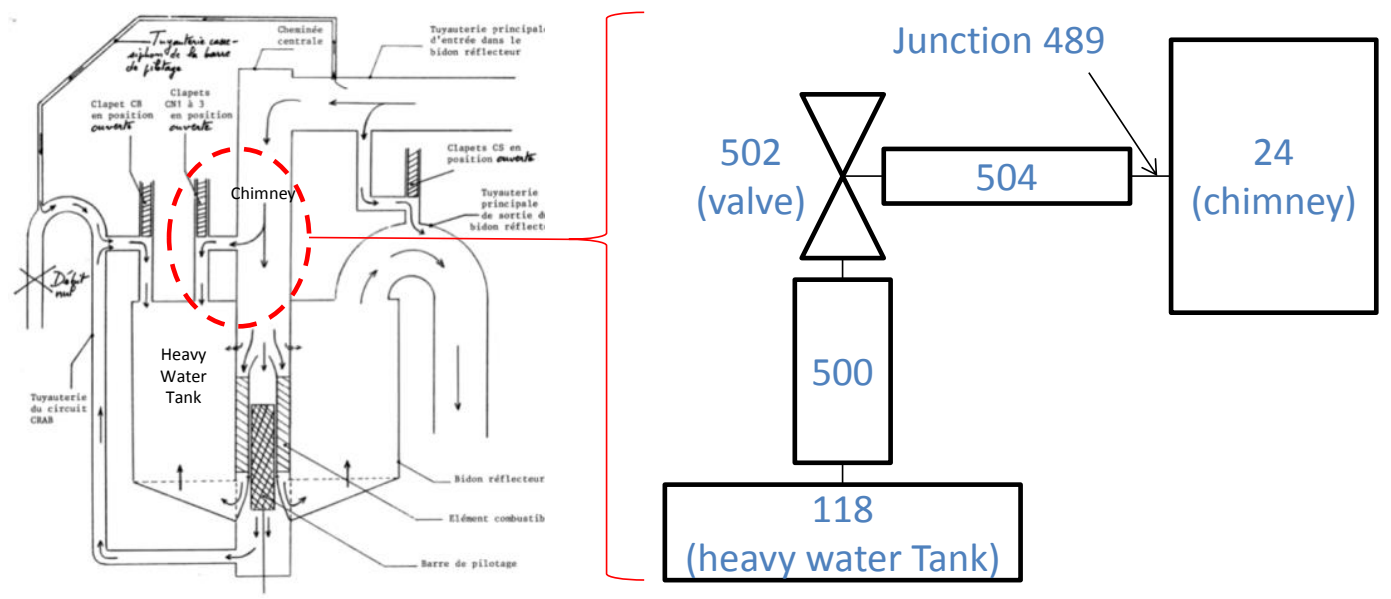

Figure 12 RELAP5 description of the natural circulation lines connecting the chimney to the heavy water tank.

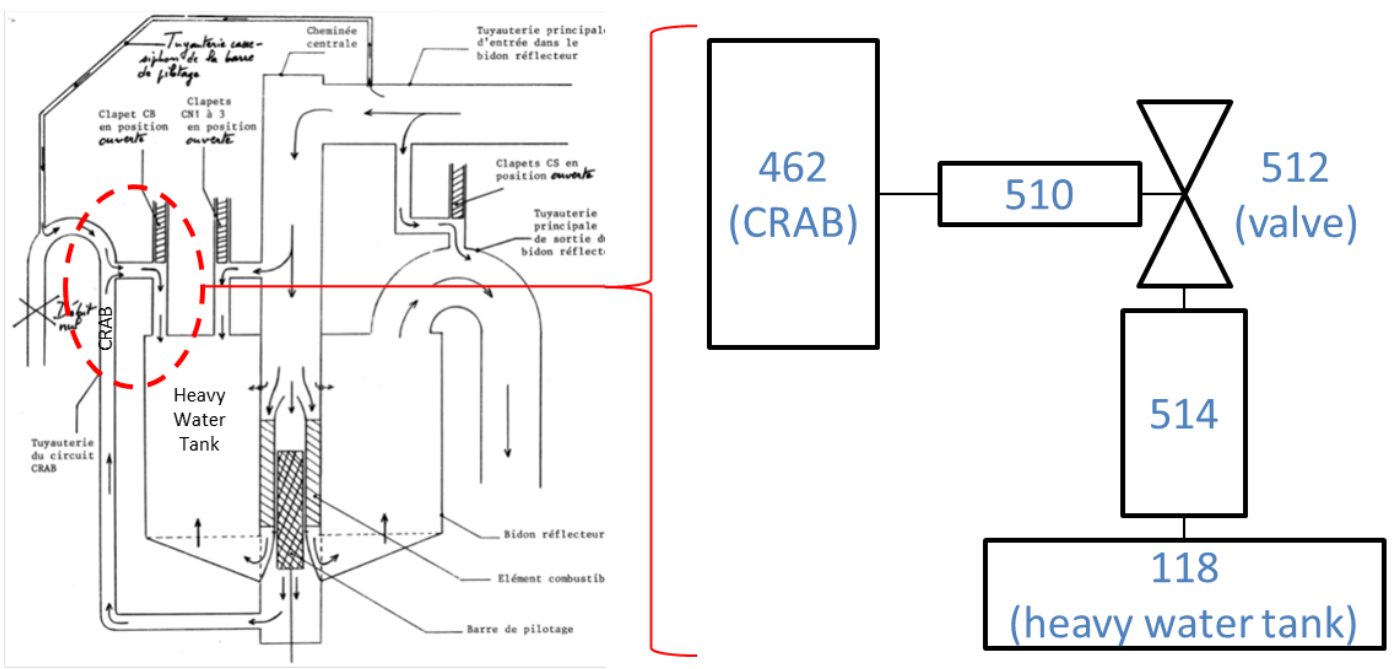

Figure 13 RELAP5 description of the natural circulation line connecting the CRAB loop to the heavy water tank. 

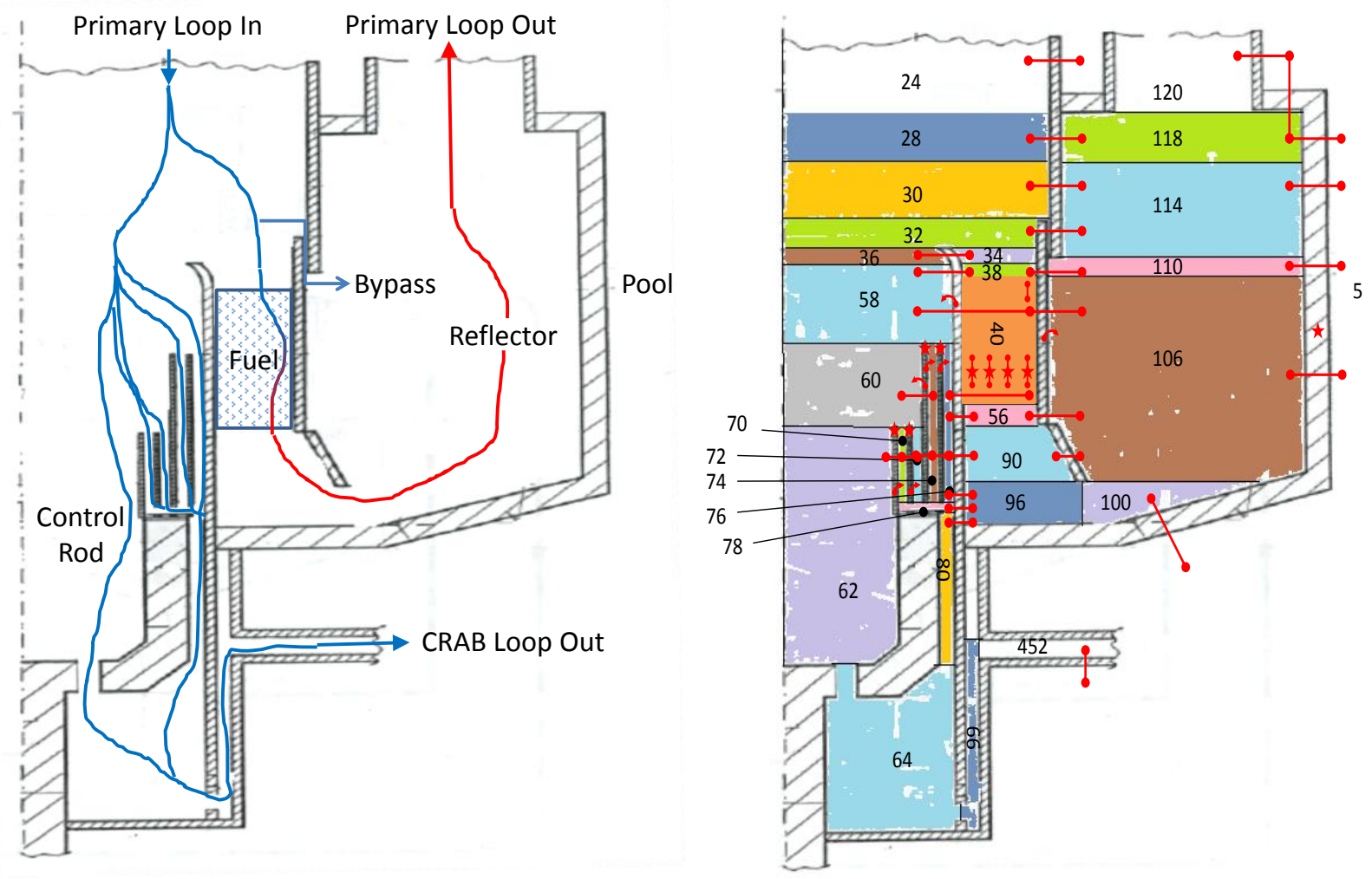

Figure 14 Coolant volume discretization scheme and heat structure linkages in RELAP5 model. 


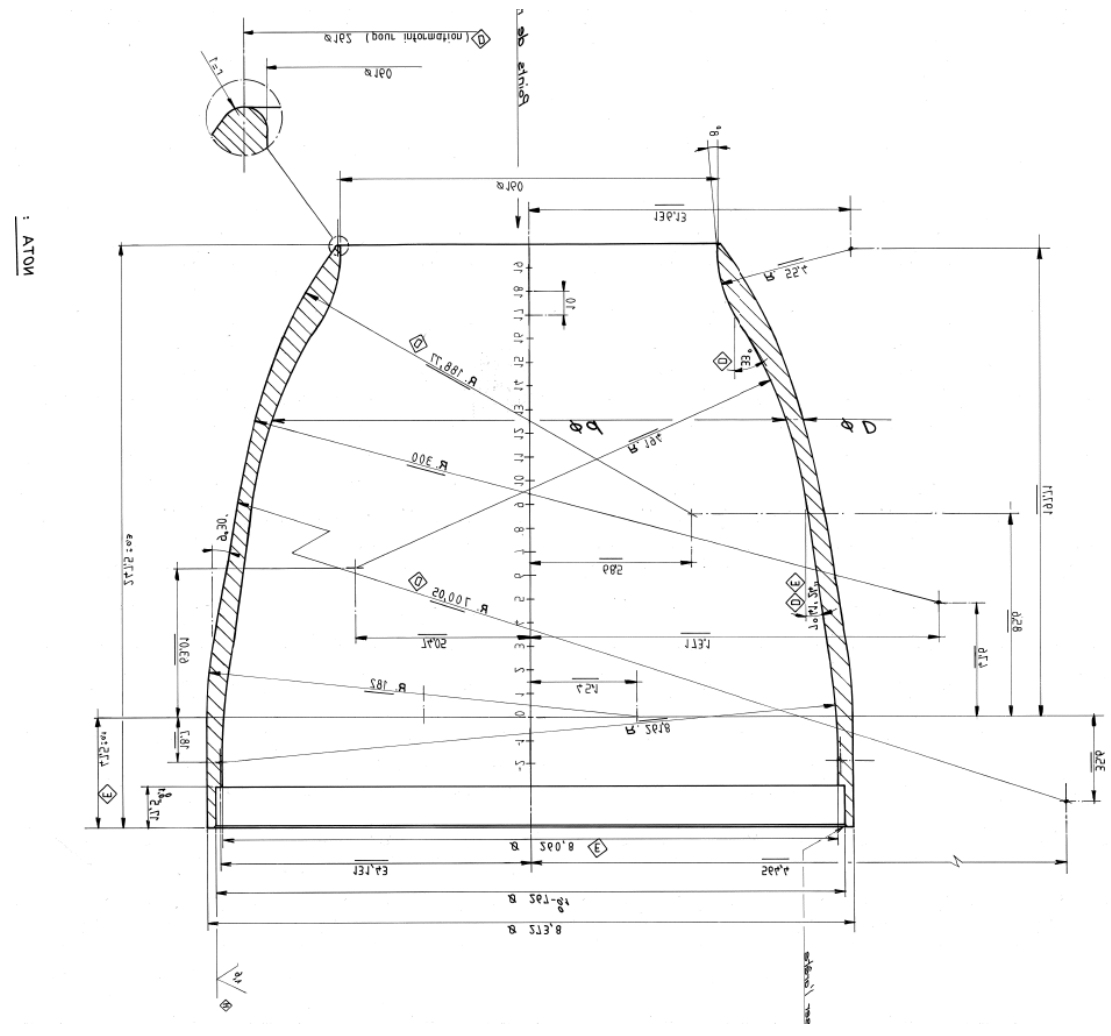

Figure 15 Diagram of the conical head separating the flow between the control rod and fuel element regions.

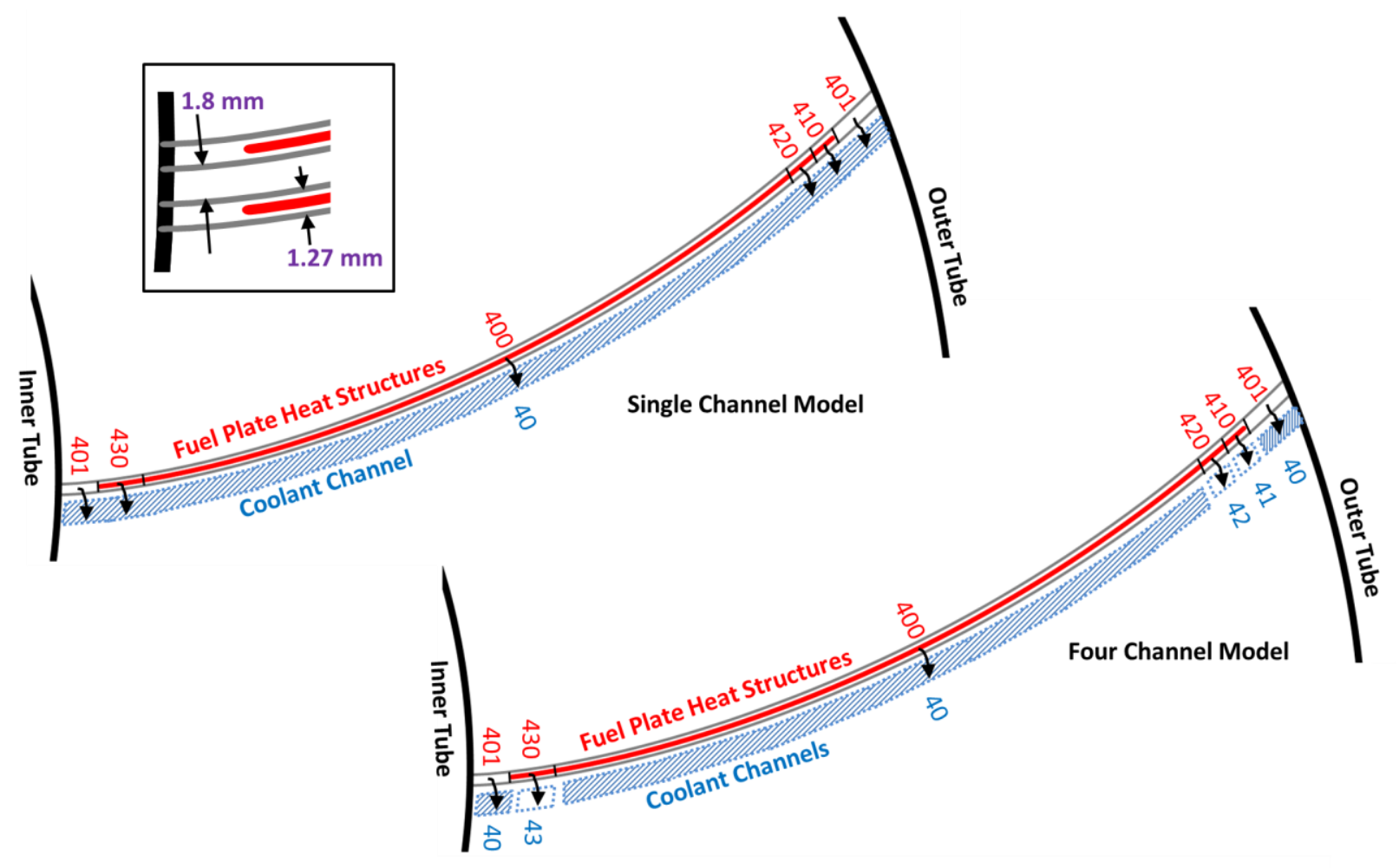

Figure 16 Discretization of the single and four channel fuel element model.

Verification of Historical System Transient Simulations for the RHF Research Reactor 


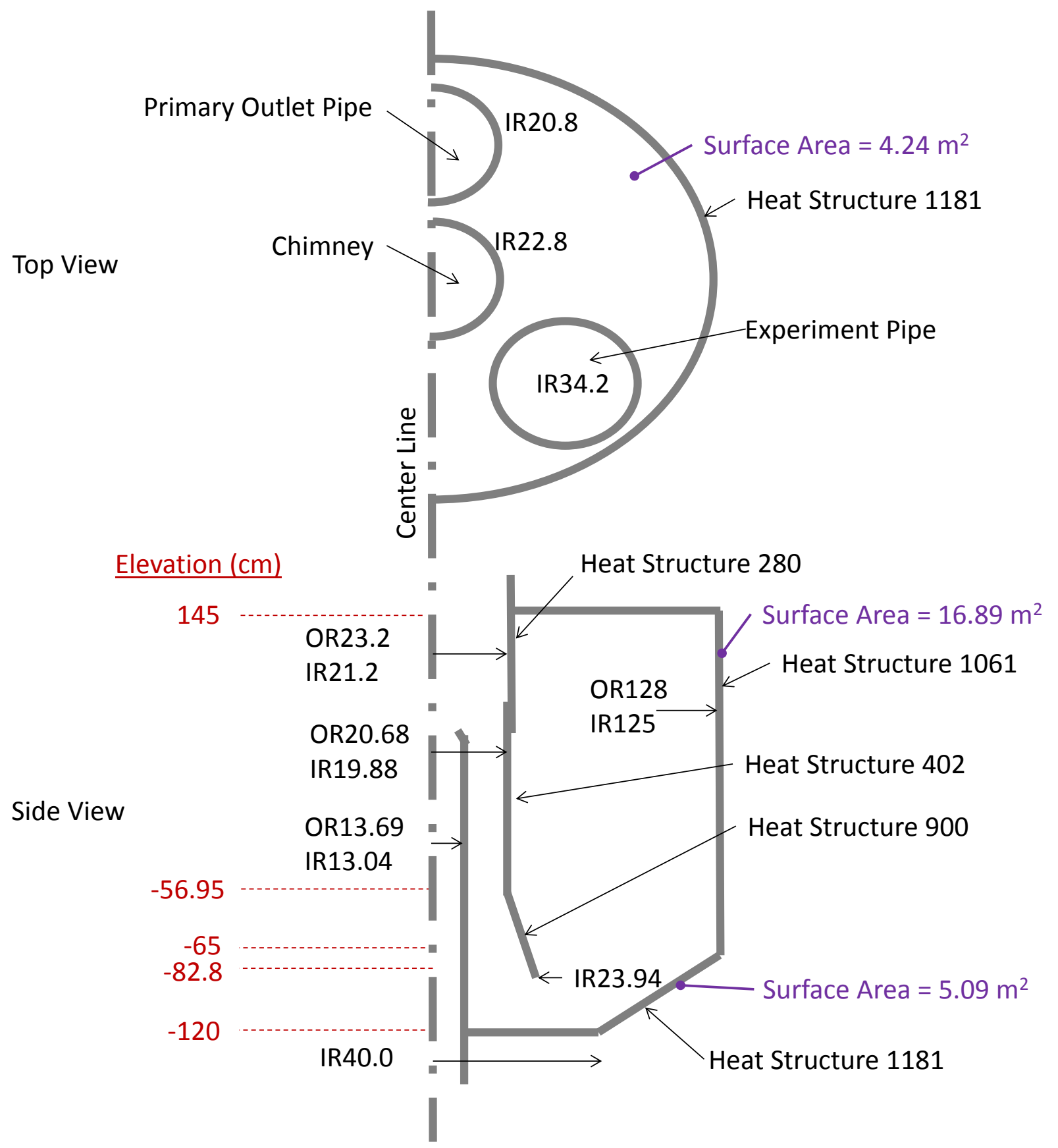

Figure 17 Conceptual drawing of RHF heavy water vessel (IR and OR = inner and outer radius, radial dimensions in $\mathrm{cm})$. 


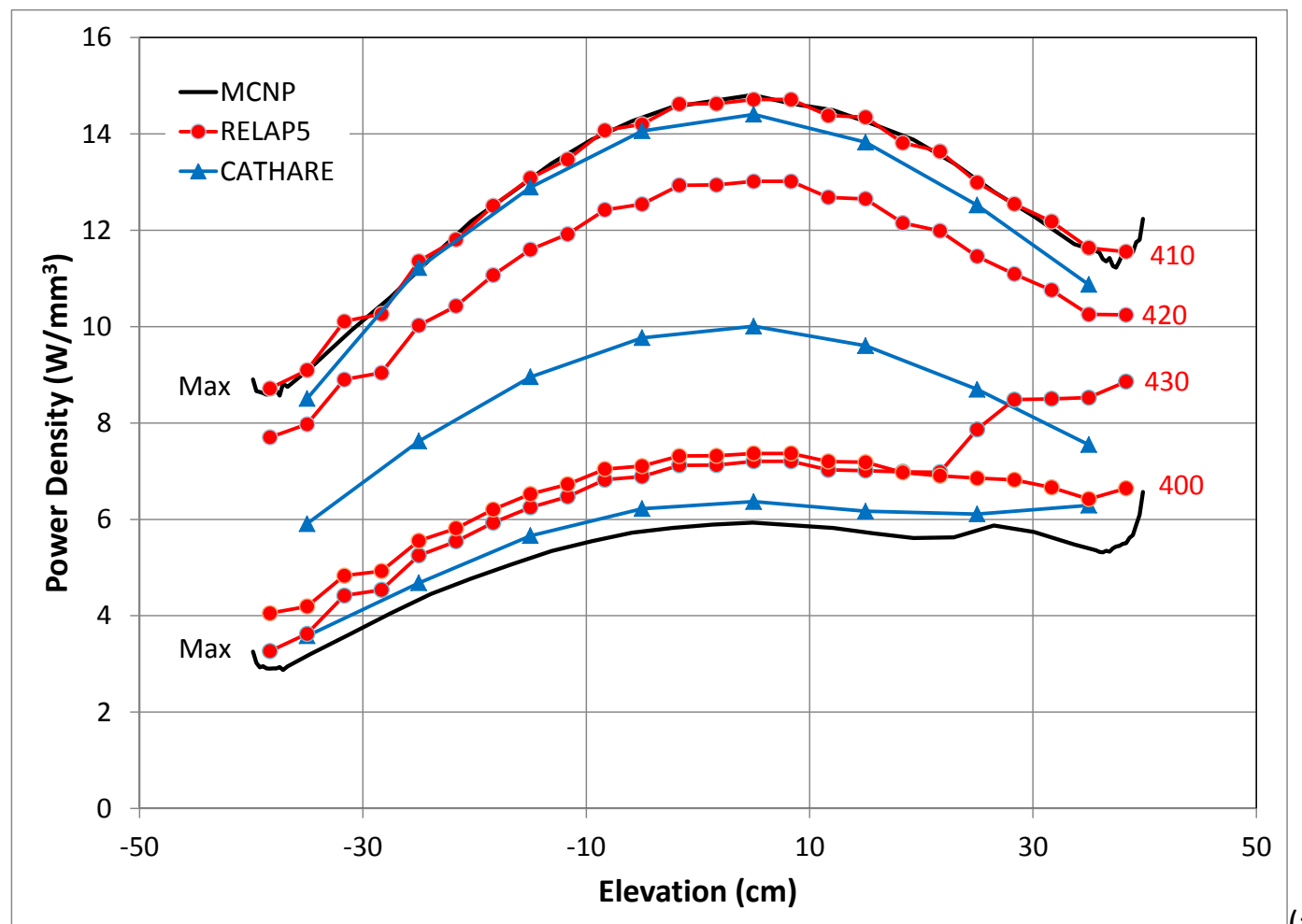

(a)

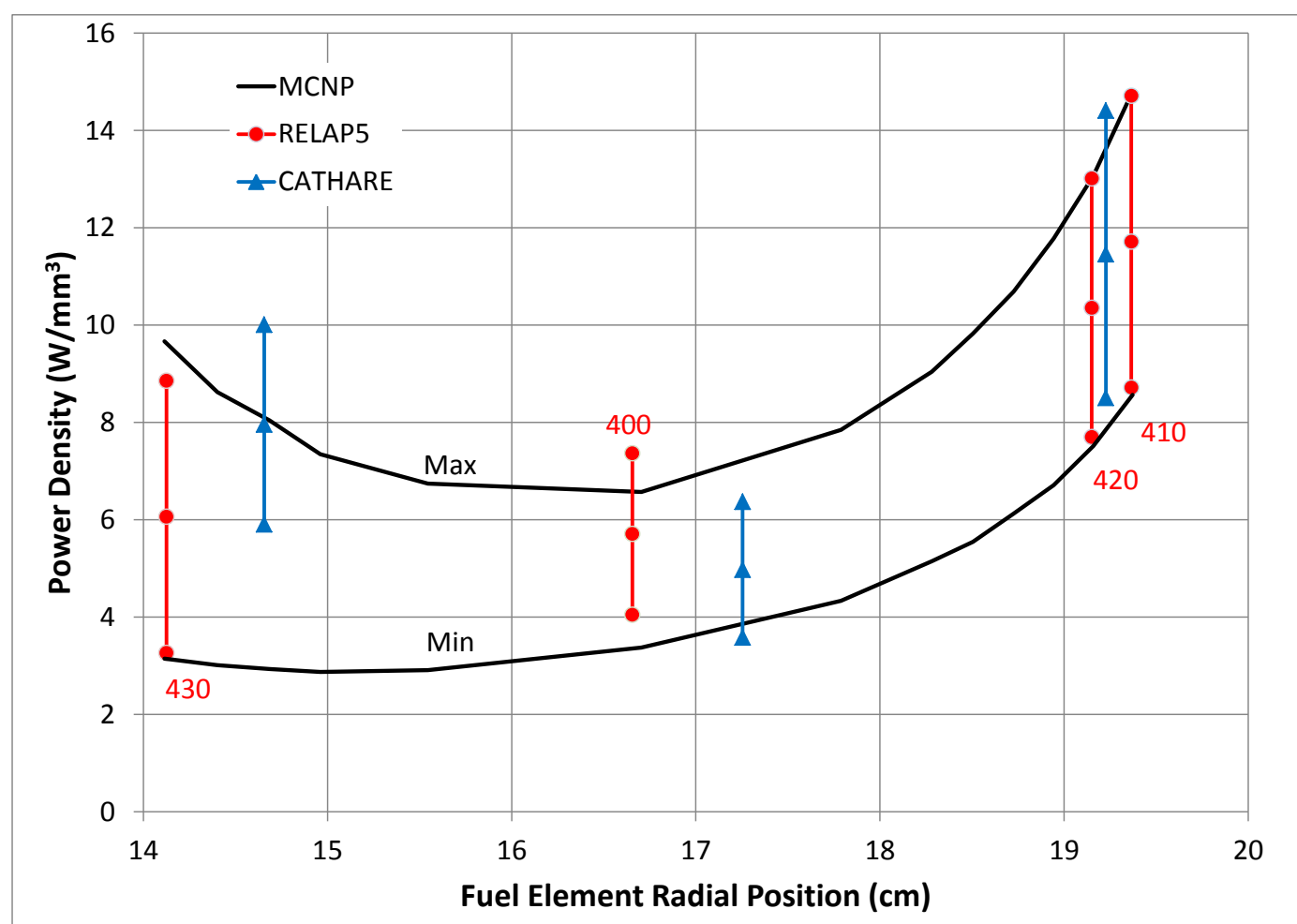

(b)

Figure 18 Comparison of axial (a) and radial (b) power density distribution in the HEU fuel element.

Verification of Historical System Transient Simulations for the RHF Research Reactor 


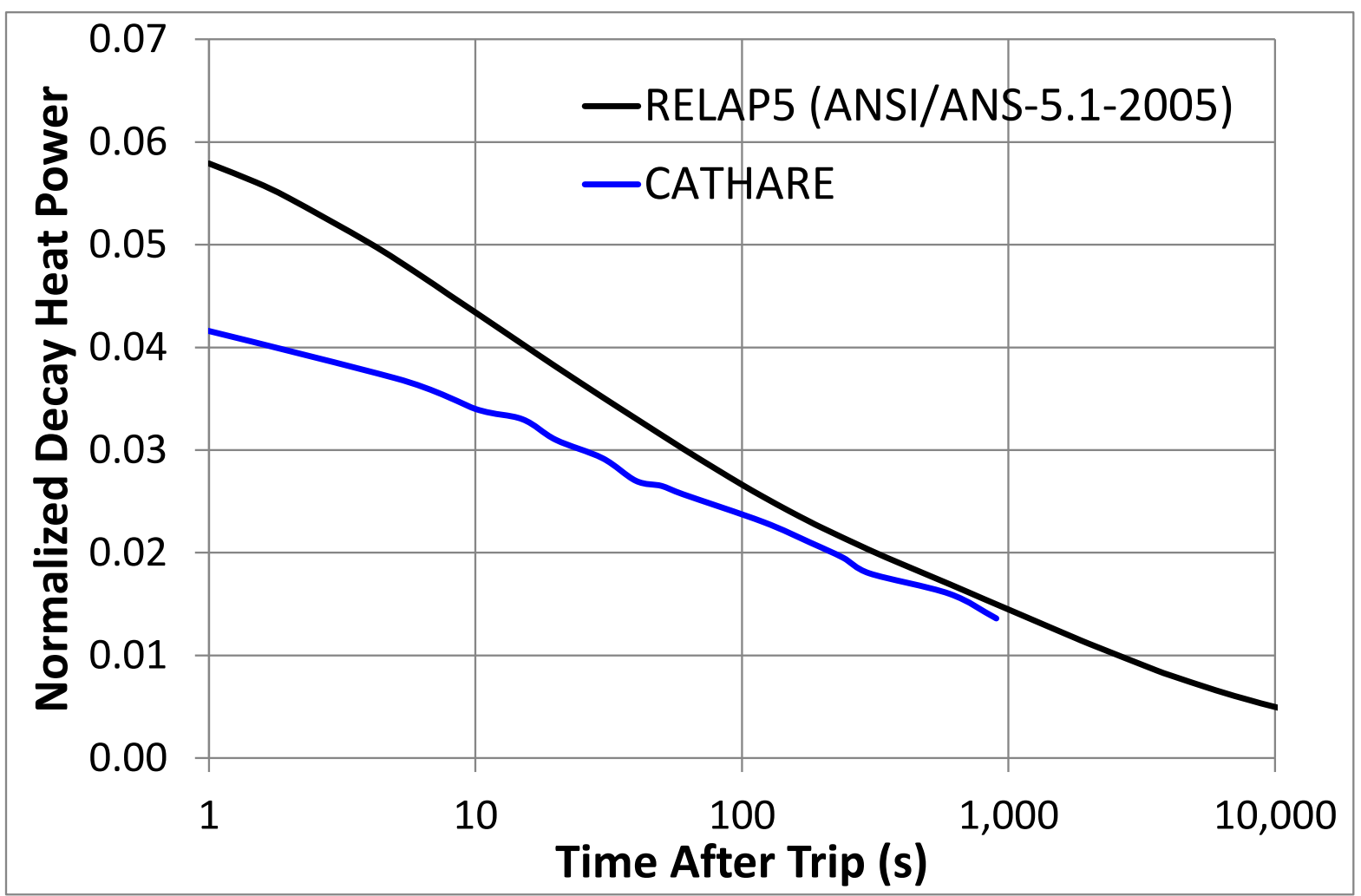

Figure 19 Comparison of the decay heat power used in RELAP5 and CATHARE. 
$\underline{\text { Total loss of electrical power }}$

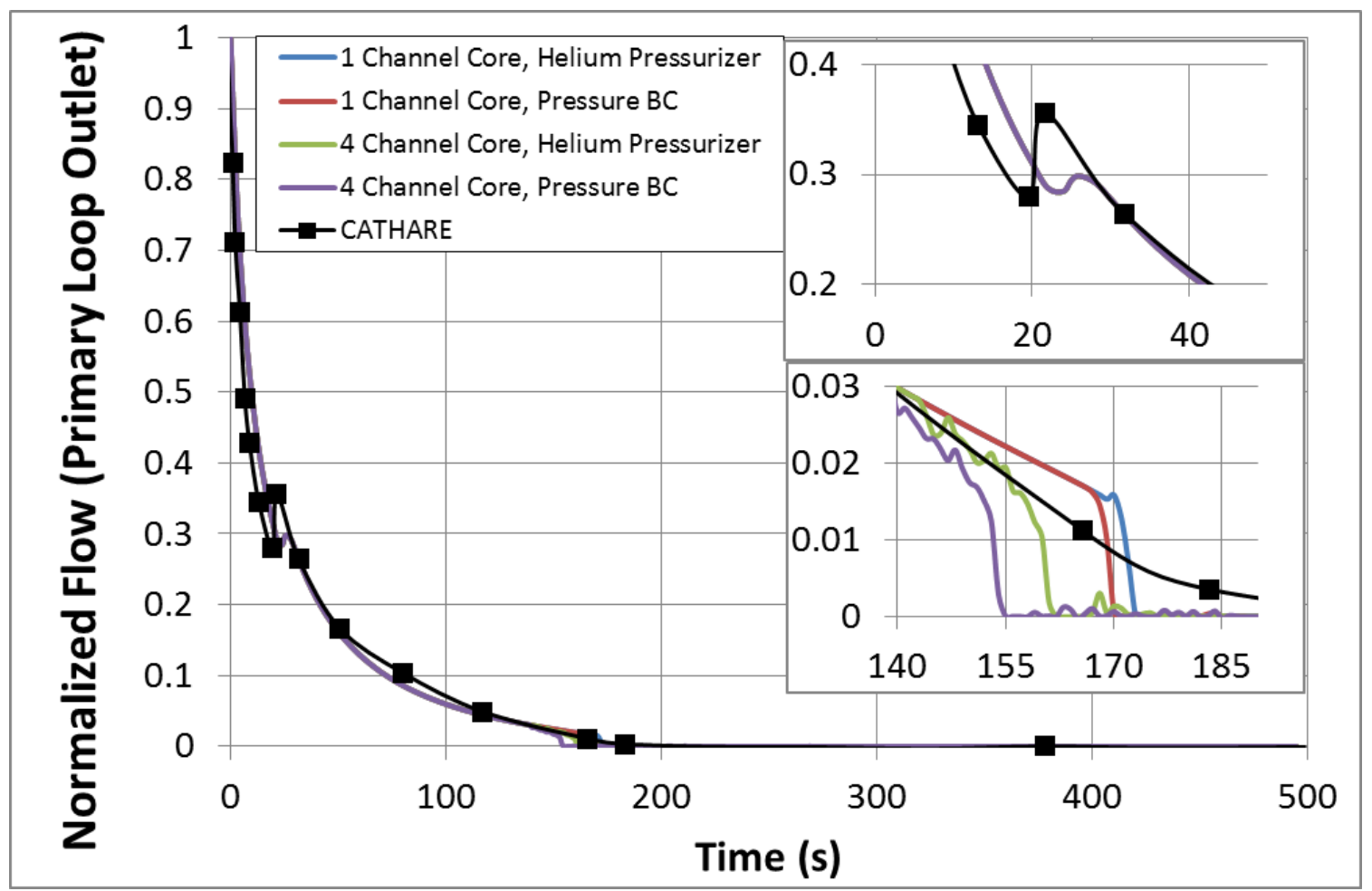

Figure 20 Normalized mass flow in the primary loop. RELAP5 174(1)

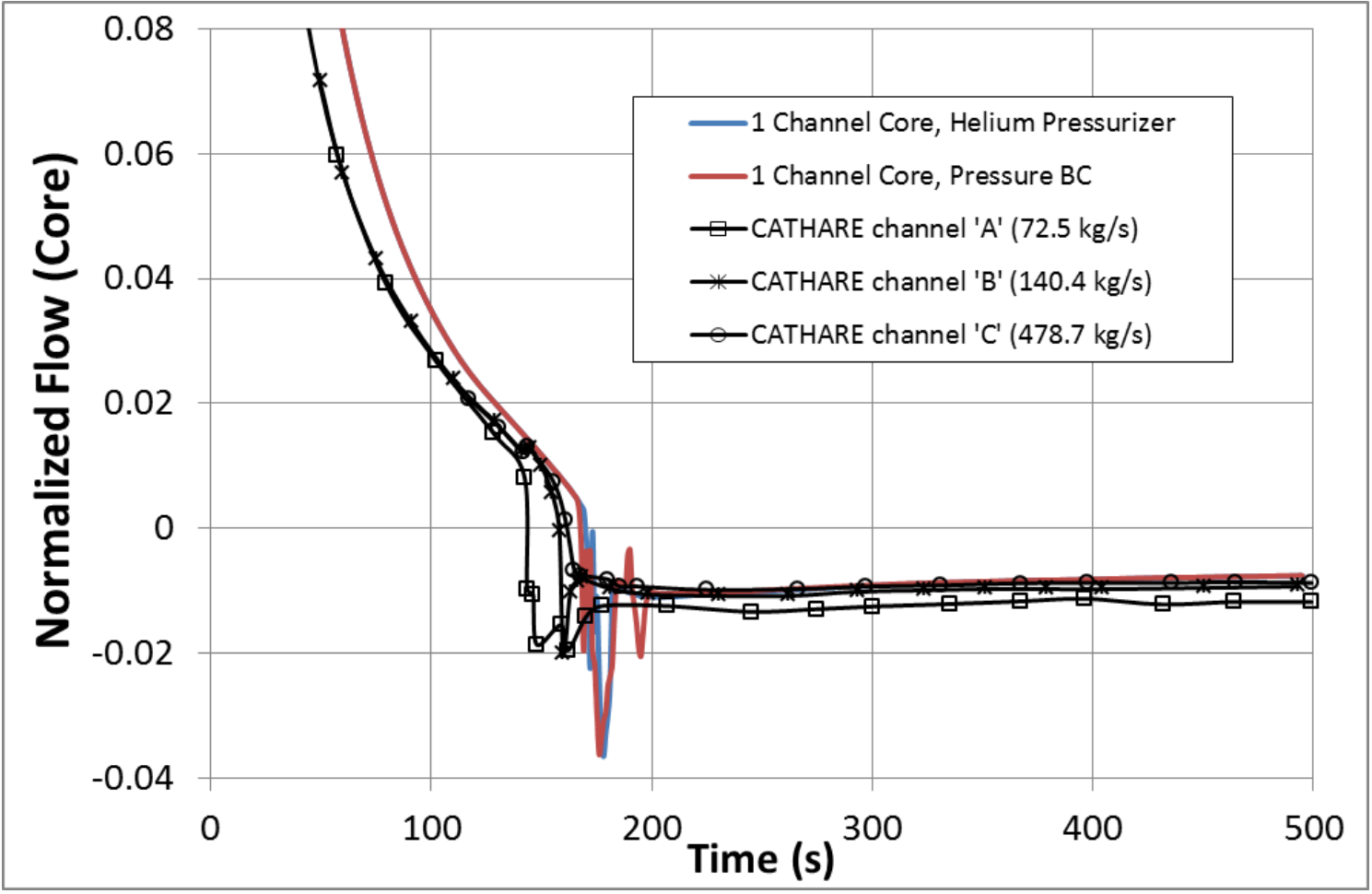

Figure 21 Normalized mass flow for single channel model. RELAP5 40(1) 


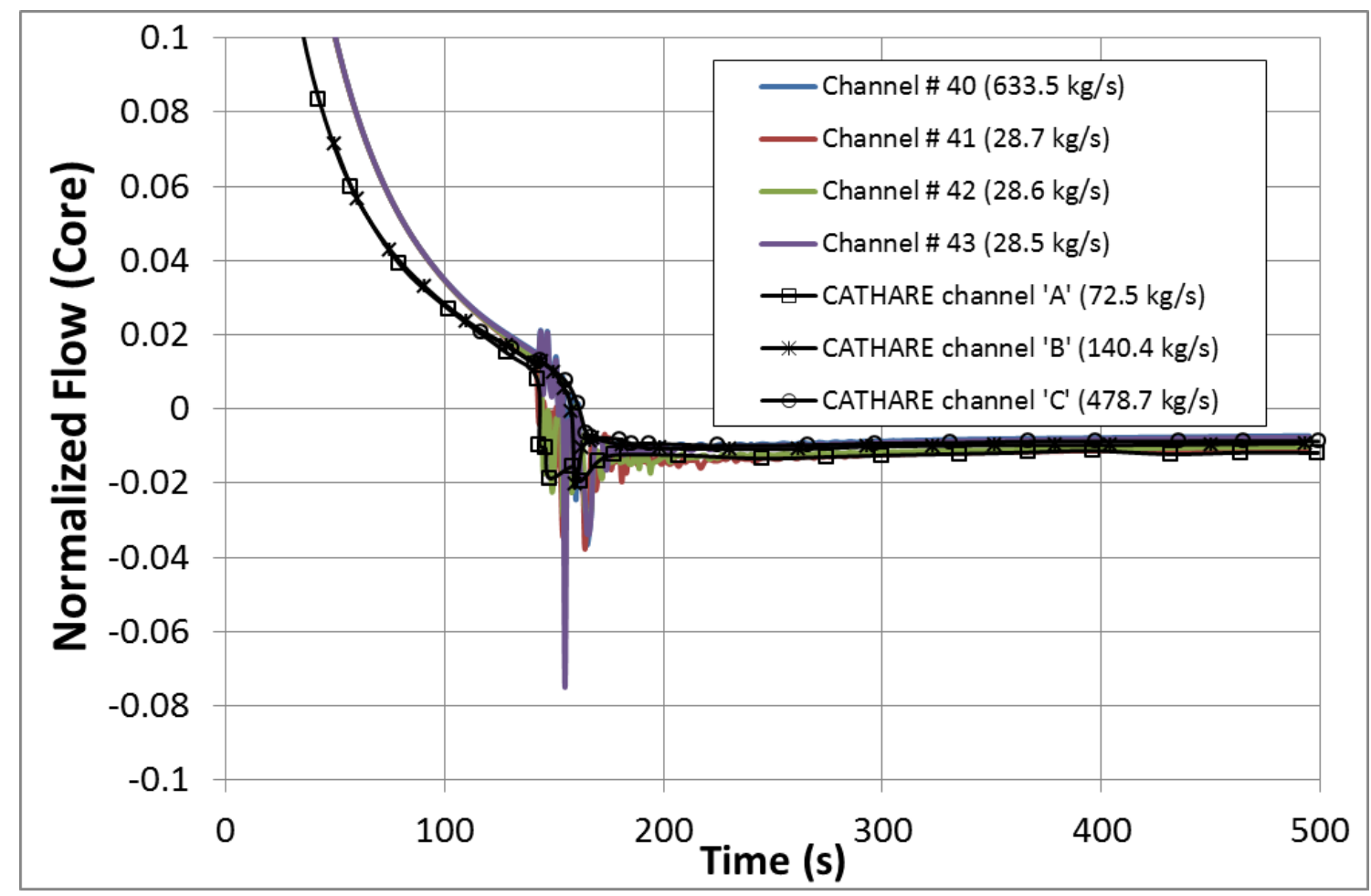

Figure 22 Normalized mass flow for four channel model with helium pressurizer. RELAP5 40-43(1)

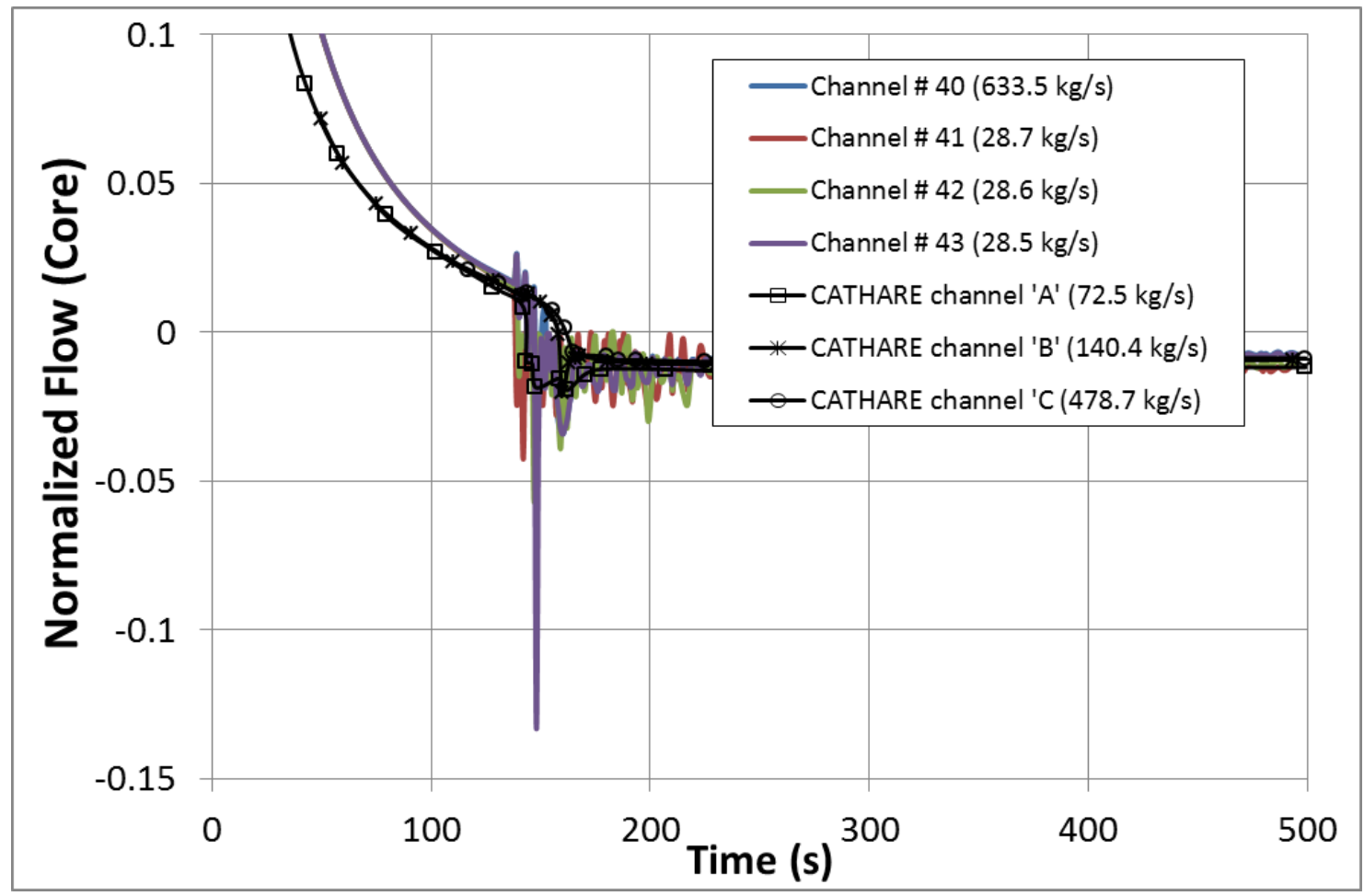

Figure 23 Normalized mass flow for four channel model with pressure BC. RELAP5 40-43(1). 


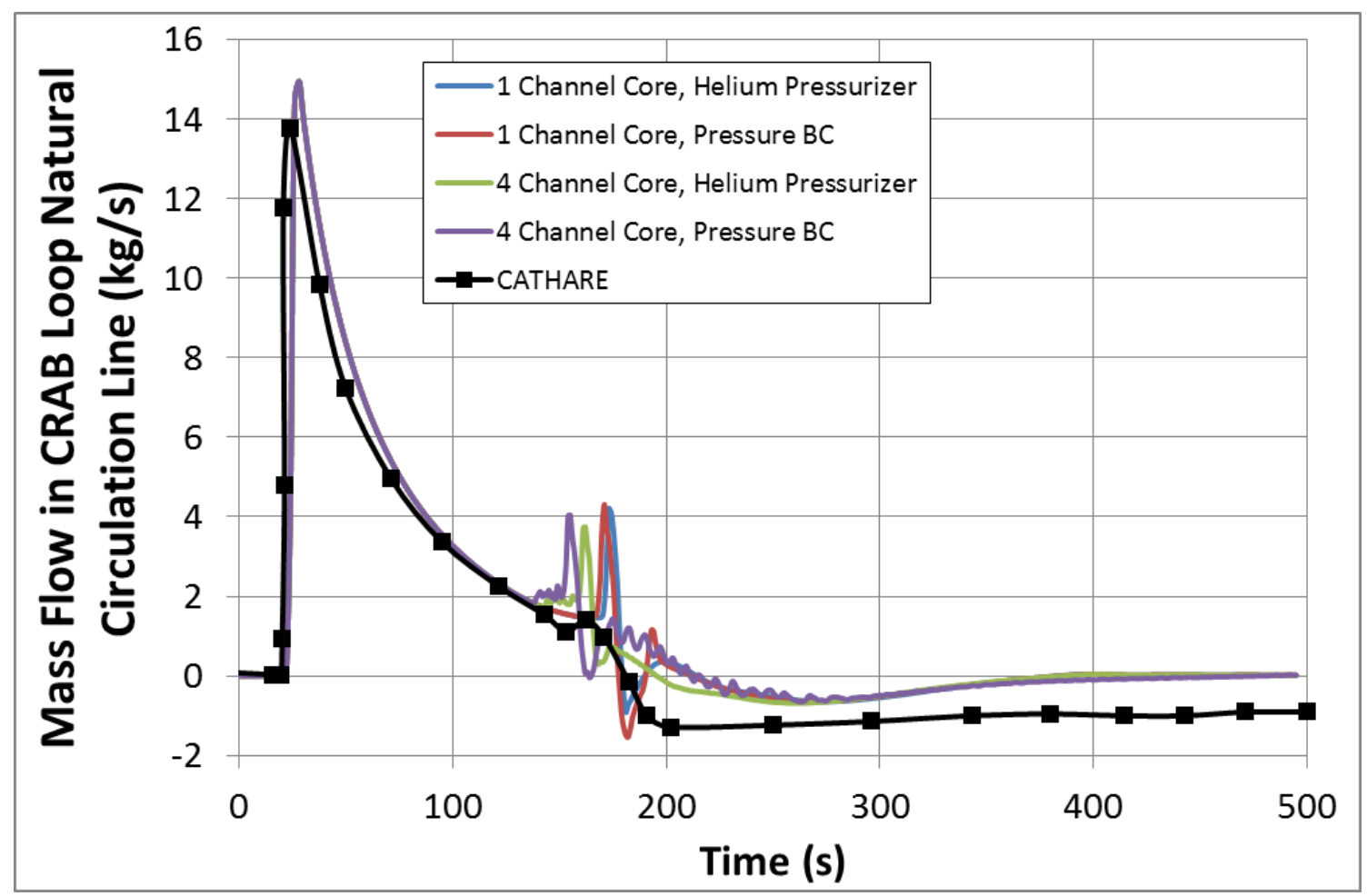

Figure 24 Mass flow in CRAB loop natural circulation line. RELAP5 512

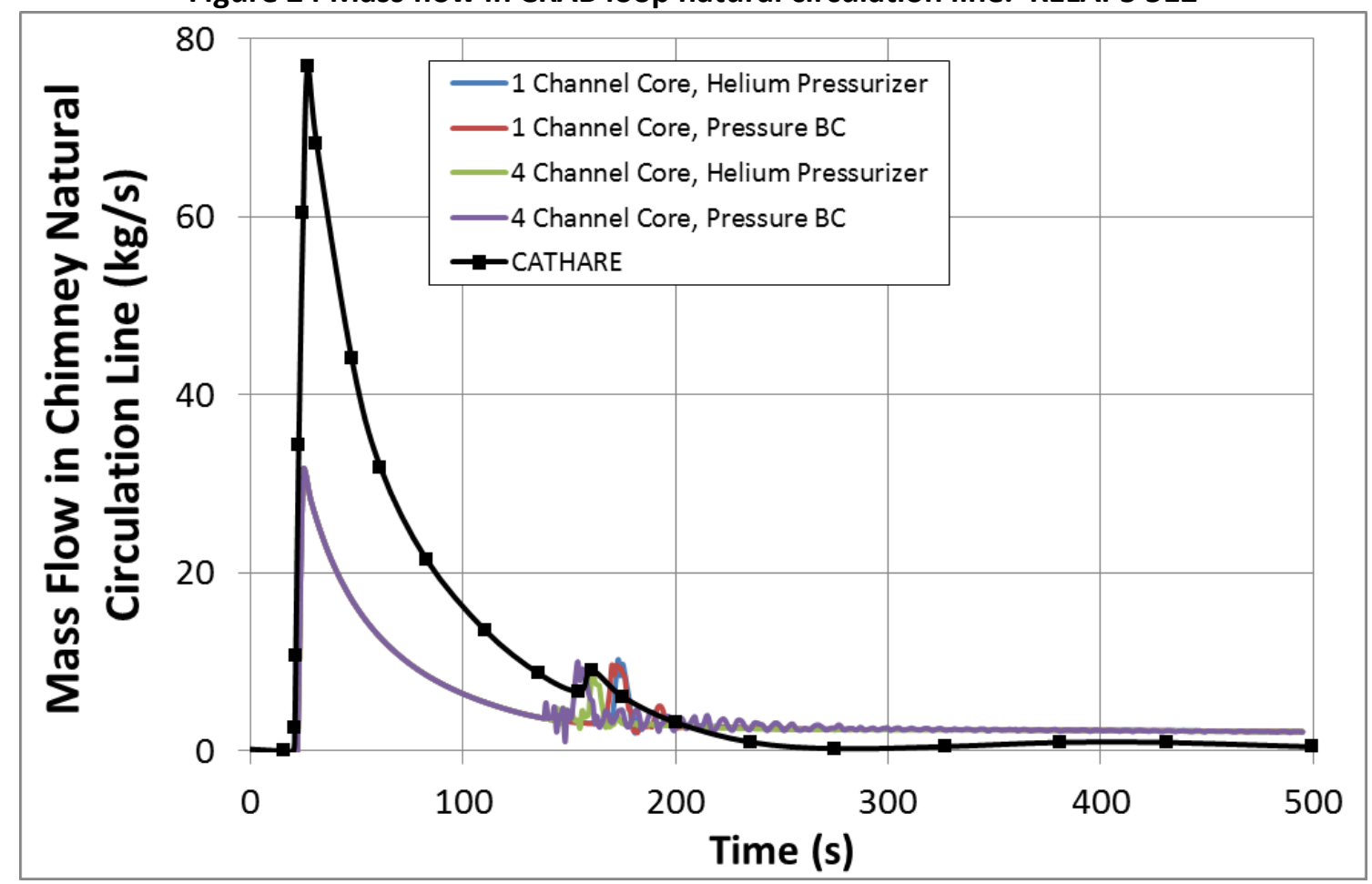

Figure 25 Mass flow in chimney natural circulation line. RELAP5 502 


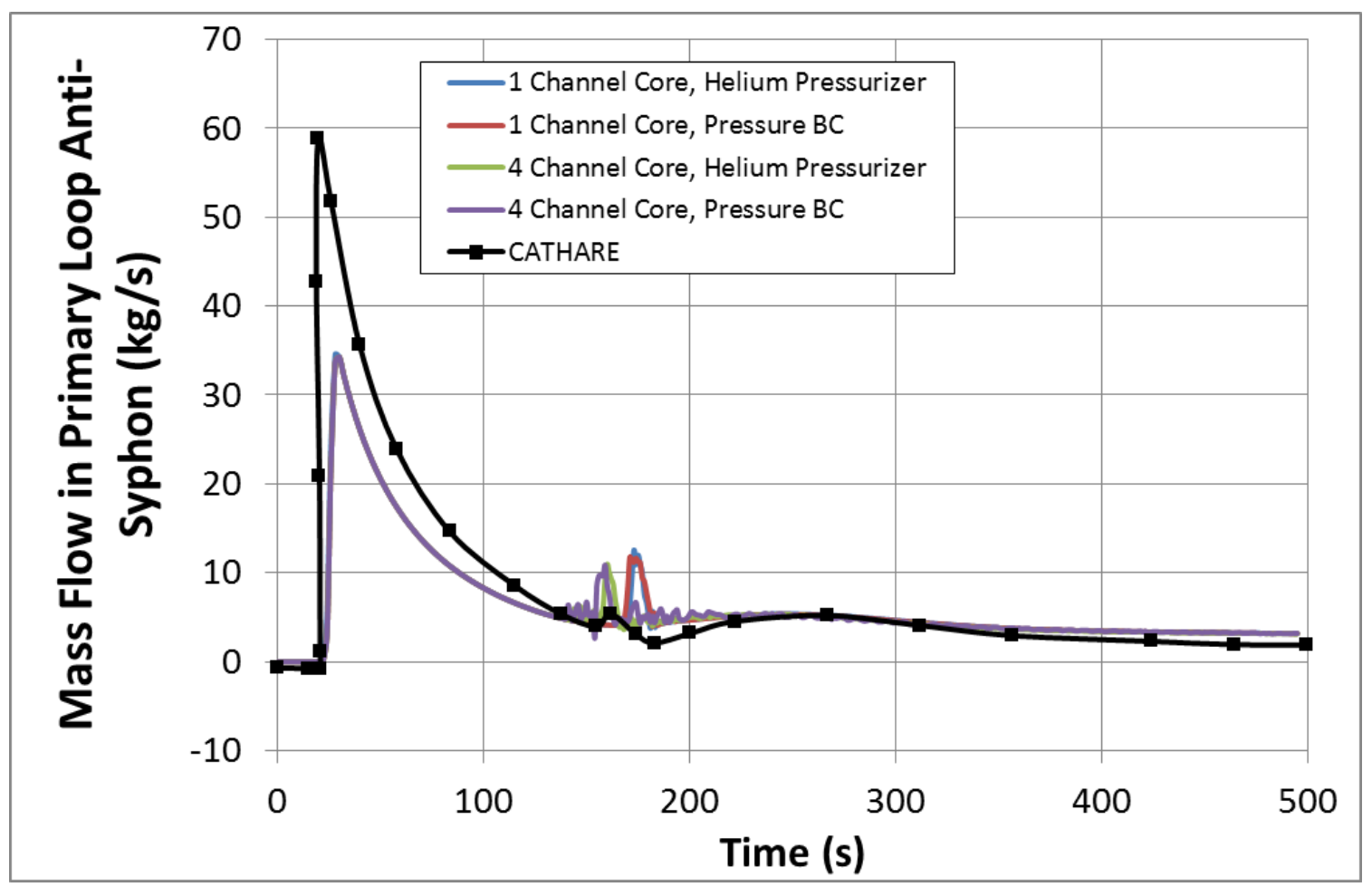

Figure 26 Mass flow in primary loop anti-syphon. RELAP5 282

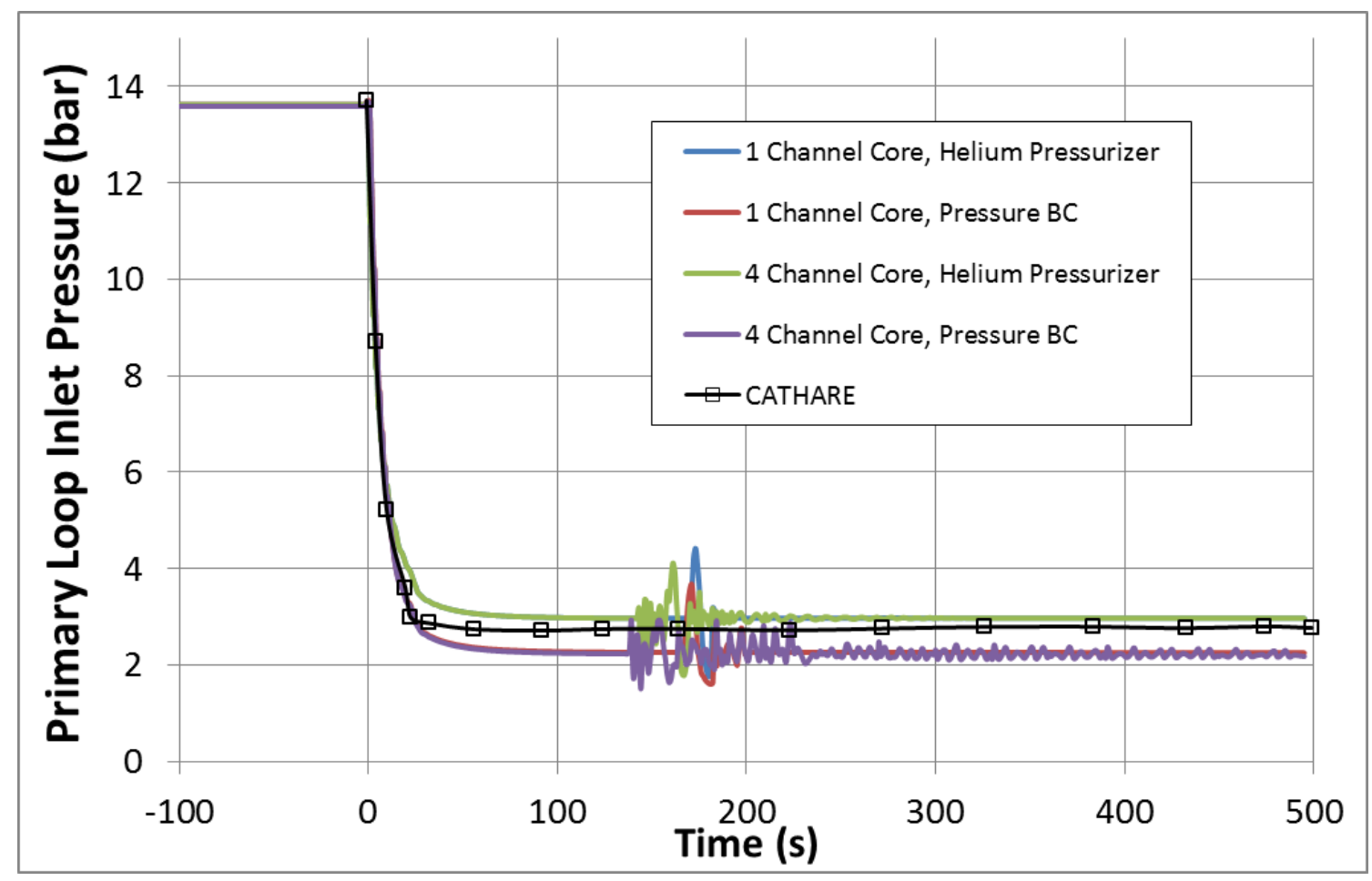

Figure 27 Primary loop inlet pressure. RELAP5 234(1) 


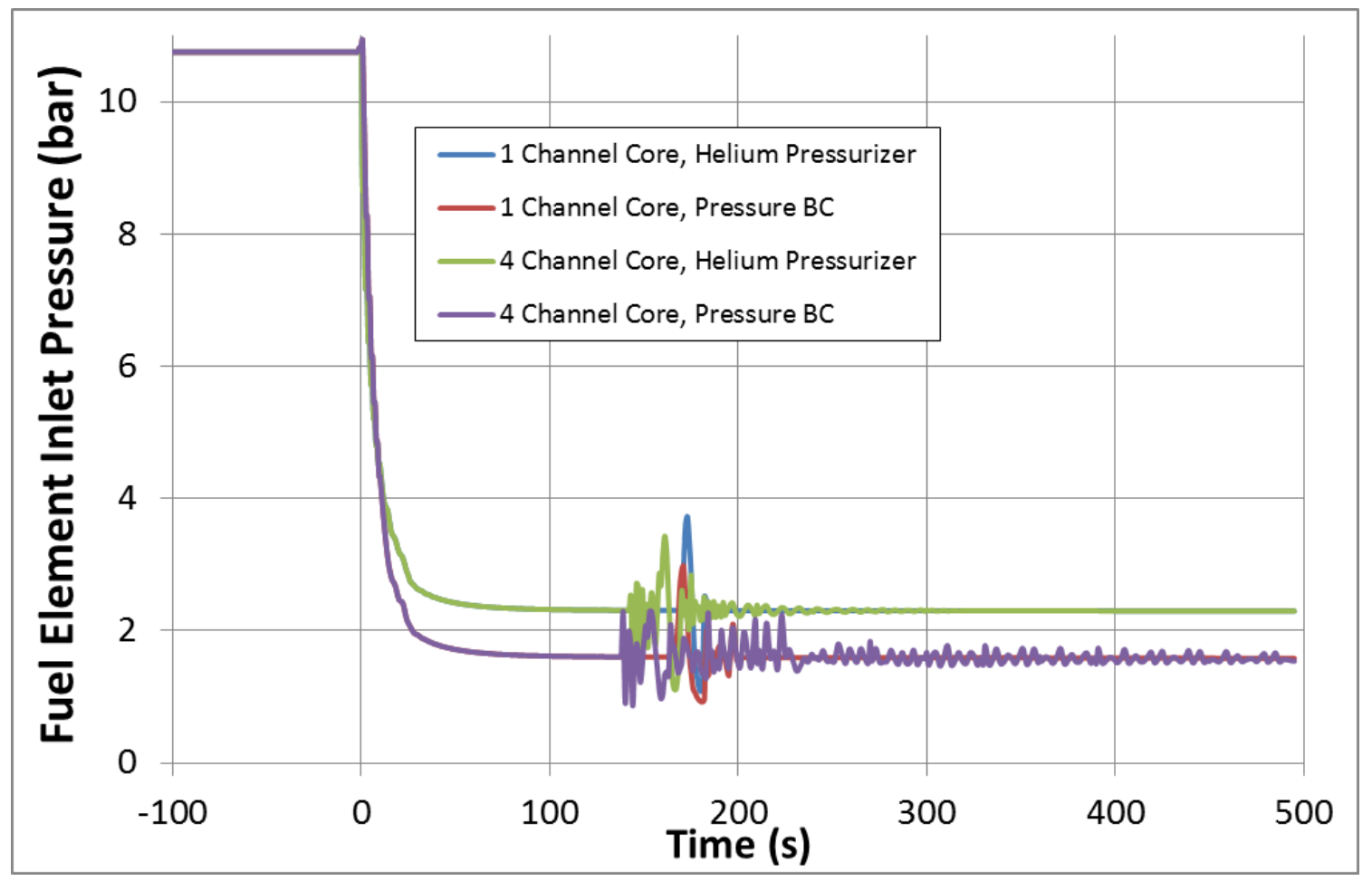

Figure 28 Fuel element inlet pressure. RELAP5 40(1)

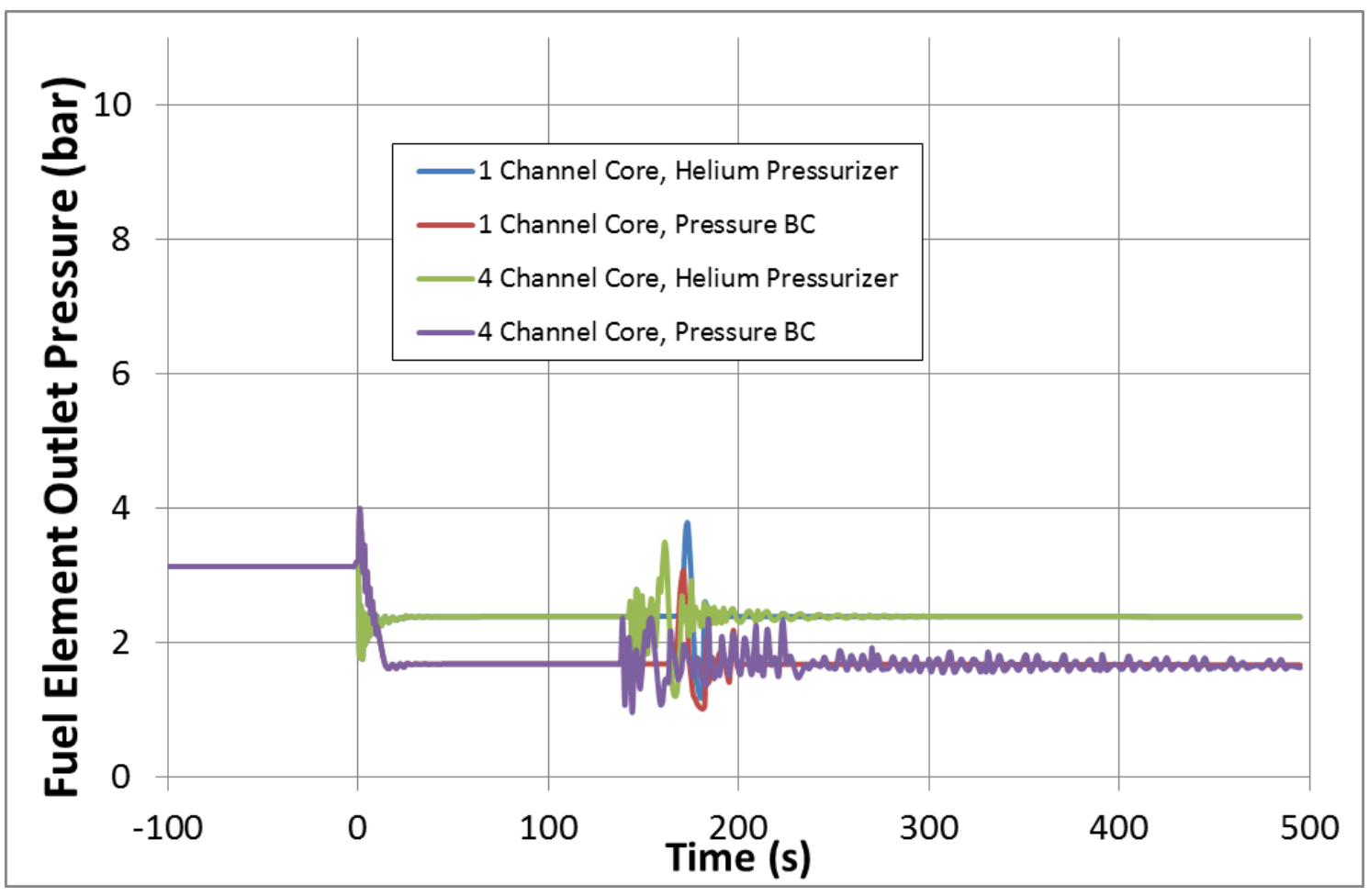

Figure 29 Fuel element outlet pressure. RELAP5 40(26) 


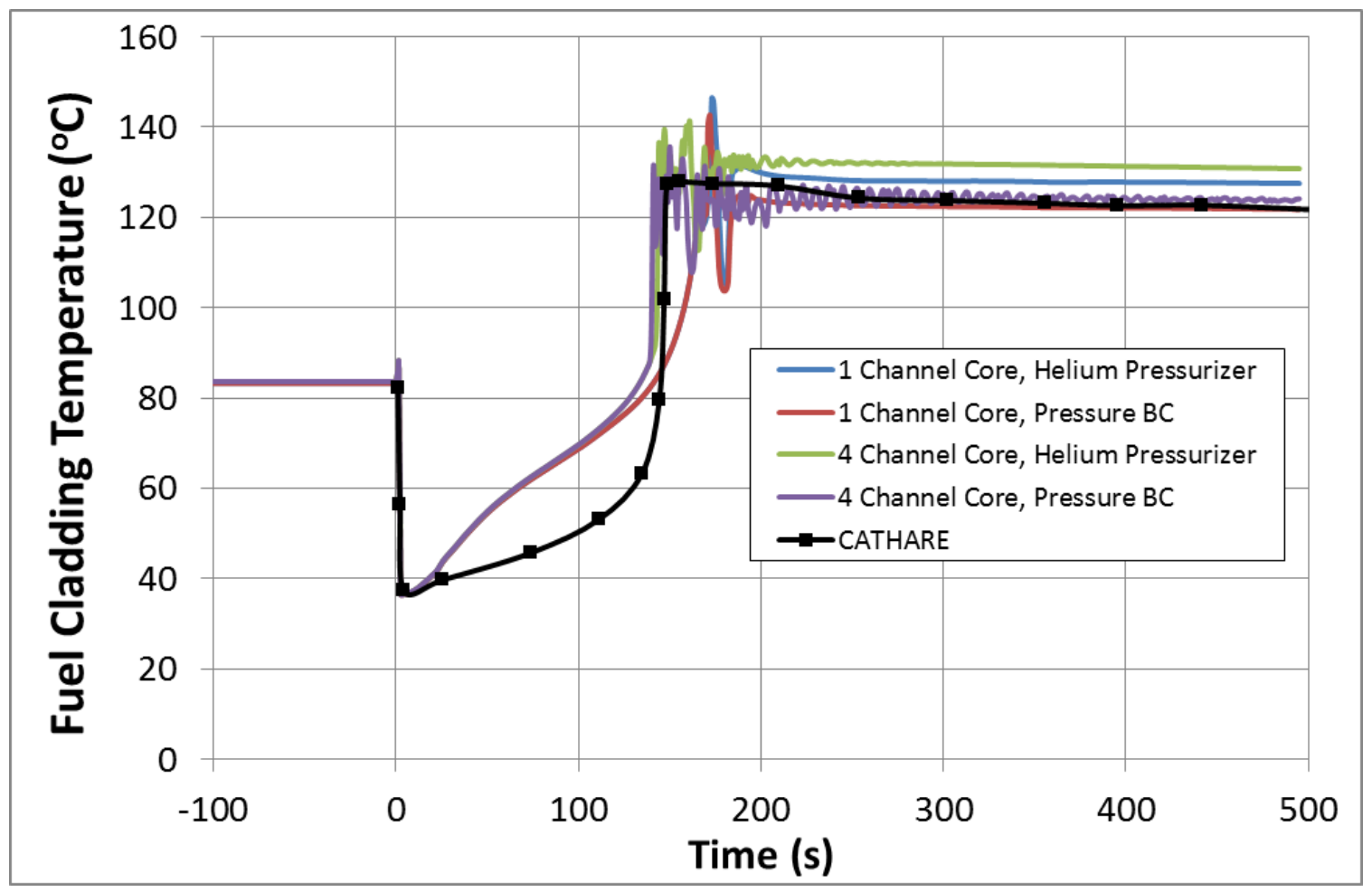

Figure 30 Peak transient fuel cladding temperature. RELAP5 41(3)

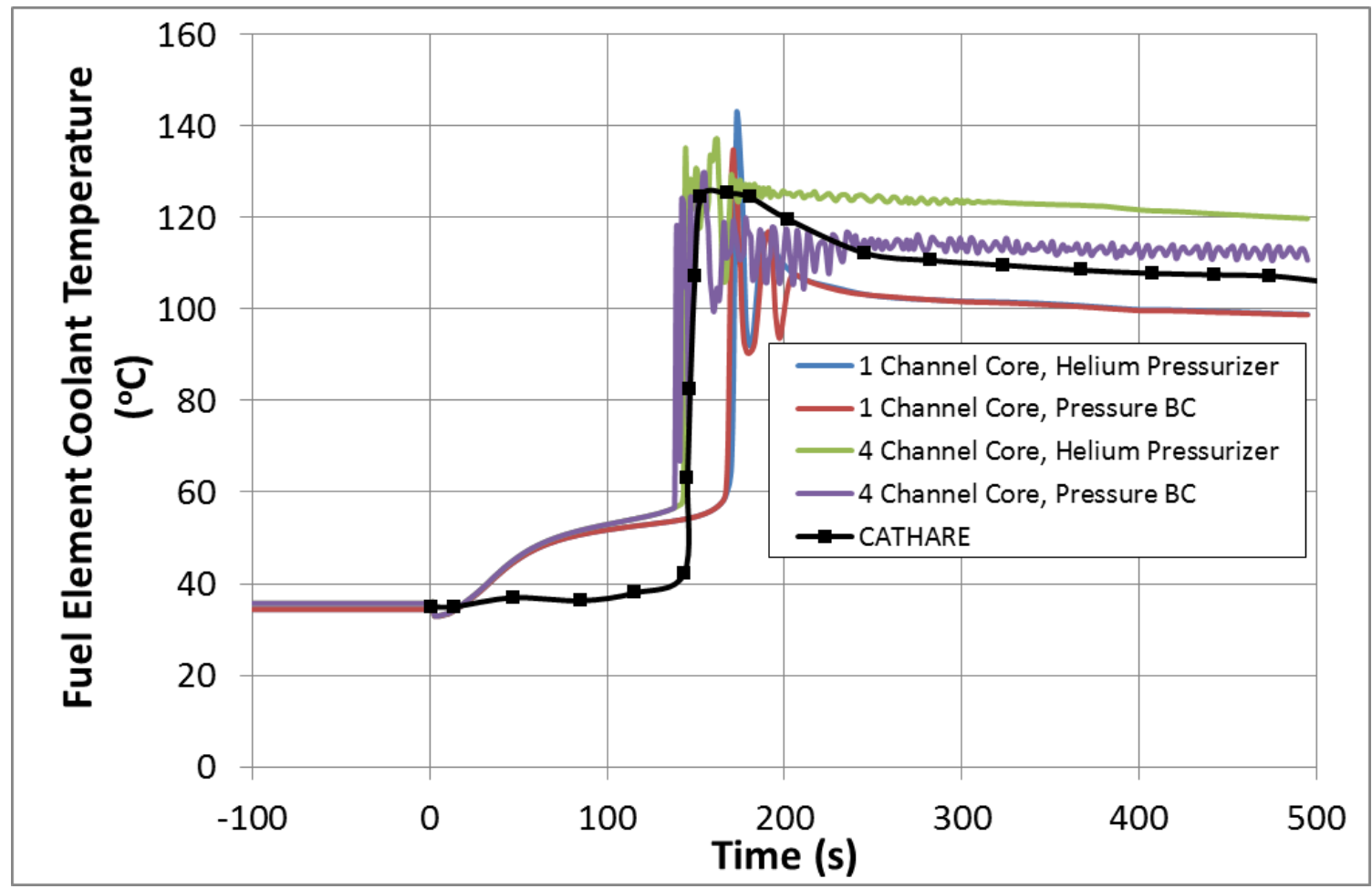

Figure 31 Fuel element coolant temperature. RELAP5 40(3) for single channel model and 41(3) for four channel model 
Total Loss of Electrical Power with Locked Pump Impellers

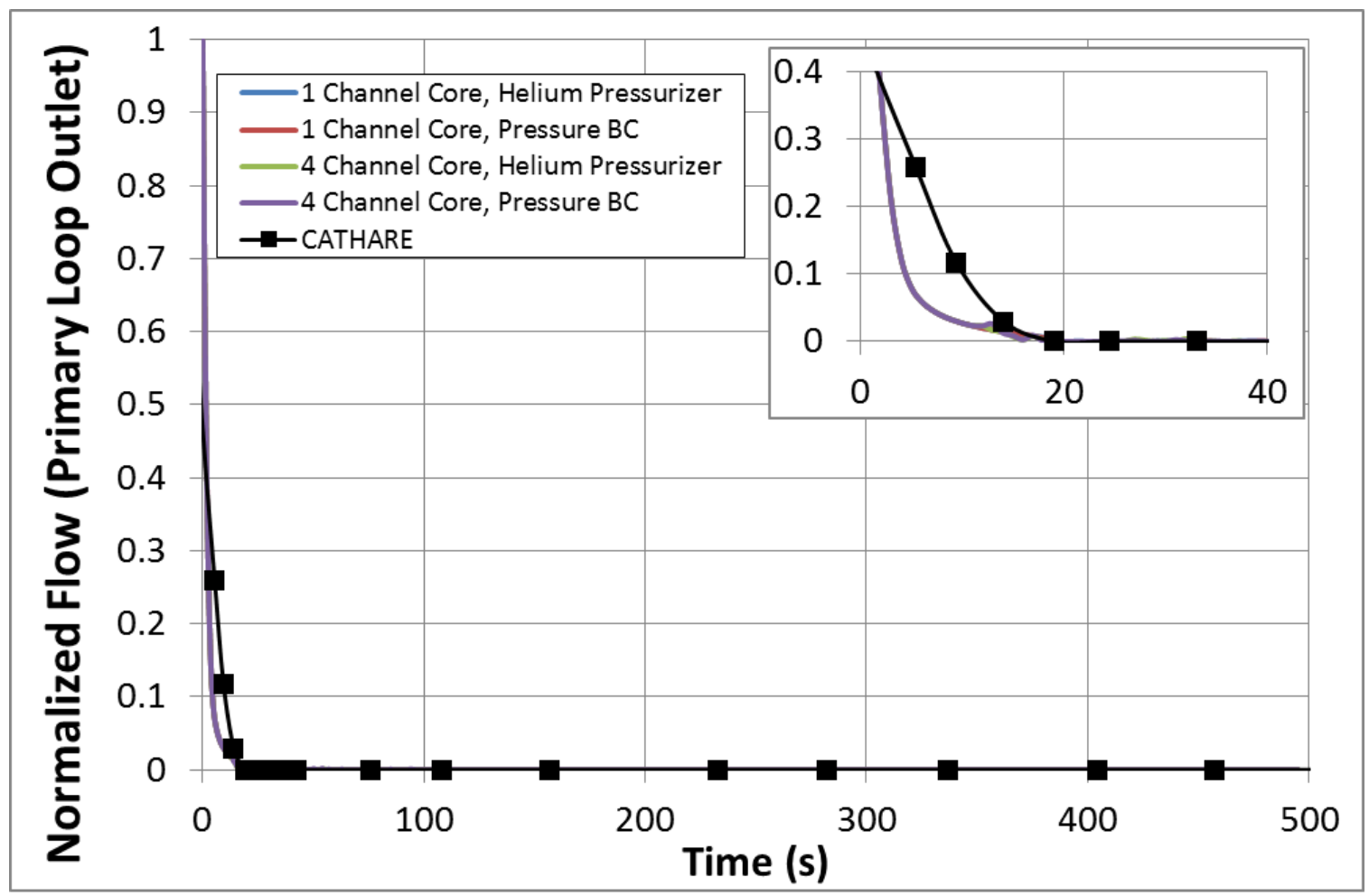

Figure 32 Normalized mass flow in the primary loop. RELAP5 174(1)

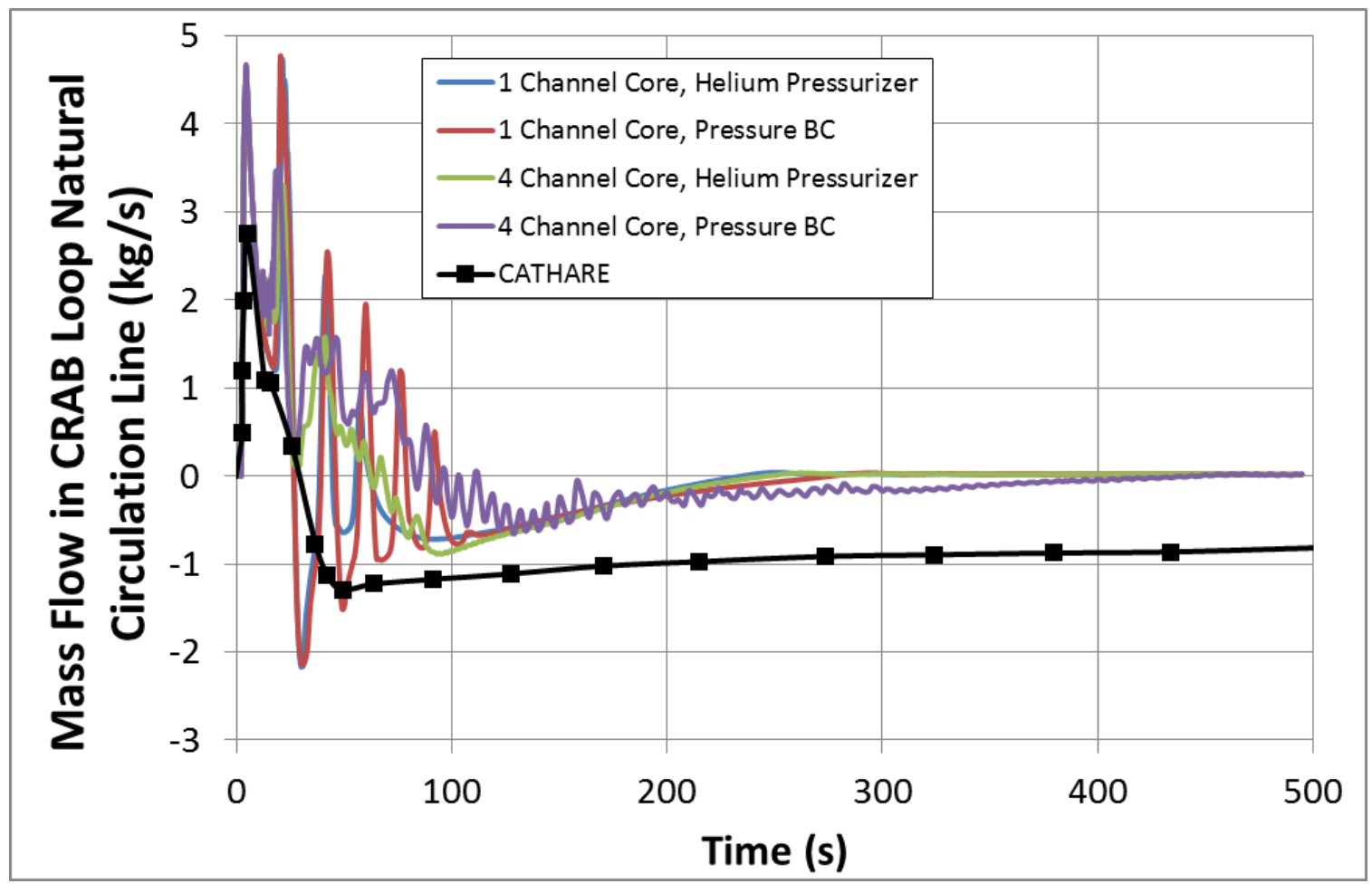

Figure 33 Mass flow in CRAB loop natural circulation line. RELAP5 512

Verification of Historical System Transient Simulations for the RHF Research Reactor 


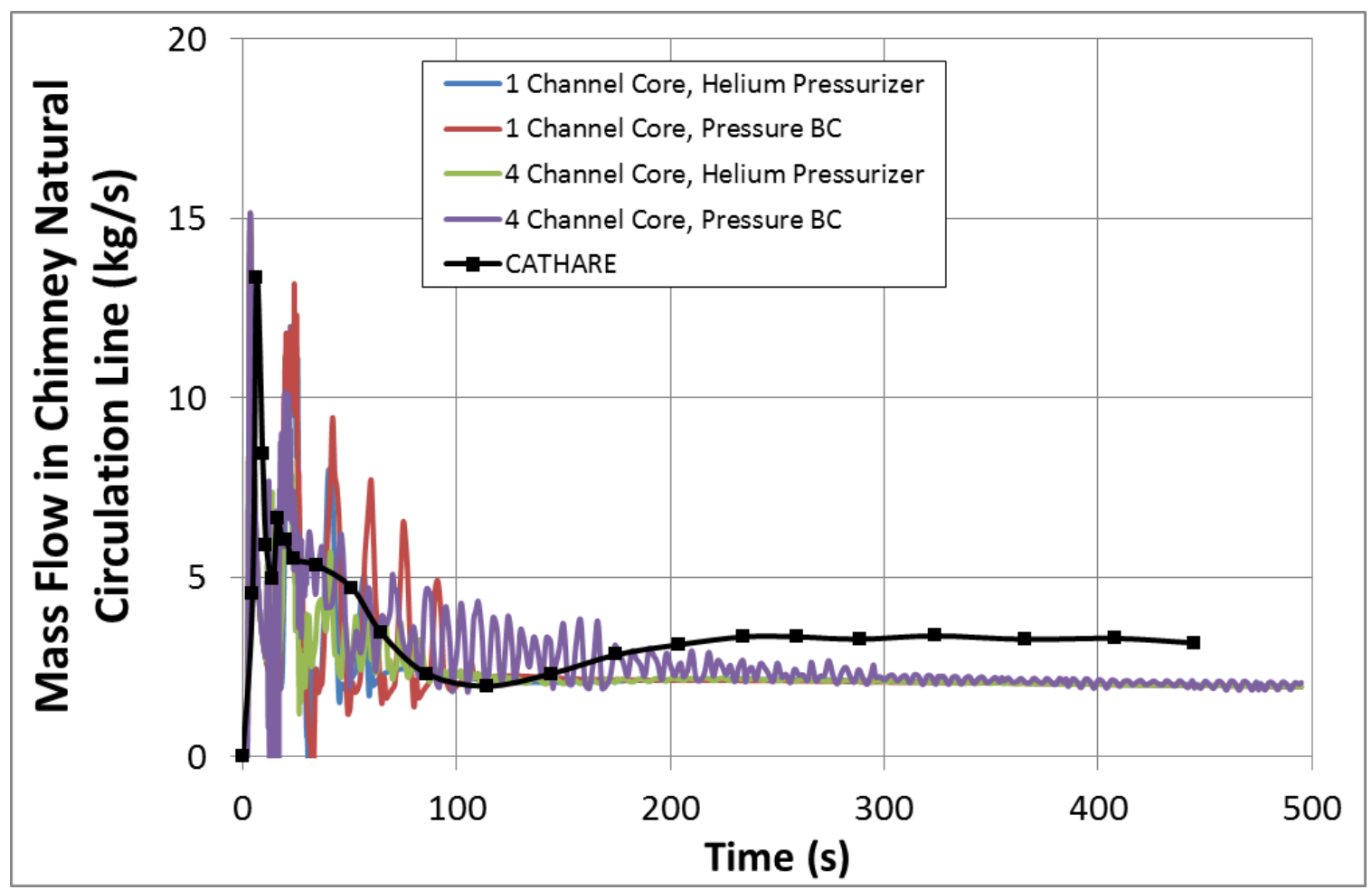

Figure 34 Mass flow in chimney natural circulation line. RELAP5 502

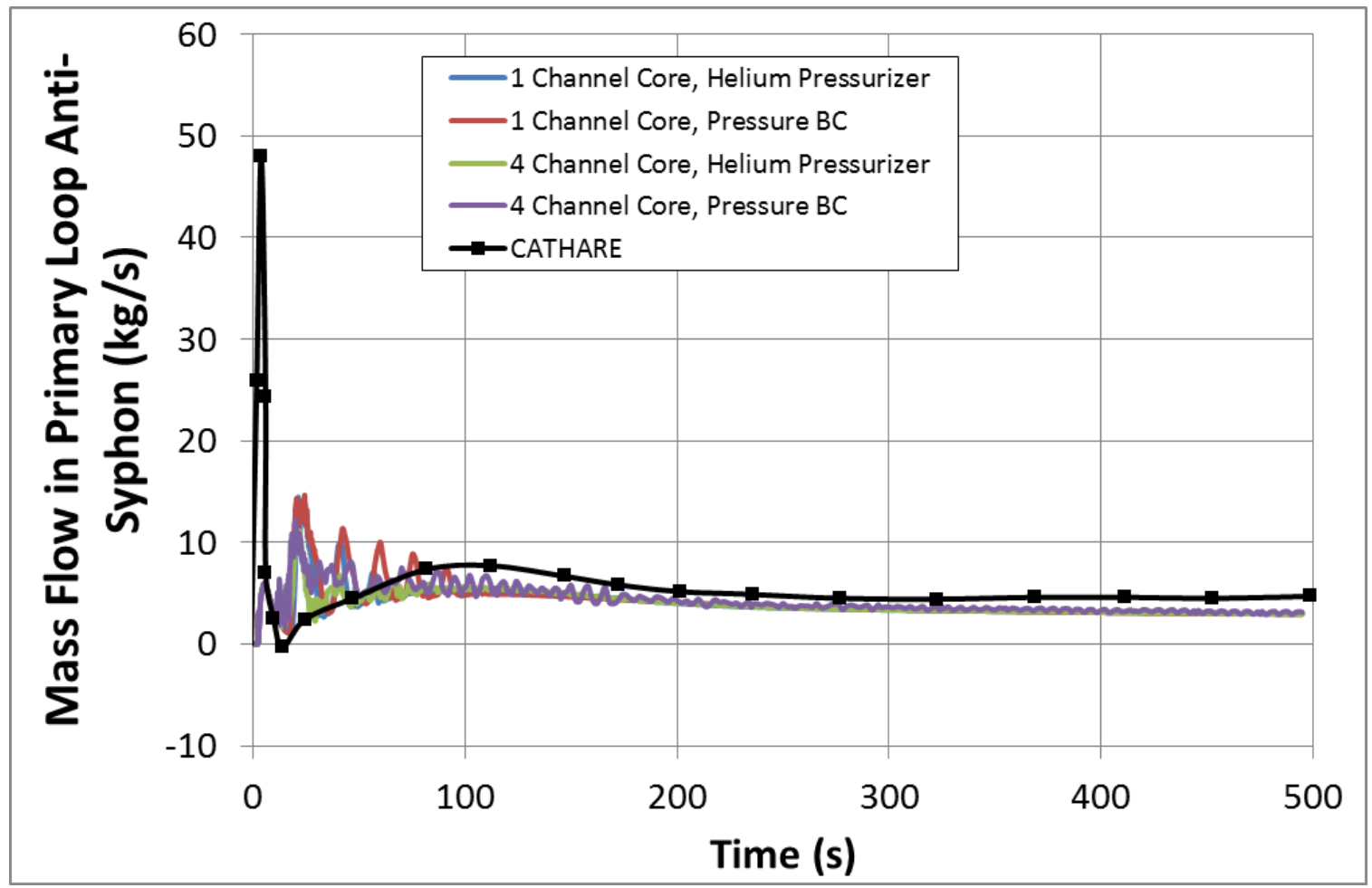

Figure 35 Mass flow in primary loop anti-syphon. RELAP5 282

Verification of Historical System Transient Simulations for the RHF Research Reactor 


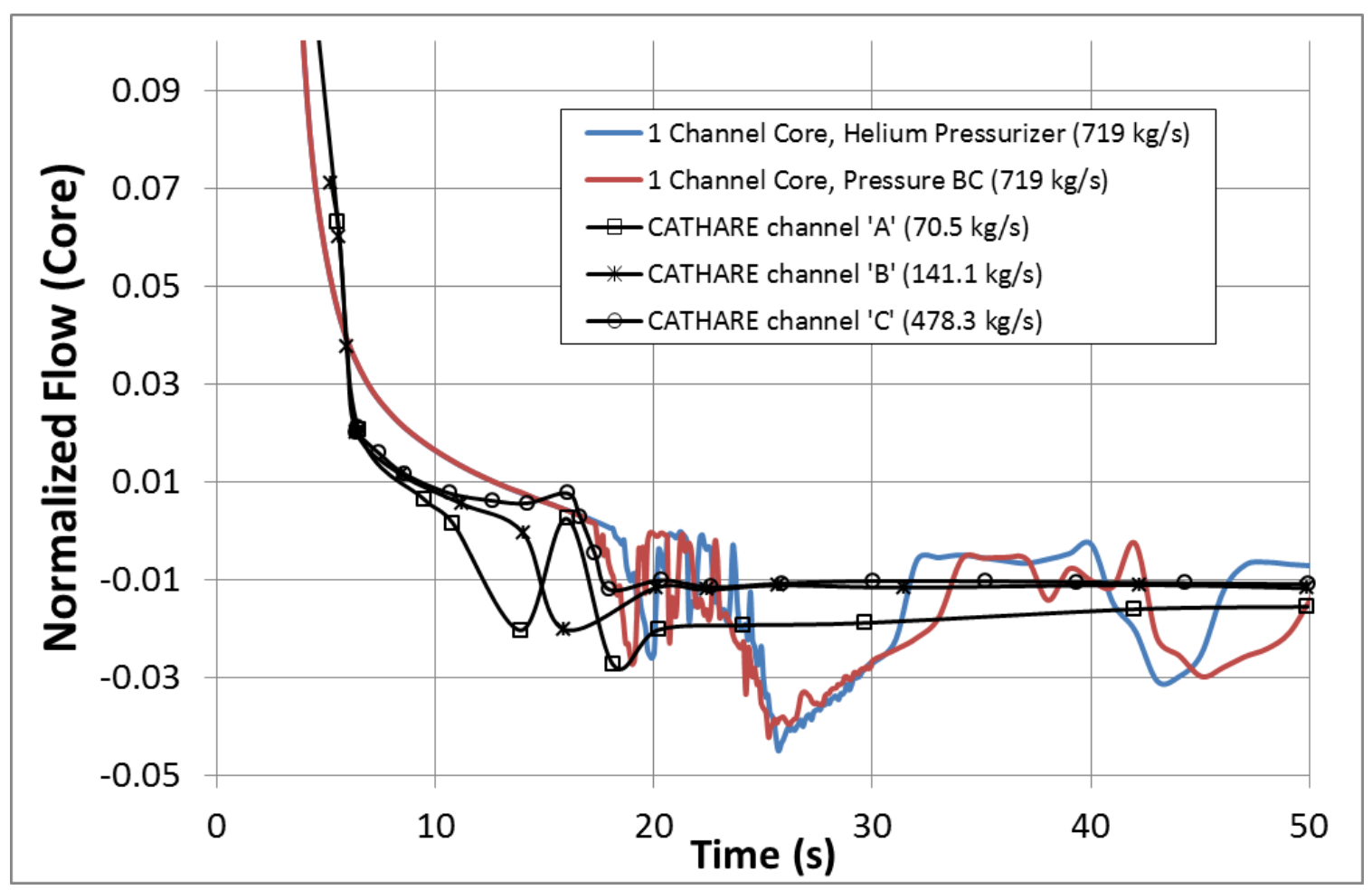

Figure 36 Normalized mass flow for single channel model. RELAP5 40(1)

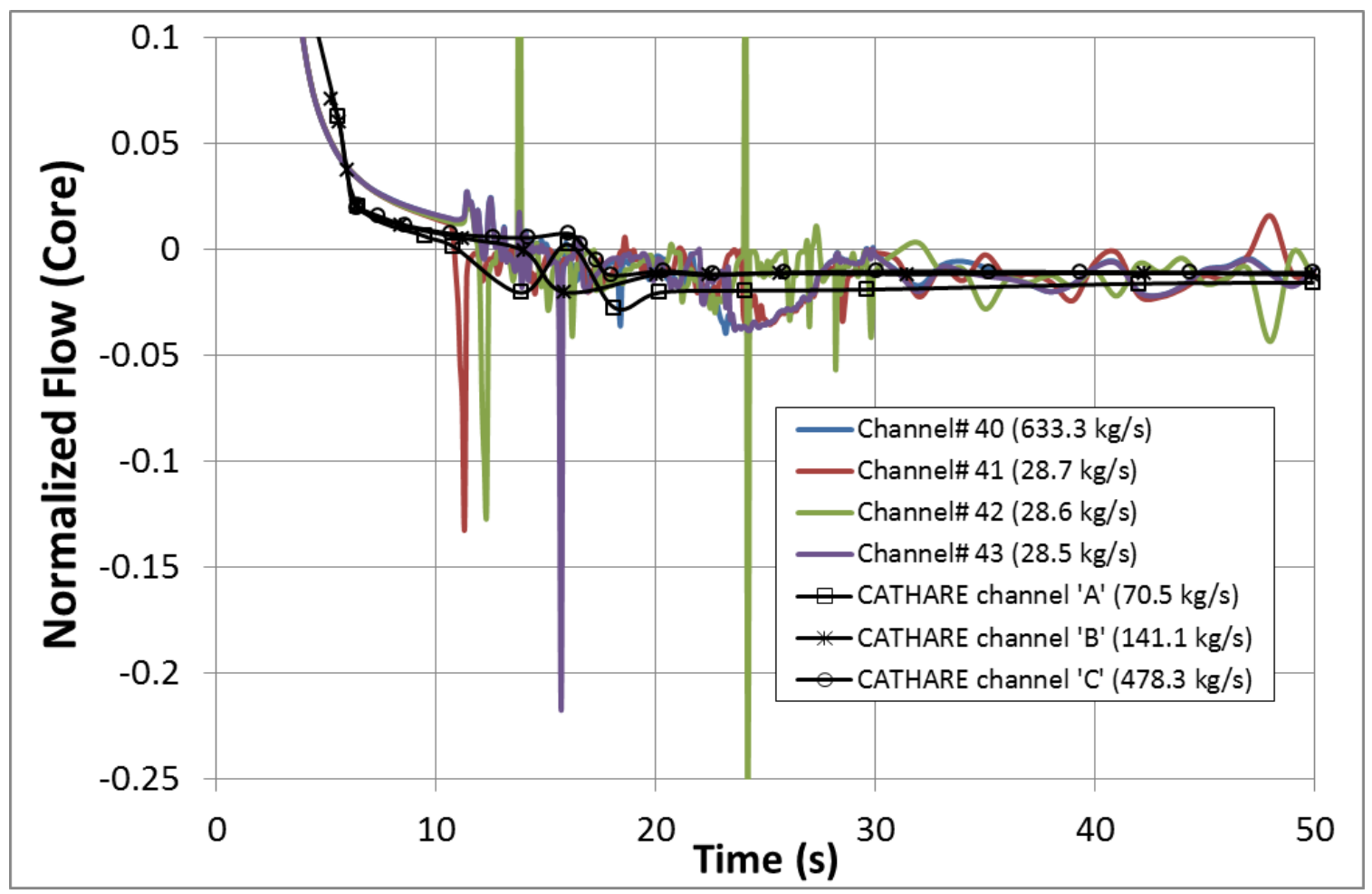

Figure 37 Normalized mass flow for four channel model with helium pressurizer. RELAP5 40-43(1)

Verification of Historical System Transient Simulations for the RHF Research Reactor 


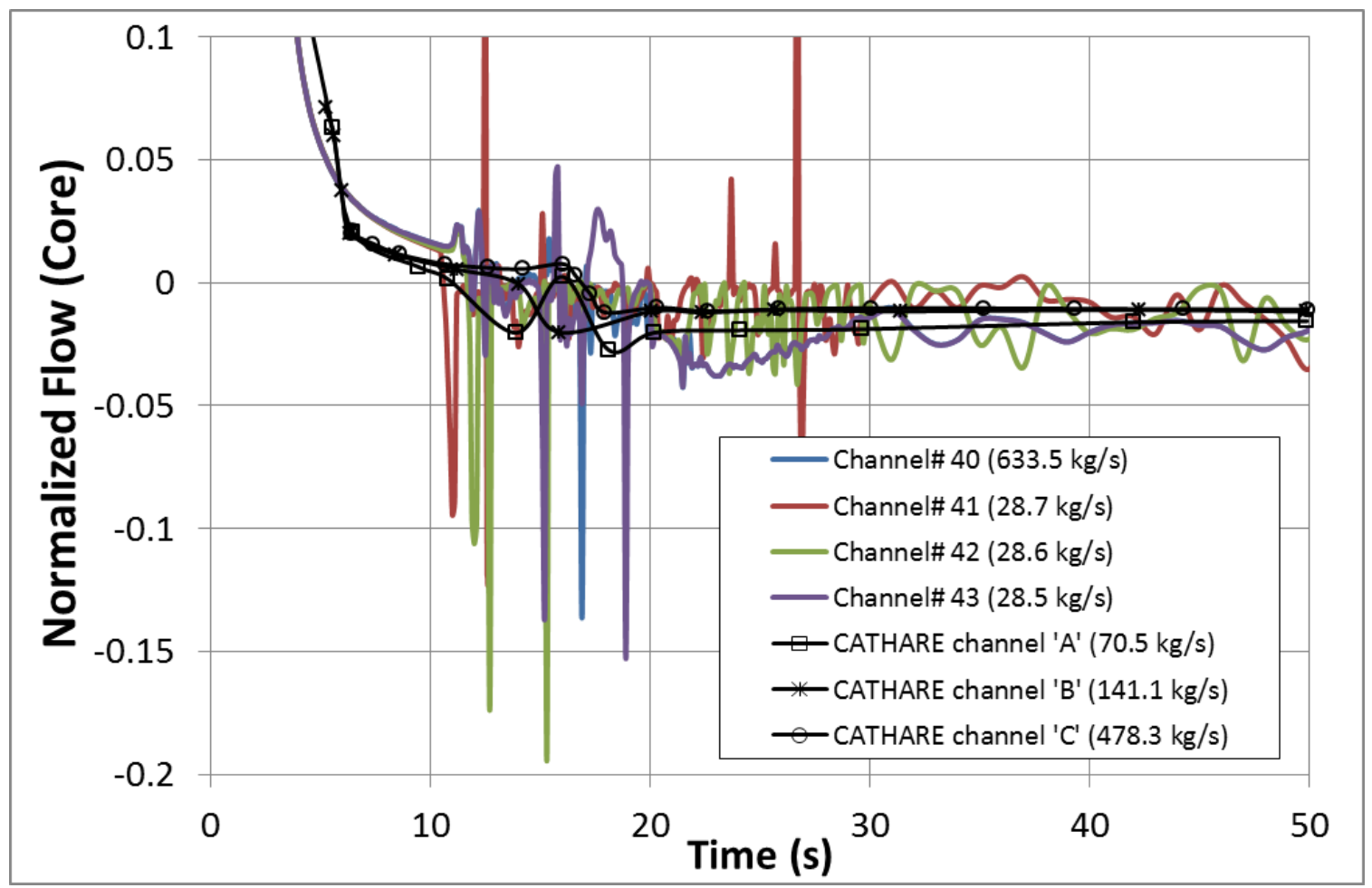

Figure 38 Normalized mass flow for four channel model with pressure BC. RELAP5 40-43(1).

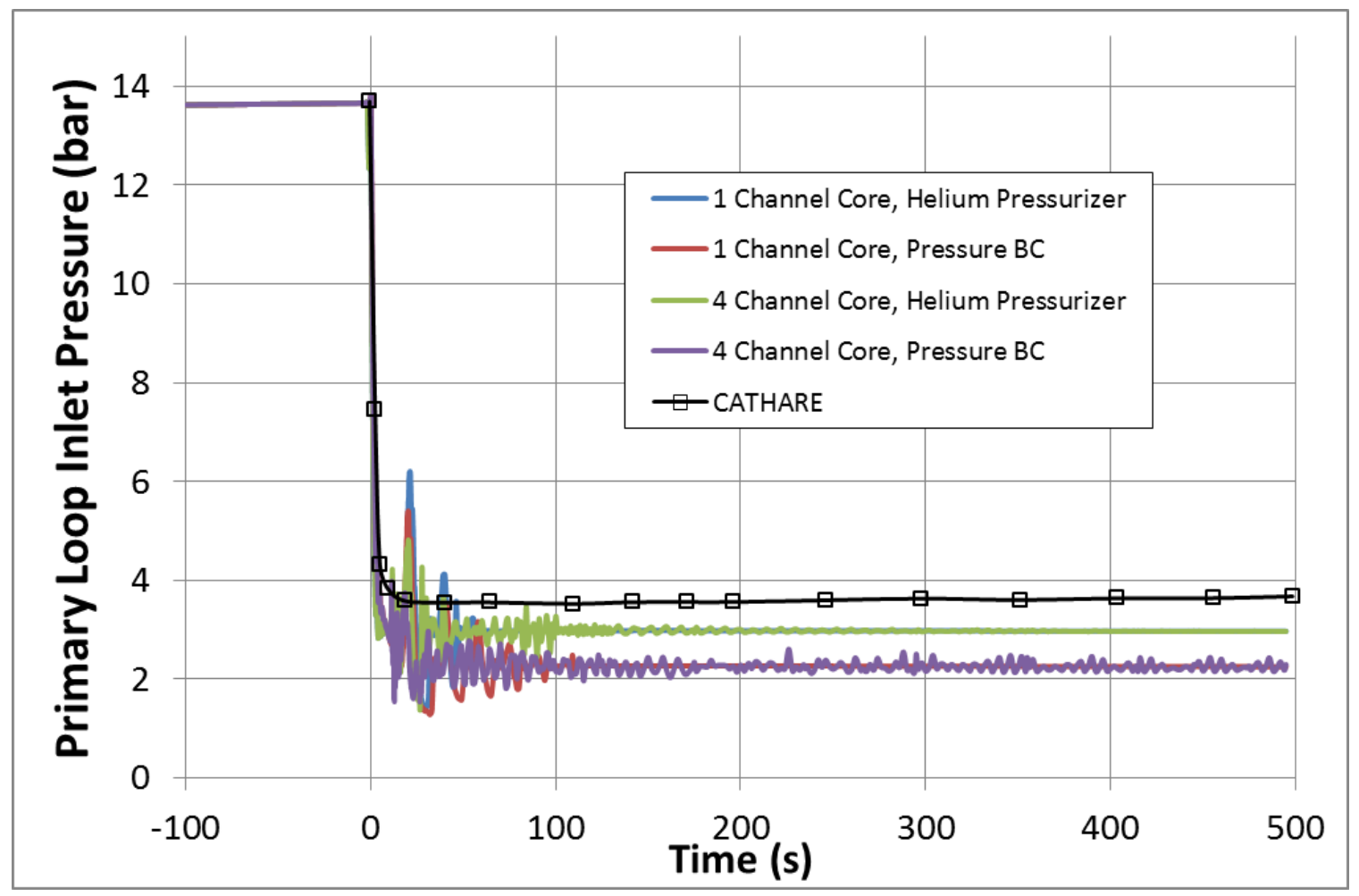

Figure 39 Primary loop inlet pressure. RELAP5 234(1)

Verification of Historical System Transient Simulations for the RHF Research Reactor 


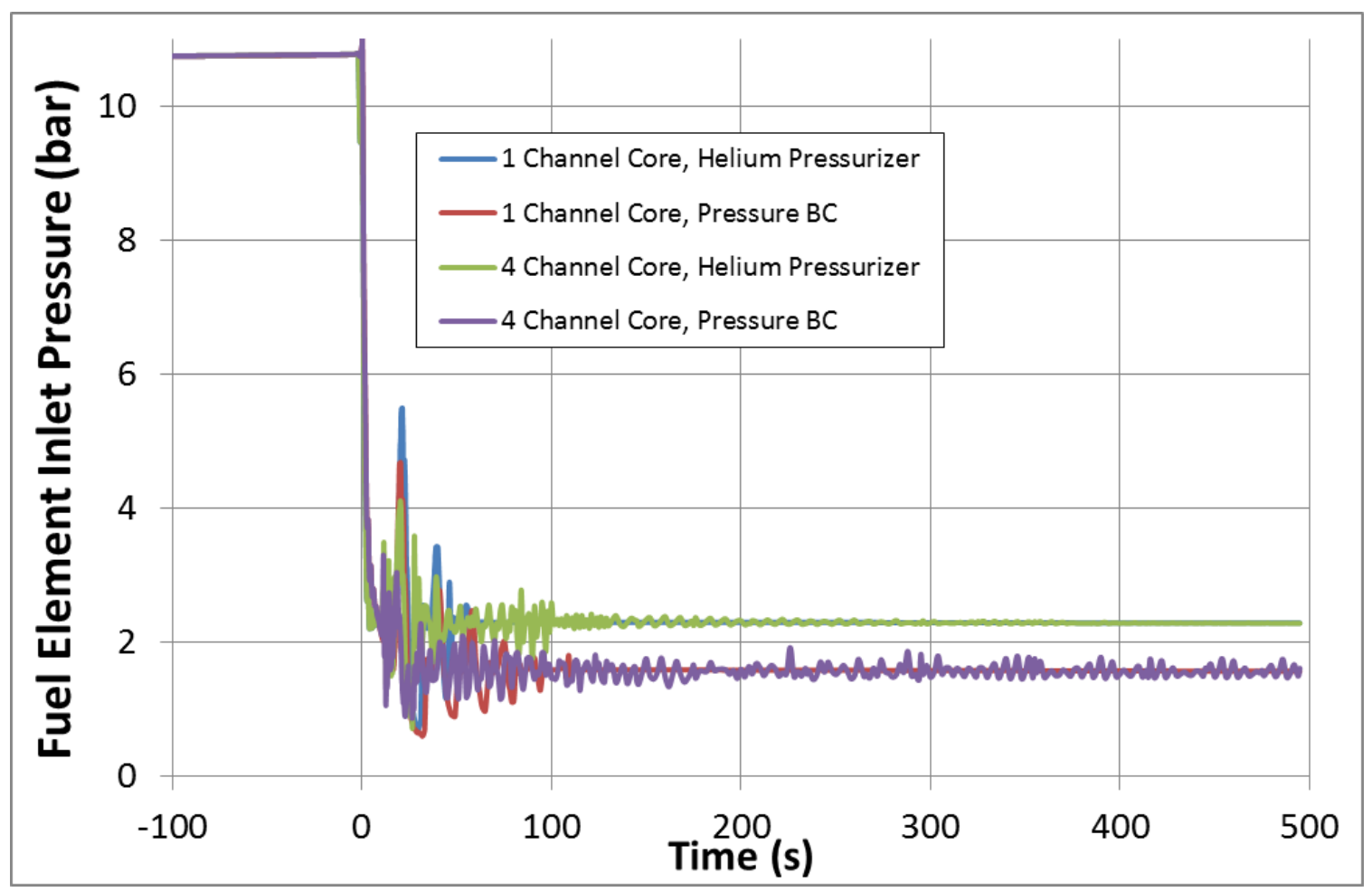

Figure 40 Fuel element inlet pressure. RELAP5 40(1)

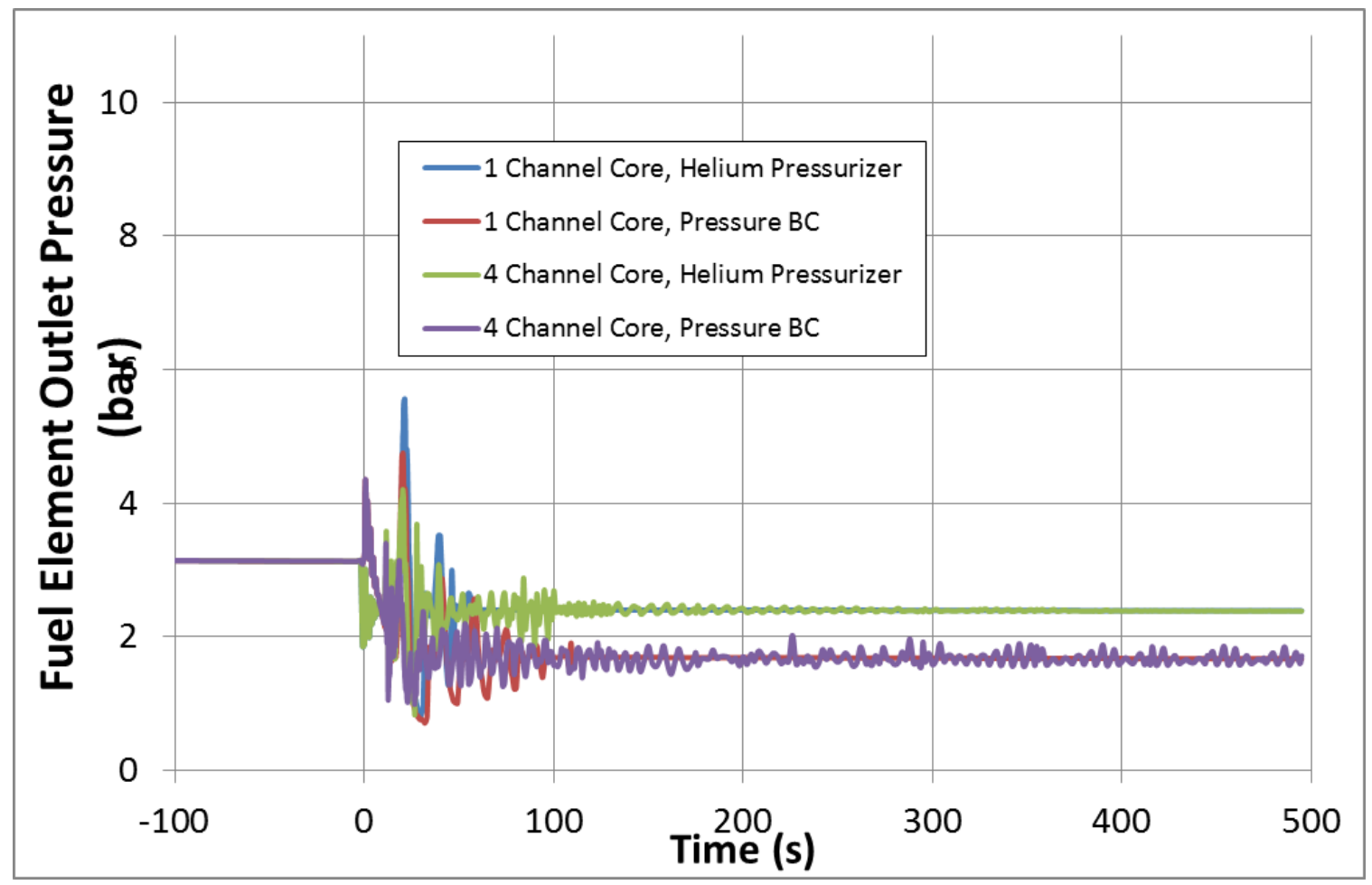

Figure 41 Fuel element outlet pressure. RELAP5 40(26) 


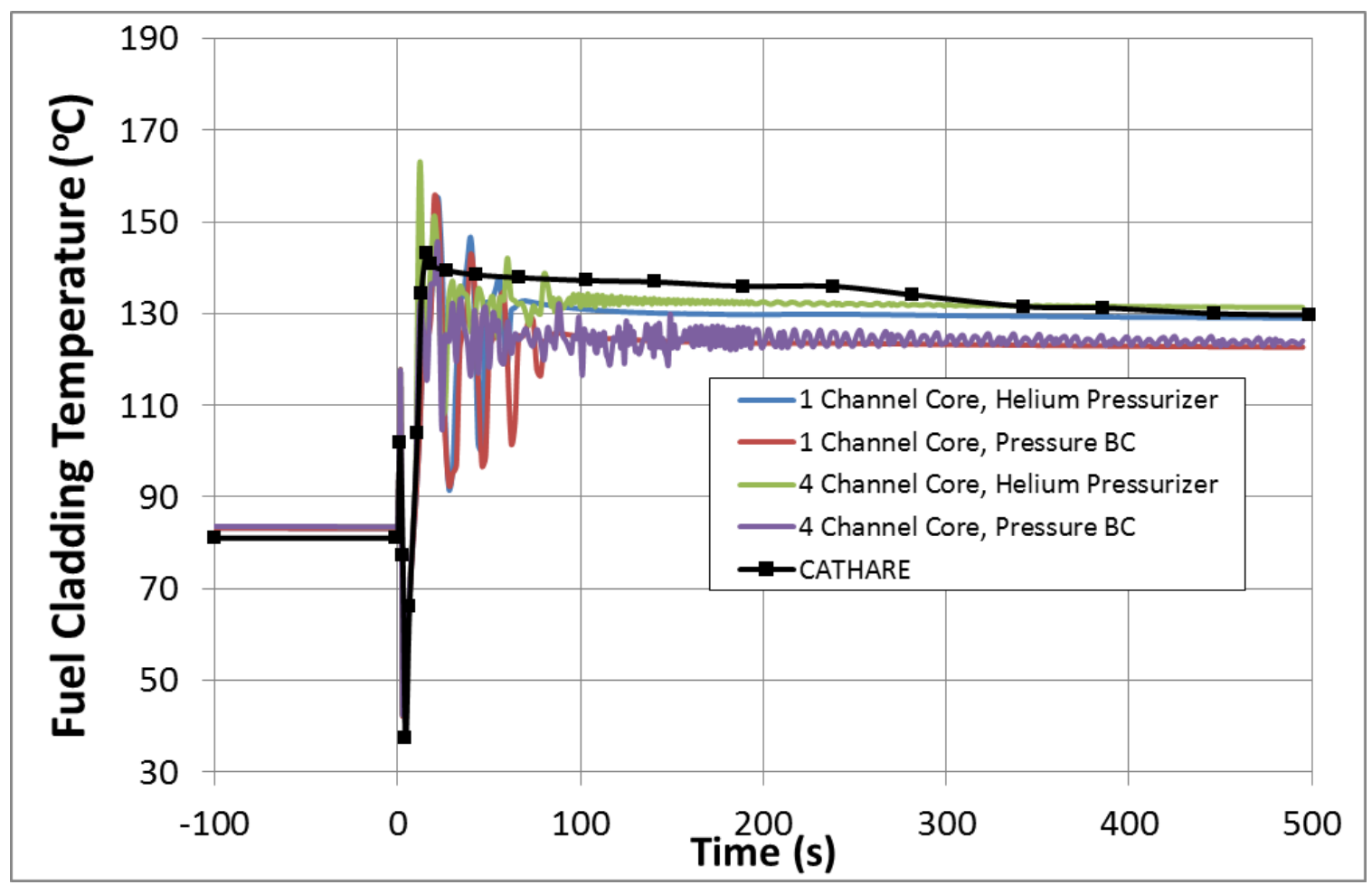

Figure 42 Peak transient fuel cladding temperature. RELAP5 41(3)

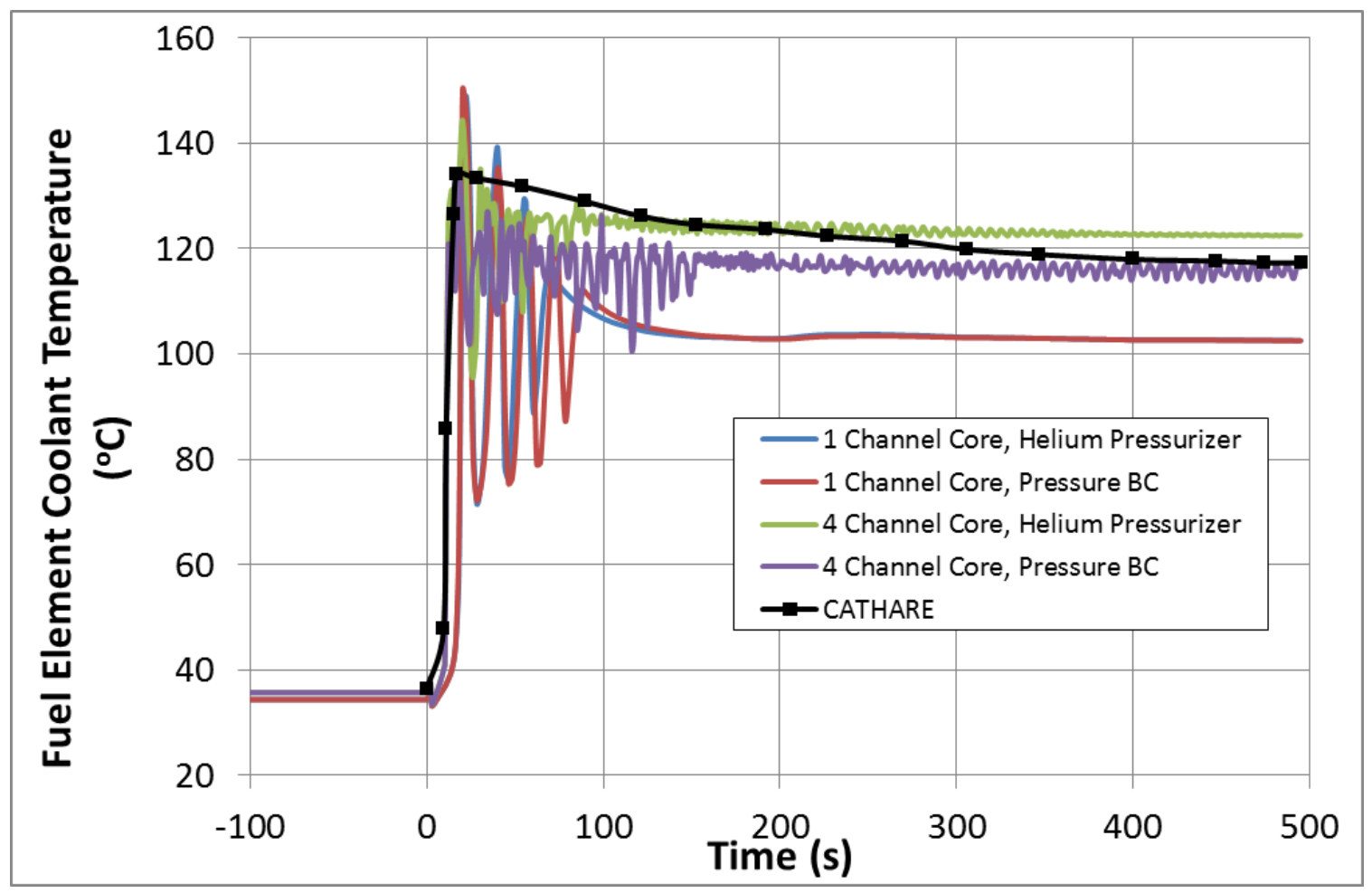

Figure 43 Fuel element coolant temperature. RELAP5 40(3) for single channel model and 41(3) for four channel model 


\section{Loss of coolant accident (hot leg break)}

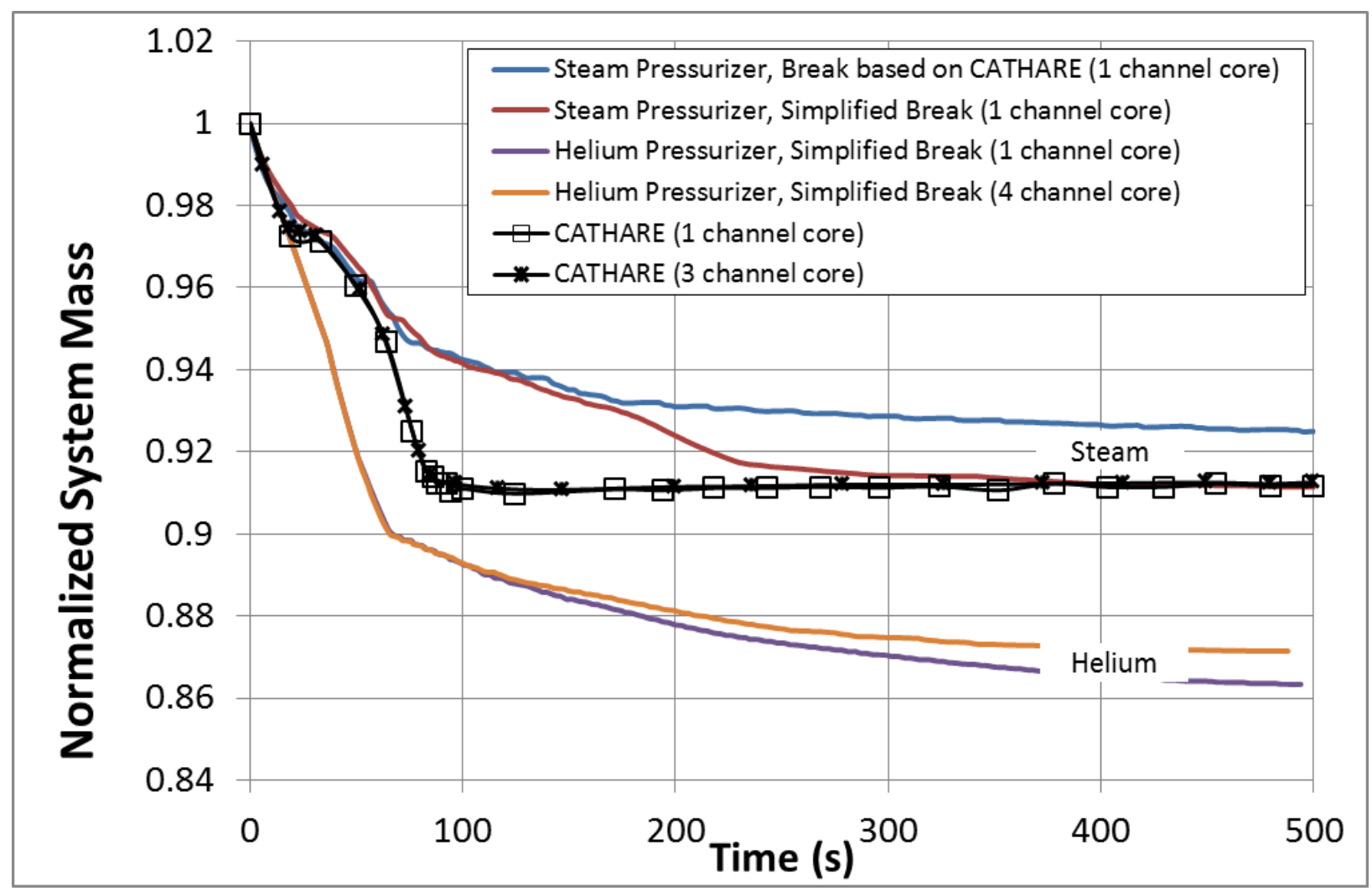

Figure 44 Normalized system mass due to pressurizer gas, break model and core model. Reference mass: RELAP5 $=31987 \mathrm{~kg}$, CATHARE $=32630 \mathrm{~kg}$. 


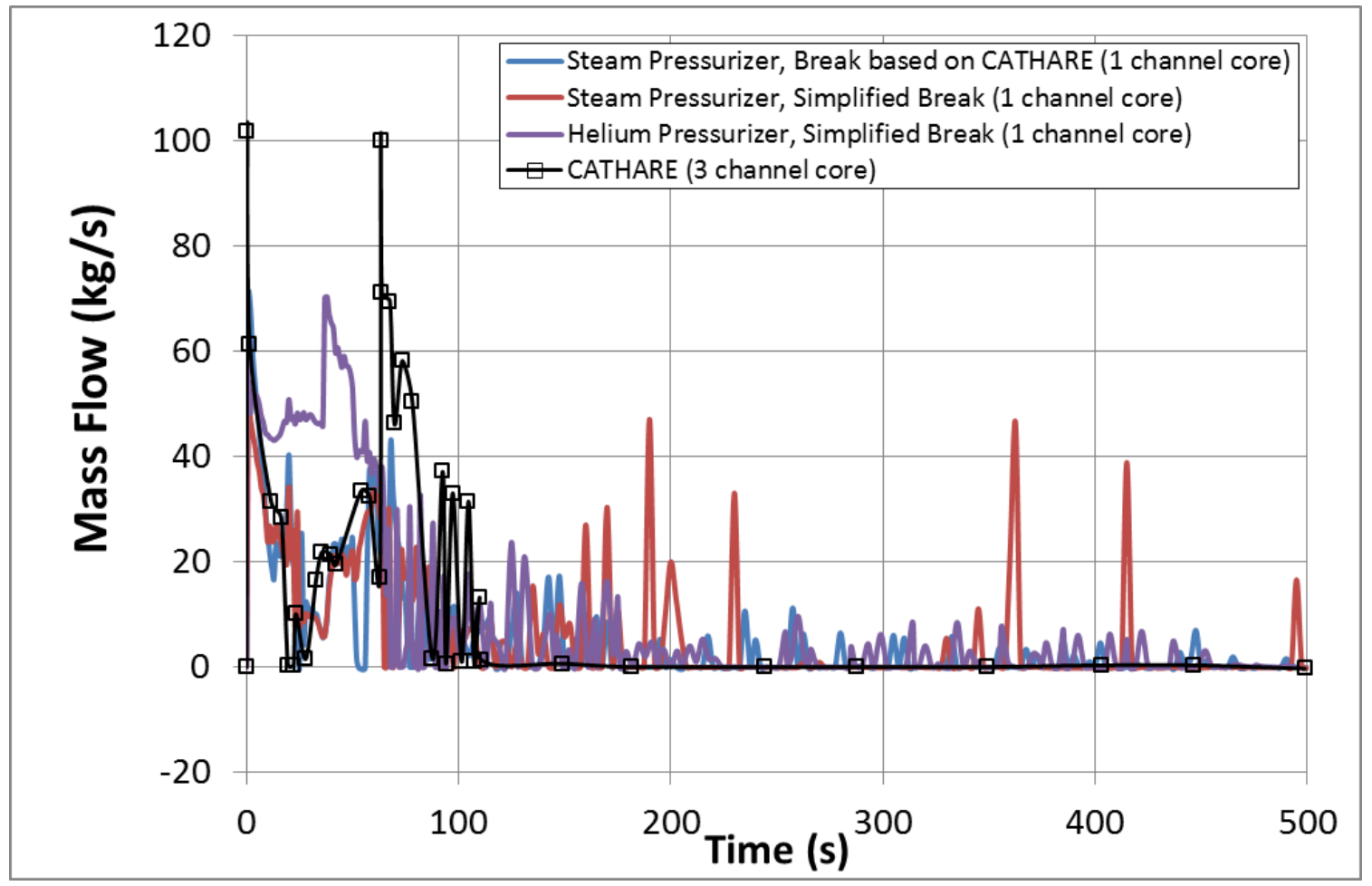

Figure 45 Mass flow through hot leg break due to pressurizer gas and break model. RELAP5 junction 828 (simplified break) and 818 (based on CATHARE).

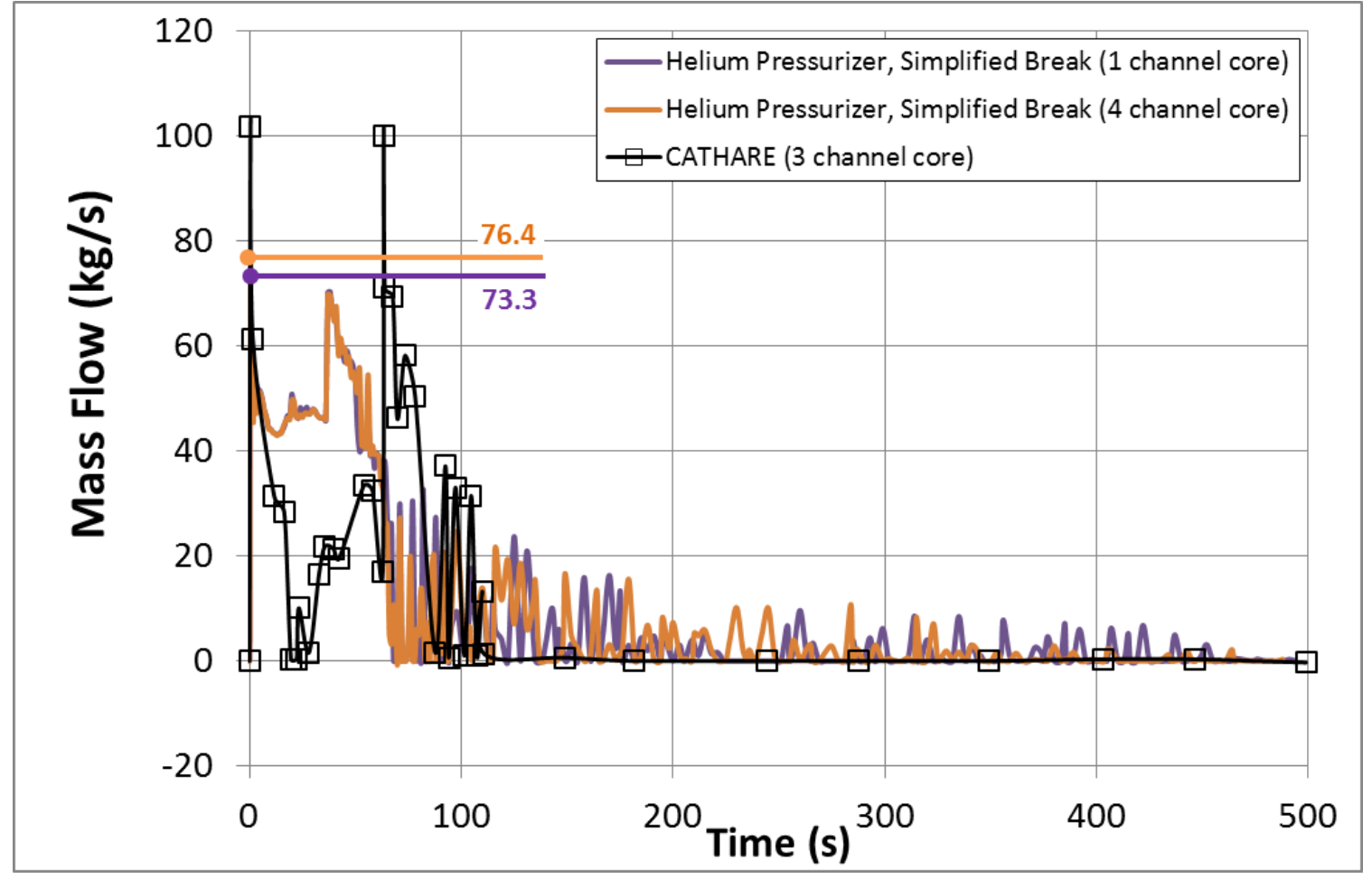

Figure 46 Mass flow through hot leg break due to core model. RELAP5 junction 828 (simplified break) and 818 (based on CATHARE).

Verification of Historical System Transient Simulations for the RHF Research Reactor 


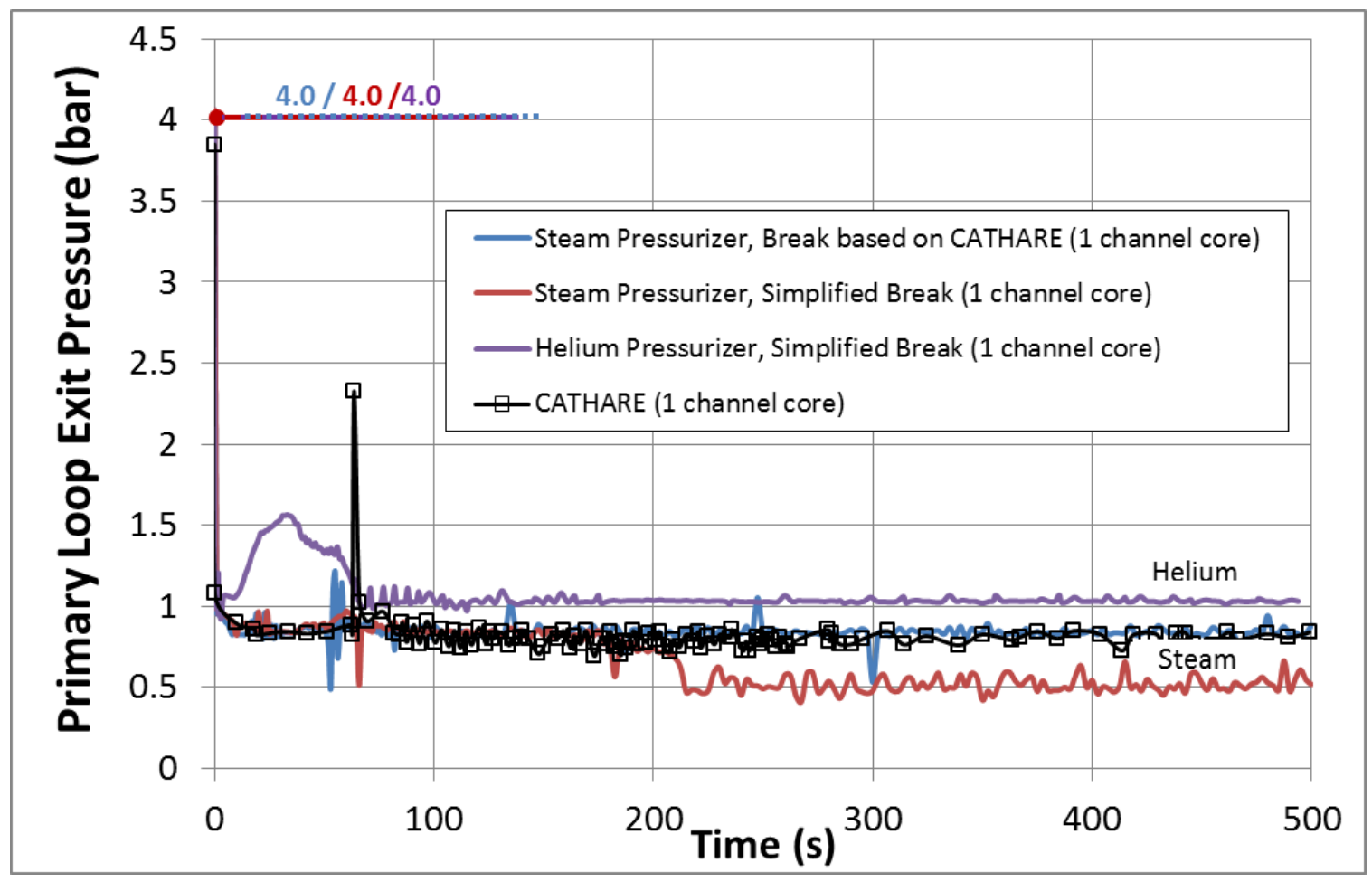

Figure 47 Exit pressure in primary loop due to pressurizer gas and break model. RELAP5 148(3)

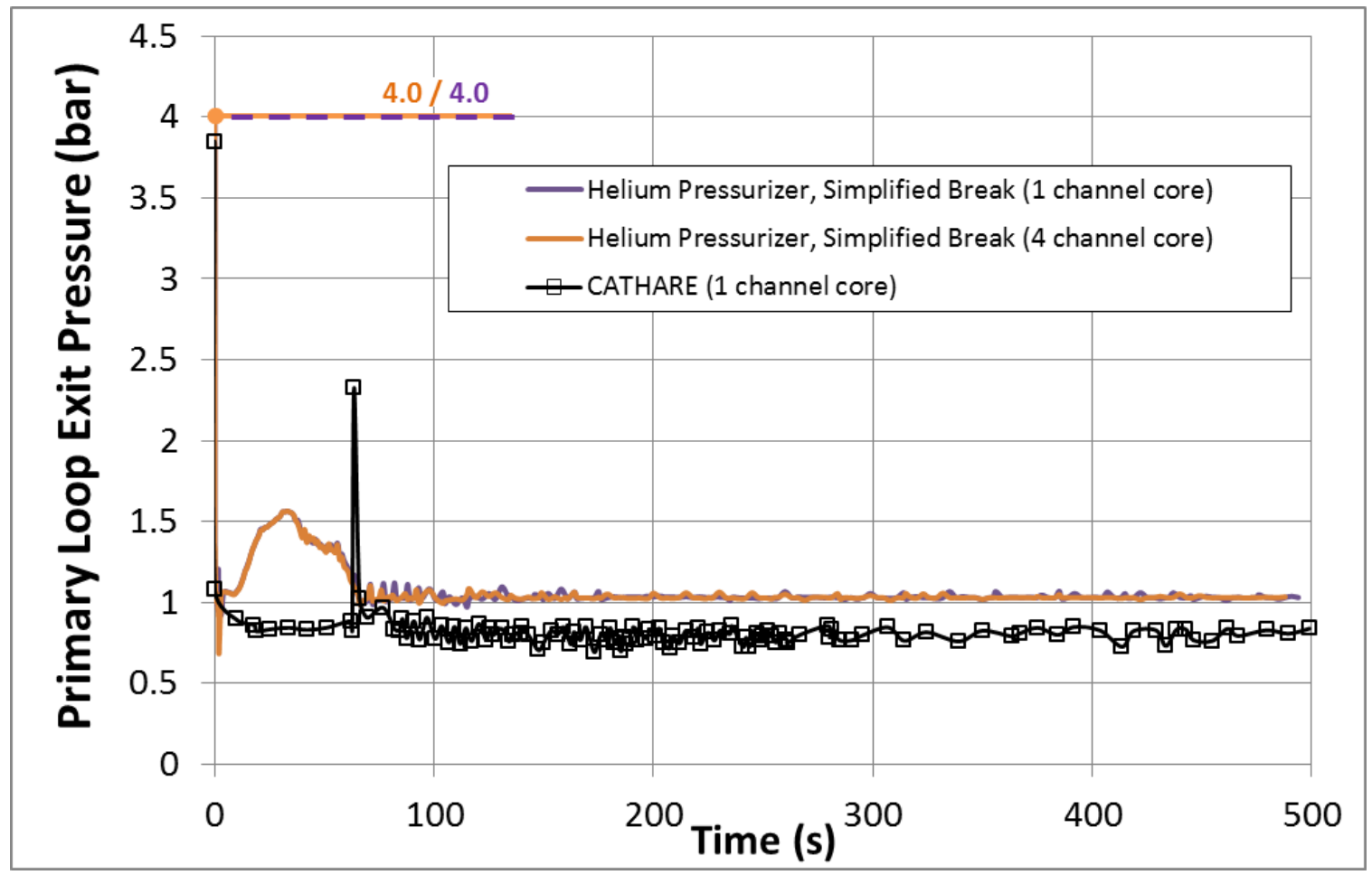

Figure 48 Exit pressure in primary loop due to core model. RELAP5 148(3)

Verification of Historical System Transient Simulations for the RHF Research Reactor 


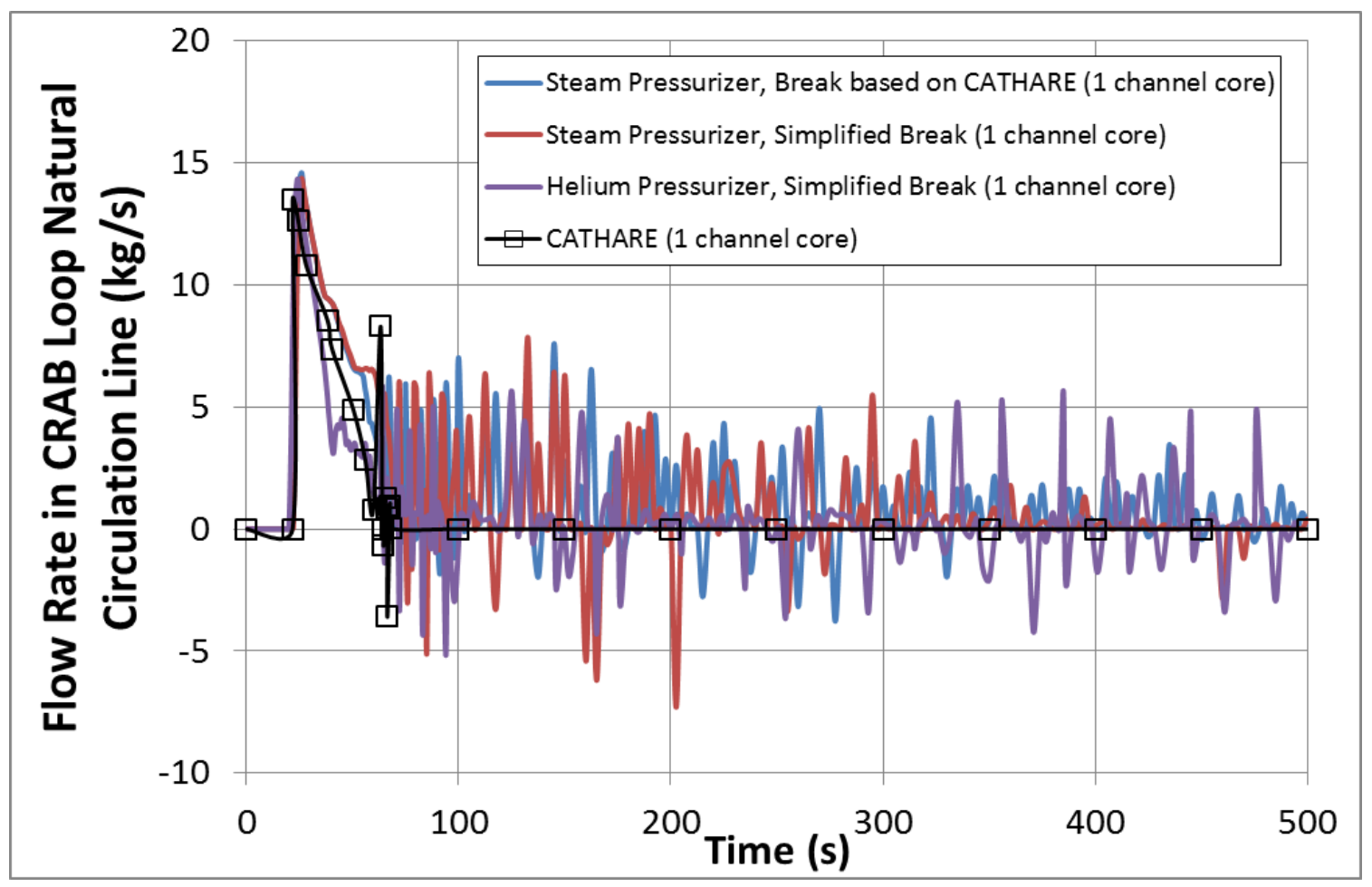

Figure 49 Flow rate in CRAB loop natural circulation line due to pressurizer gas and break model. RELAP5 junction 512

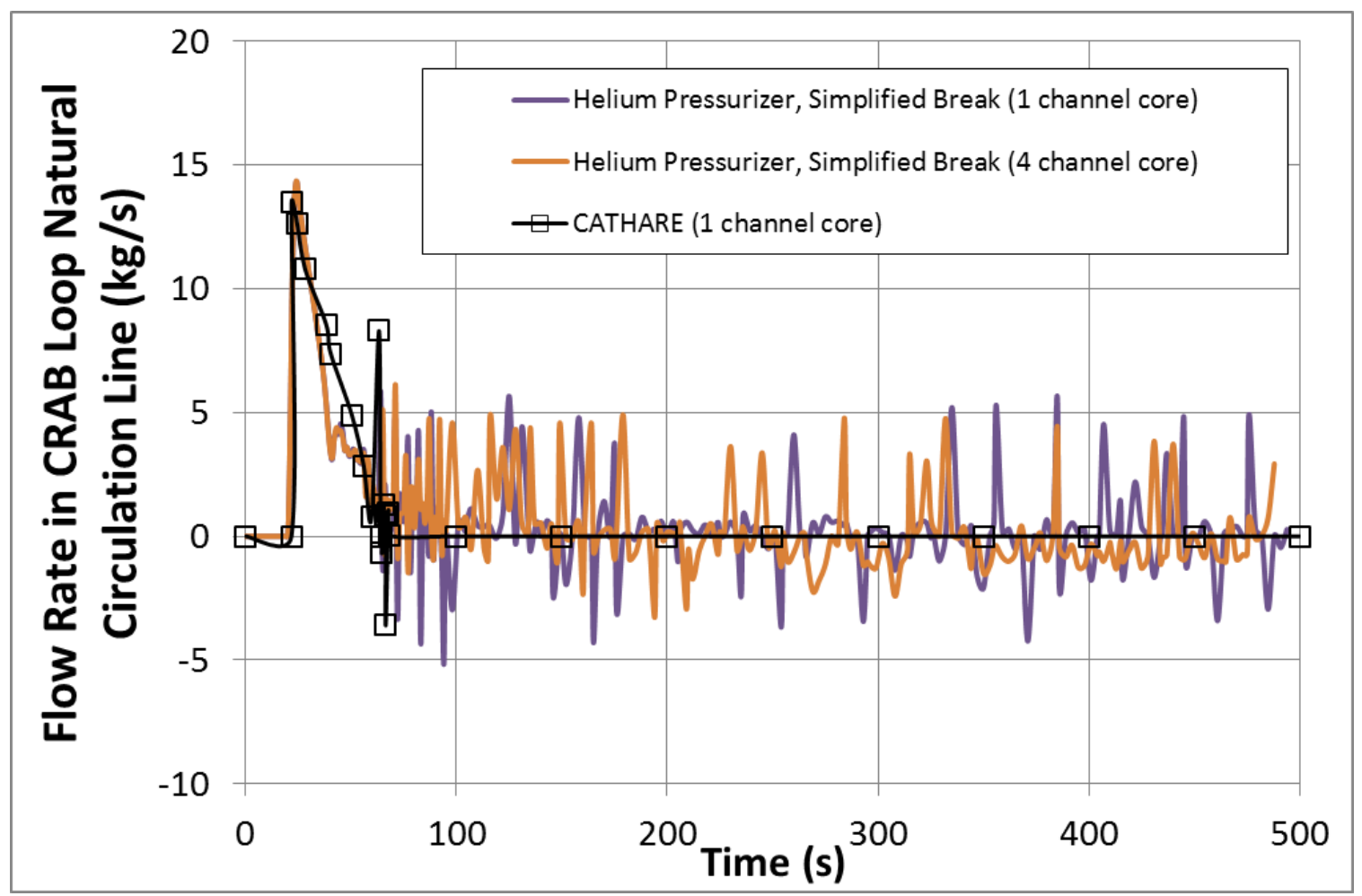

Figure 50 Flow rate in CRAB loop natural circulation line due to core model. RELAP5 junction 512

Verification of Historical System Transient Simulations for the RHF Research Reactor 


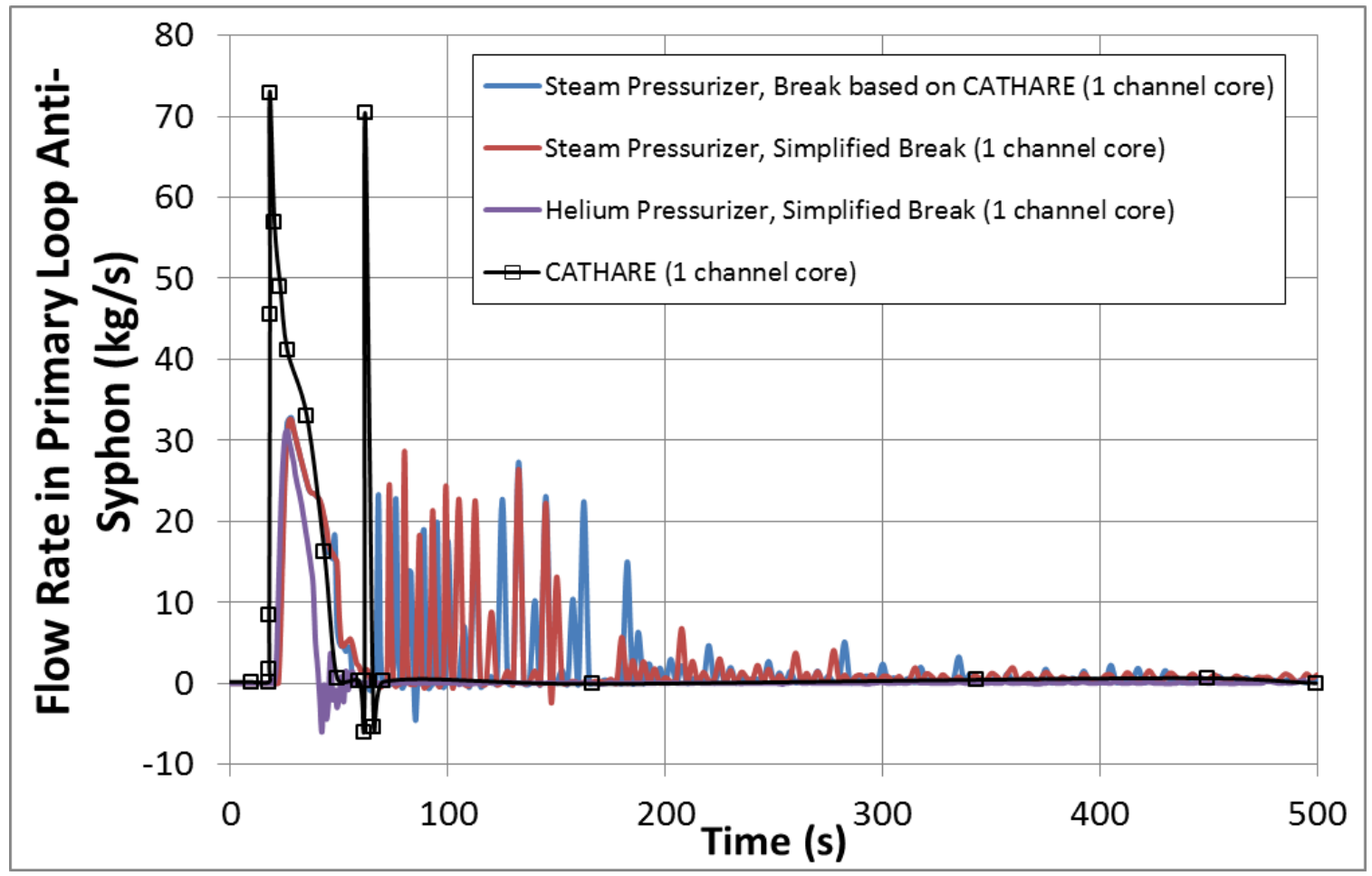

Figure 51 Flow rate in CRAB loop primary loop anti-syphon due to pressurizer gas and break model. RELAP5 junction 282

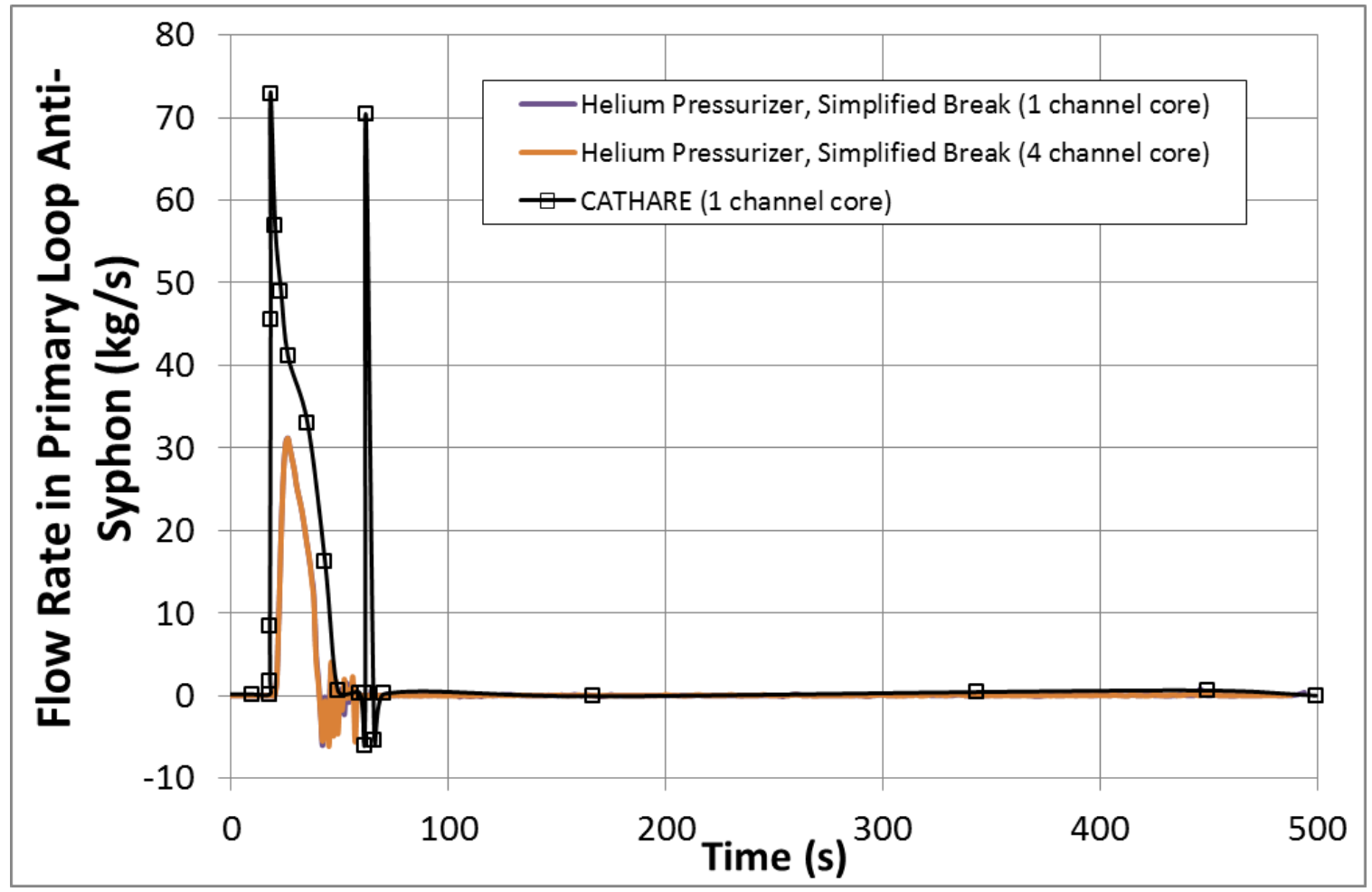

Figure 52 Flow rate in CRAB loop primary loop anti-syphon due to core model. RELAP5 junction 282

Verification of Historical System Transient Simulations for the RHF Research Reactor 


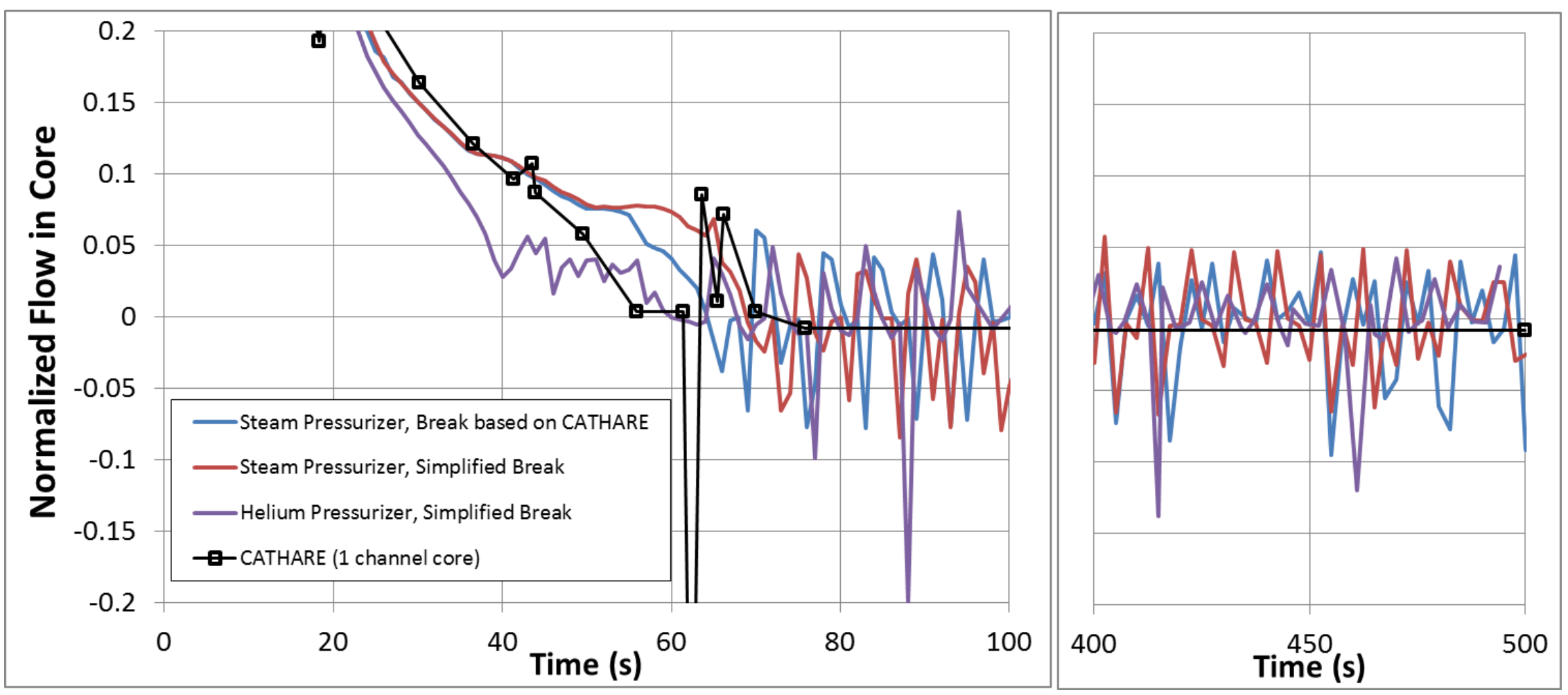

Figure 53 Normalized flow rate in core for single channel model due to pressurizer gas and break model. RELAP5 40(1) 

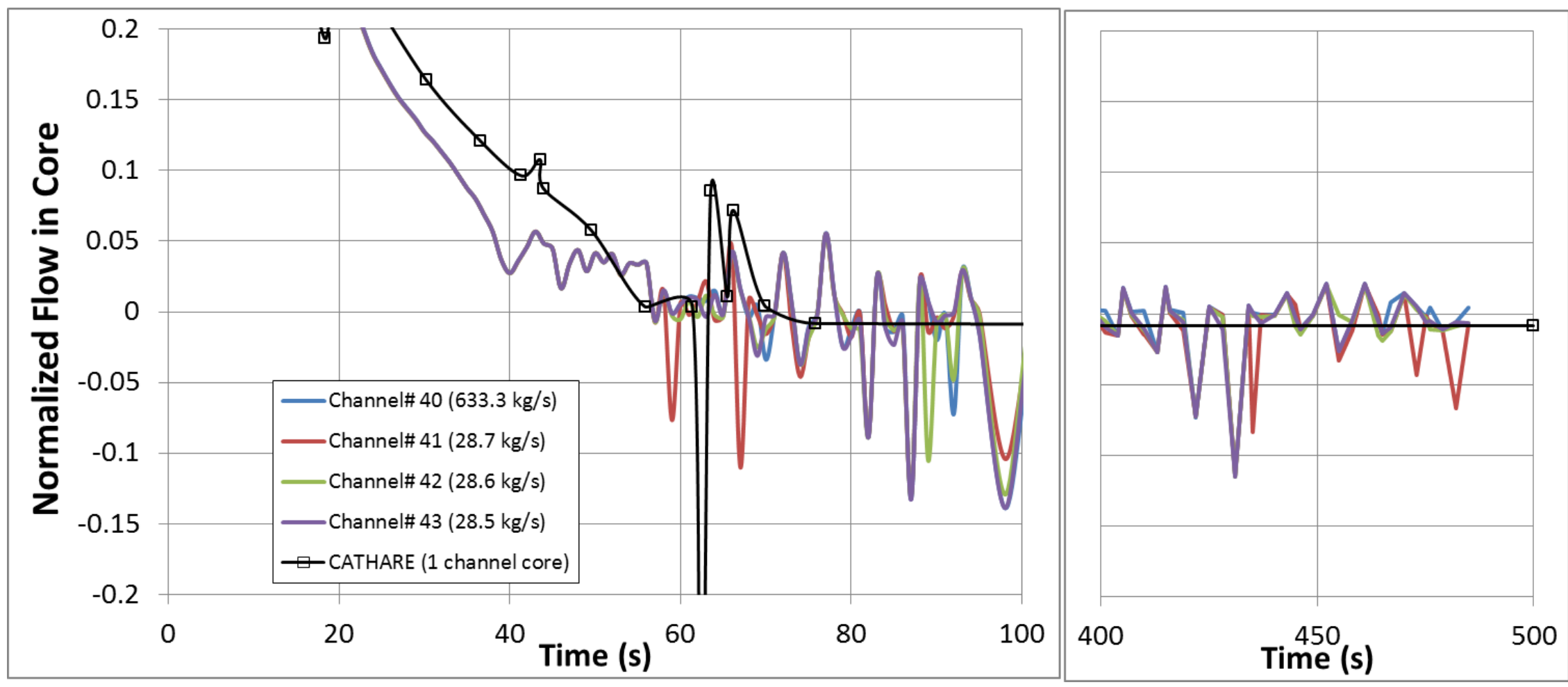

Figure 54 Normalized flow rate in core for four channel model. RELAP5 40(1) 


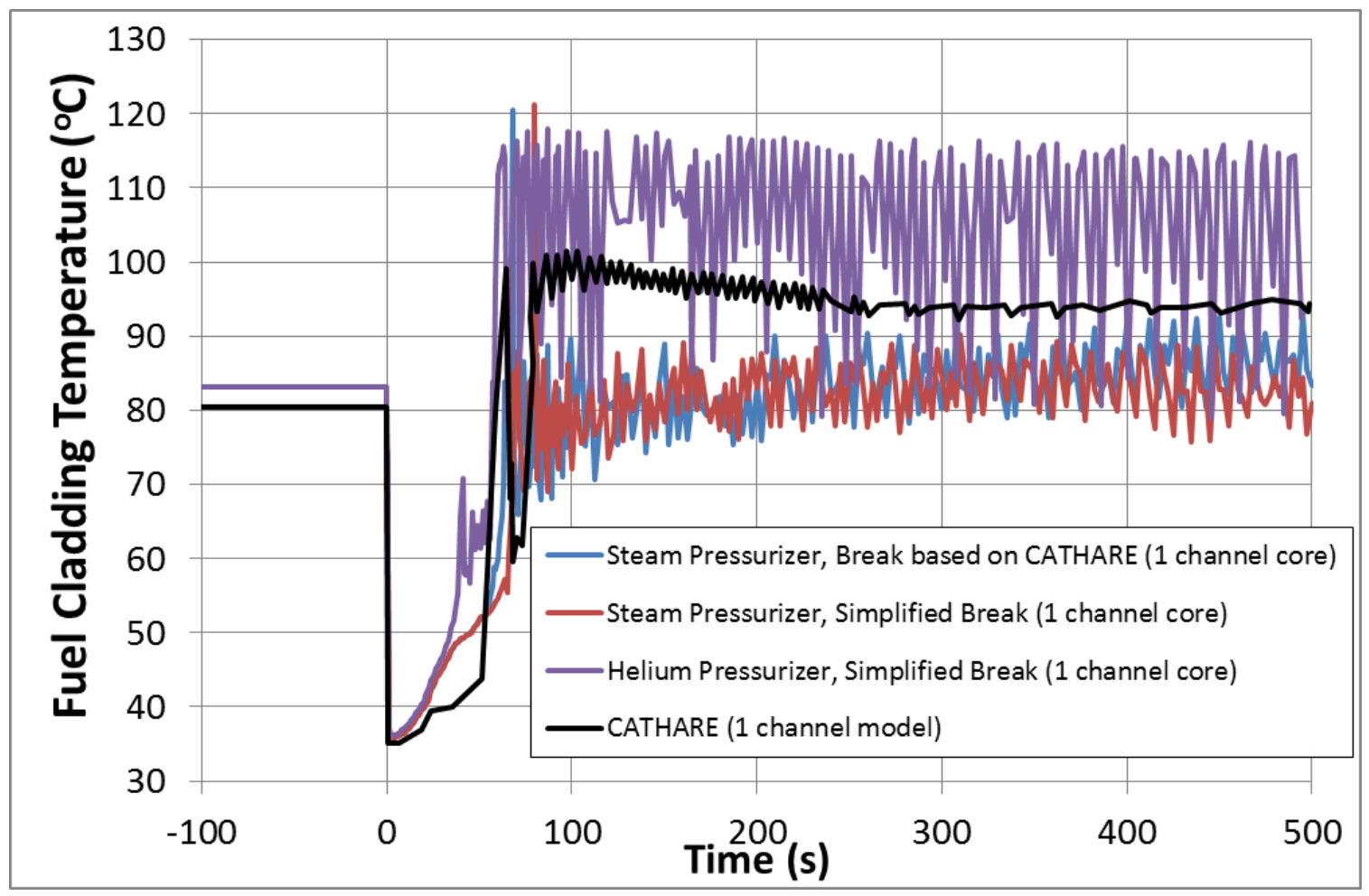

Figure 55 Fuel cladding temperature due to pressurizer gas and break model. RELAP5 41(3)

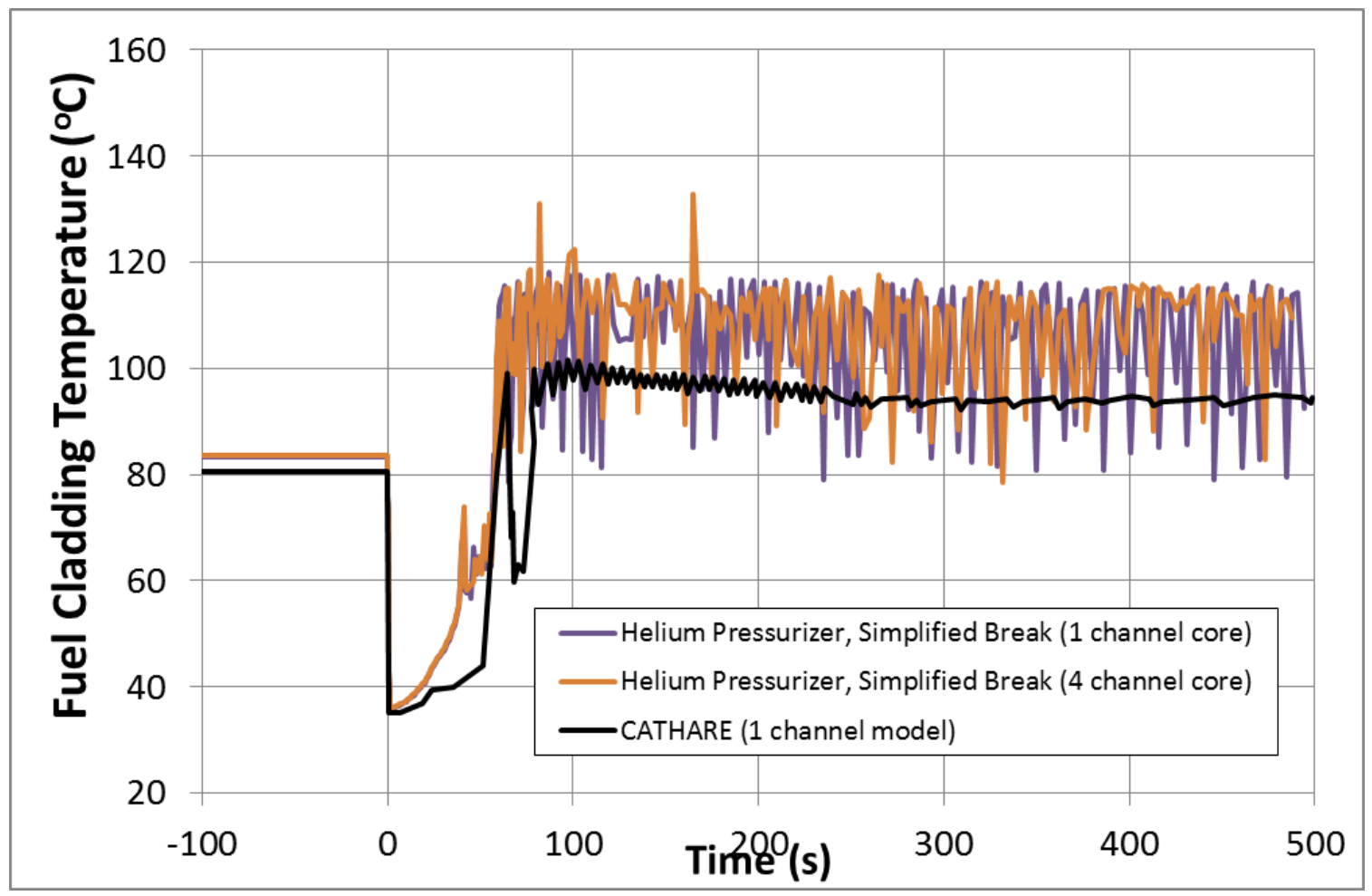

Figure 56 Fuel cladding temperature due to core model. RELAP5 40(3)

Verification of Historical System Transient Simulations for the RHF Research Reactor 


\section{Loss of coolant accident (cold leg break)}

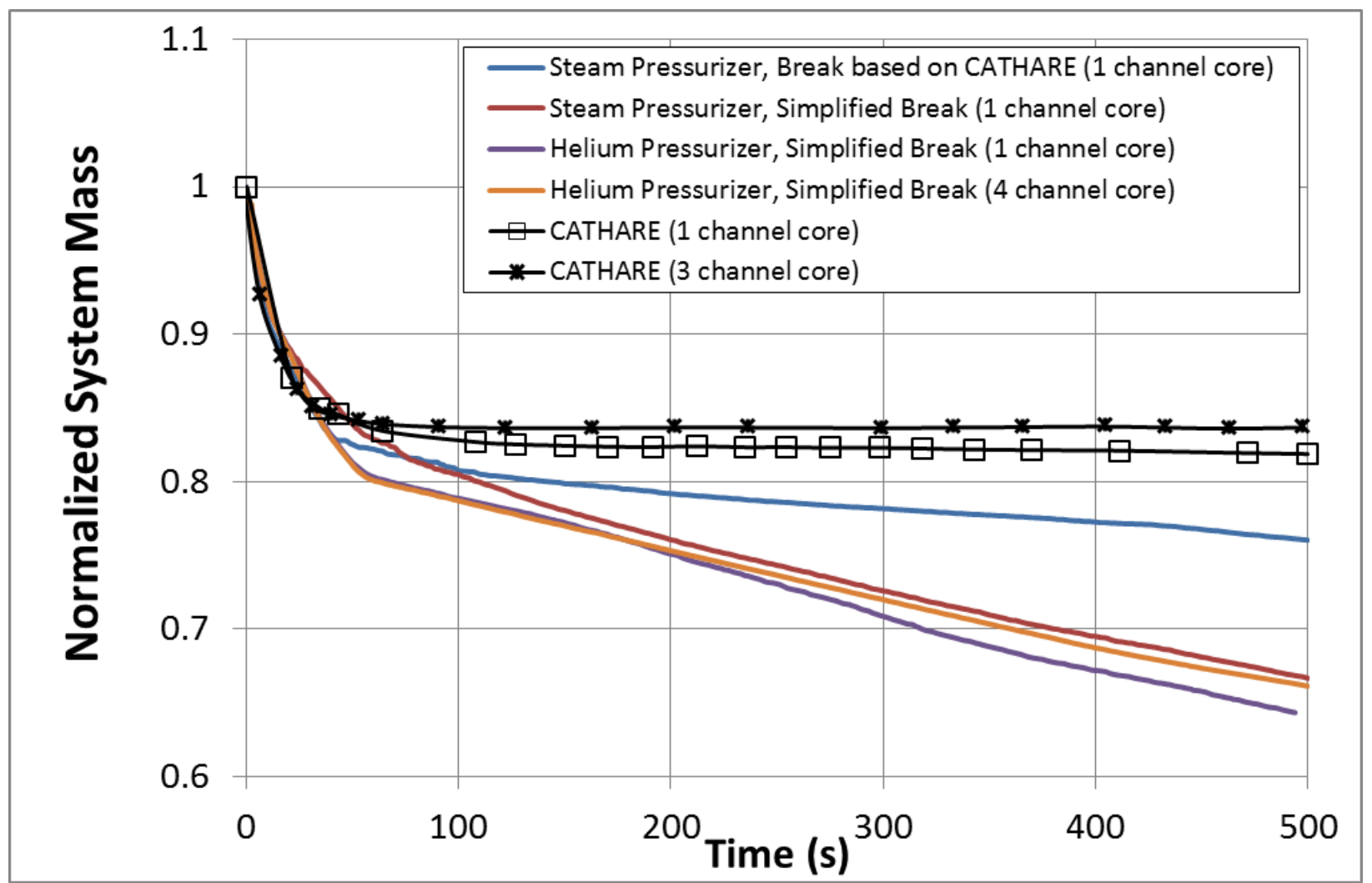

Figure 57 Normalized system mass due to pressurizer gas, break model and core model. Reference mass: RELAP5 = $31987 \mathrm{~kg}$, CATHARE $=32630 \mathrm{~kg}$. 


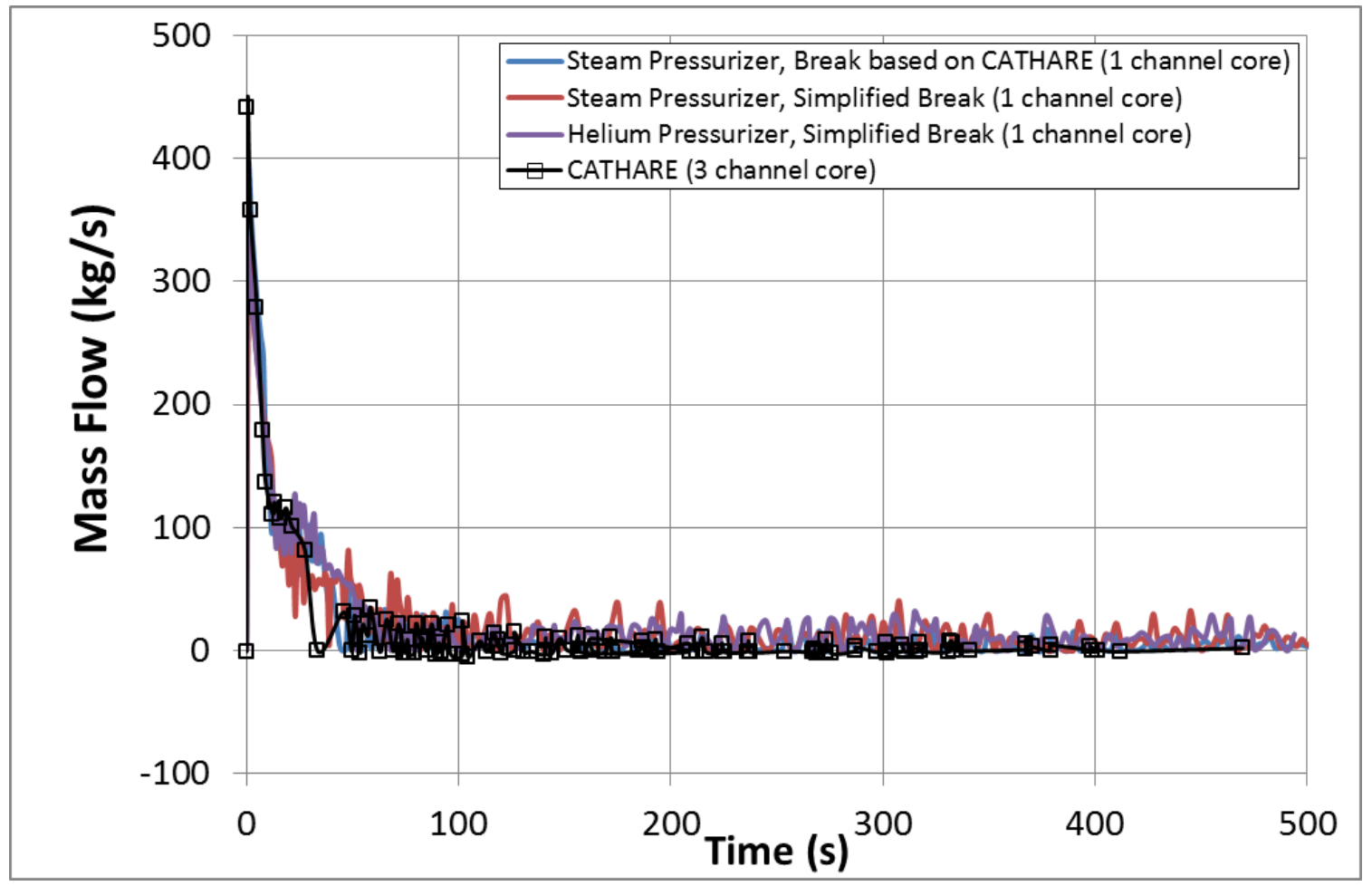

Figure 58 Mass flow through hot leg break due to pressurizer gas and break model. RELAP5 junction 828 (simplified break) and 818 (based on CATHARE).

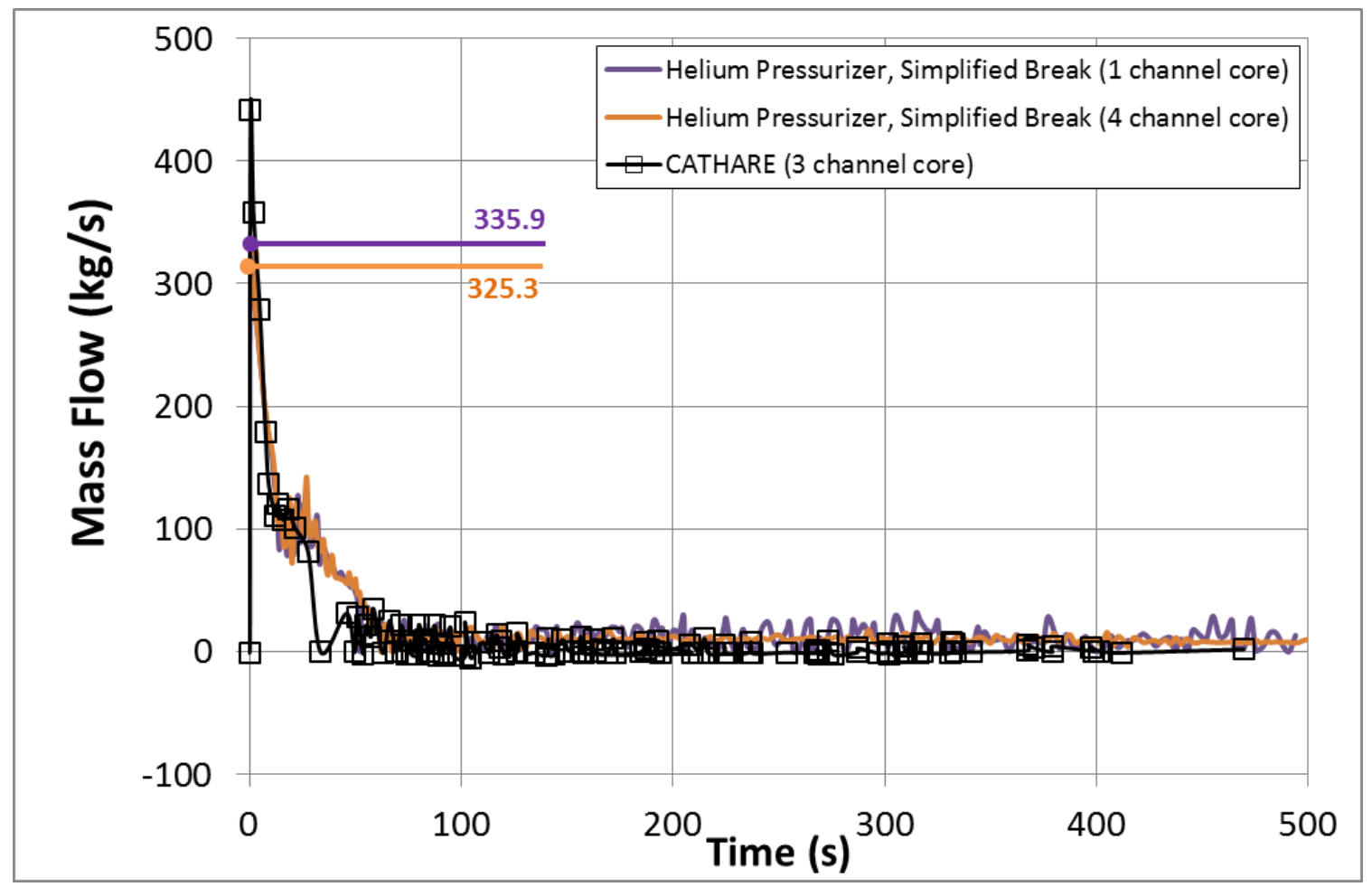

Figure 59 Mass flow through hot leg break due to core model. RELAP5 junction 828 (simplified break) and 818 (based on CATHARE).

Verification of Historical System Transient Simulations for the RHF Research Reactor 


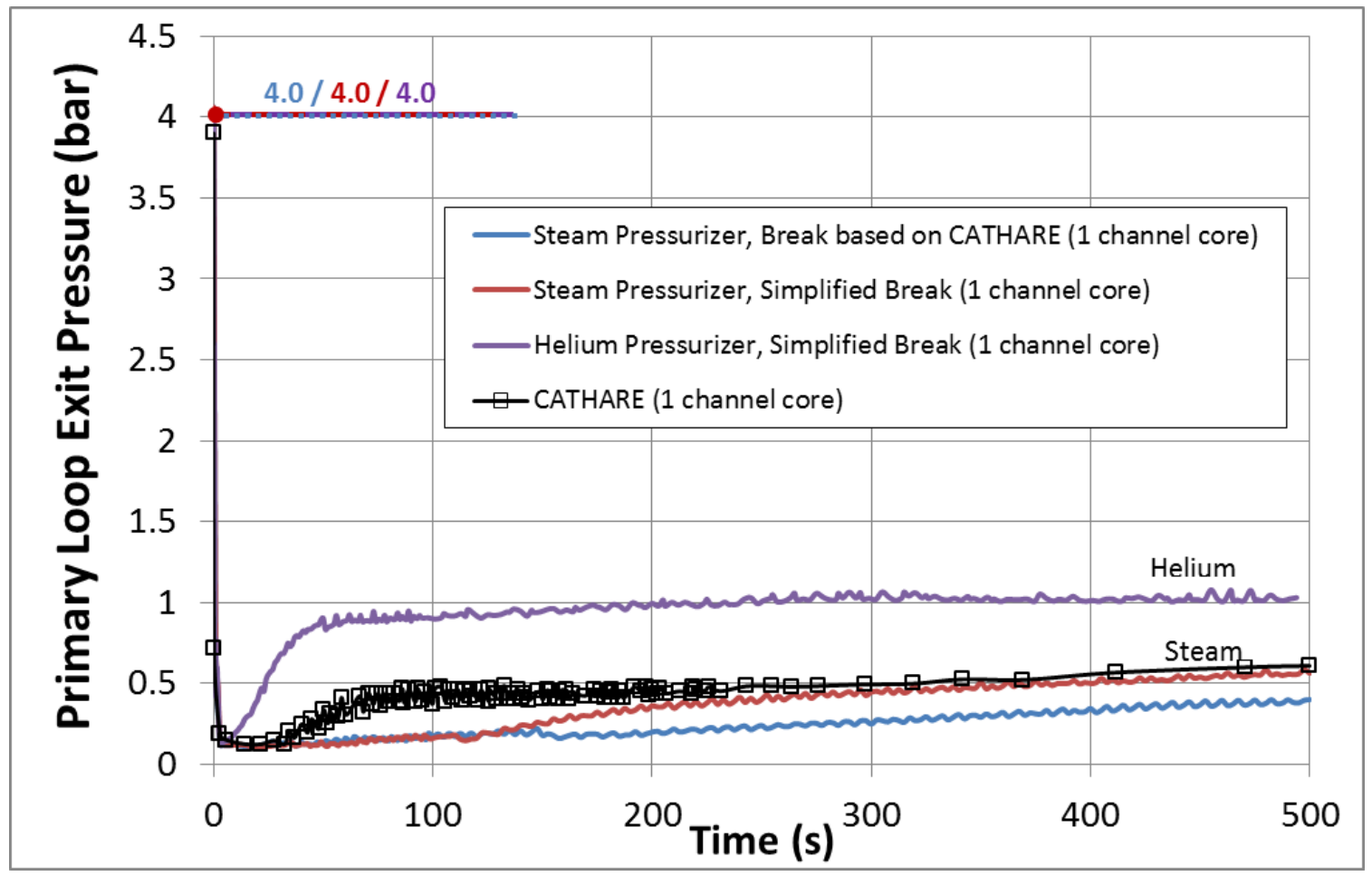

Figure 60 Exit pressure in primary loop due to pressurizer gas and break model. RELAP5 148(3)

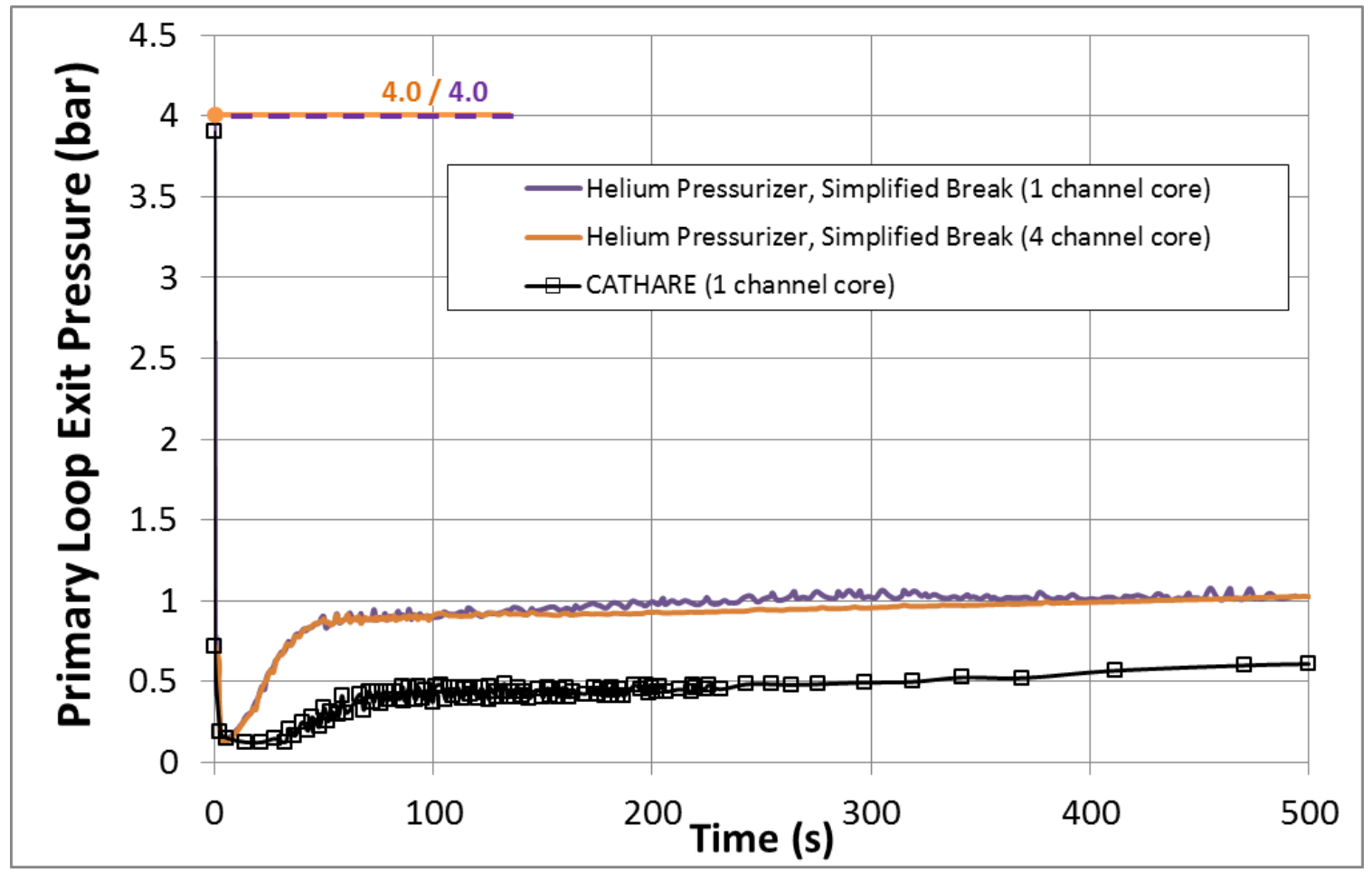

Figure 61 Exit pressure in primary loop due to core model. RELAP5 148(3)

Verification of Historical System Transient Simulations for the RHF Research Reactor 


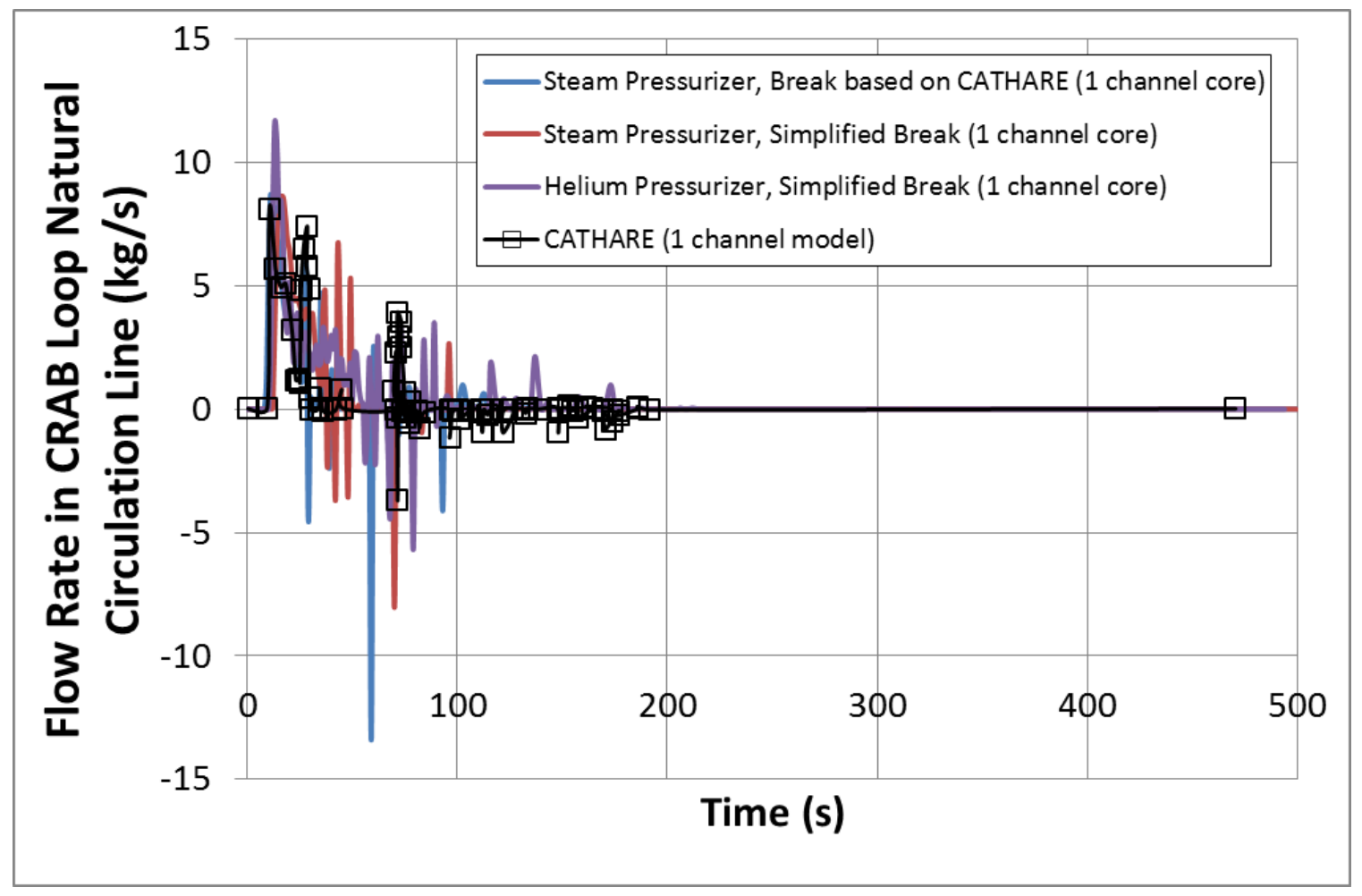

Figure 62 Flow rate in CRAB loop natural circulation line due to pressurizer gas and break model. RELAP5 junction 512

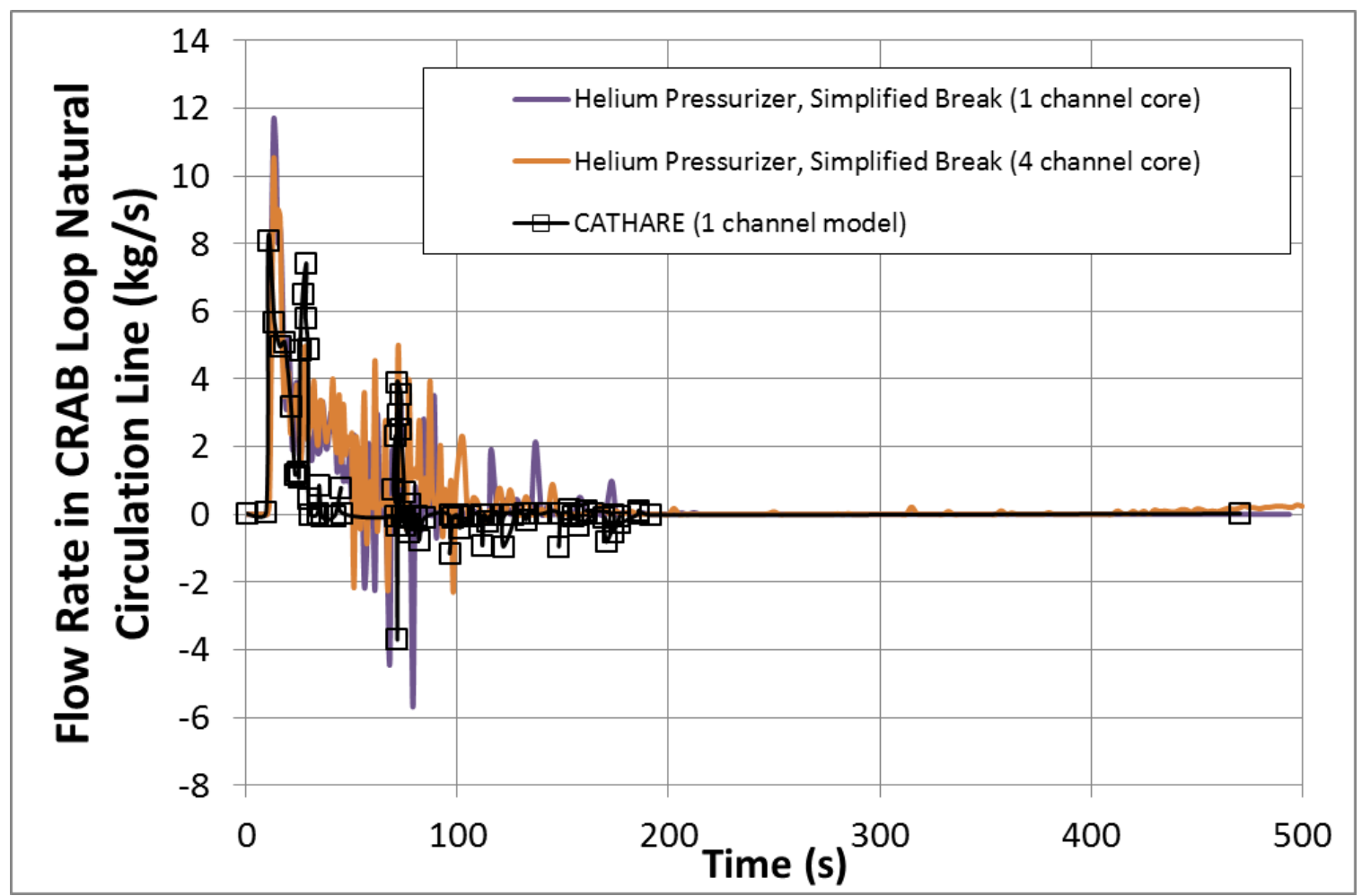

Figure 63 Flow rate in CRAB loop natural circulation line due to core model. RELAP5 junction 512

Verification of Historical System Transient Simulations for the RHF Research Reactor 


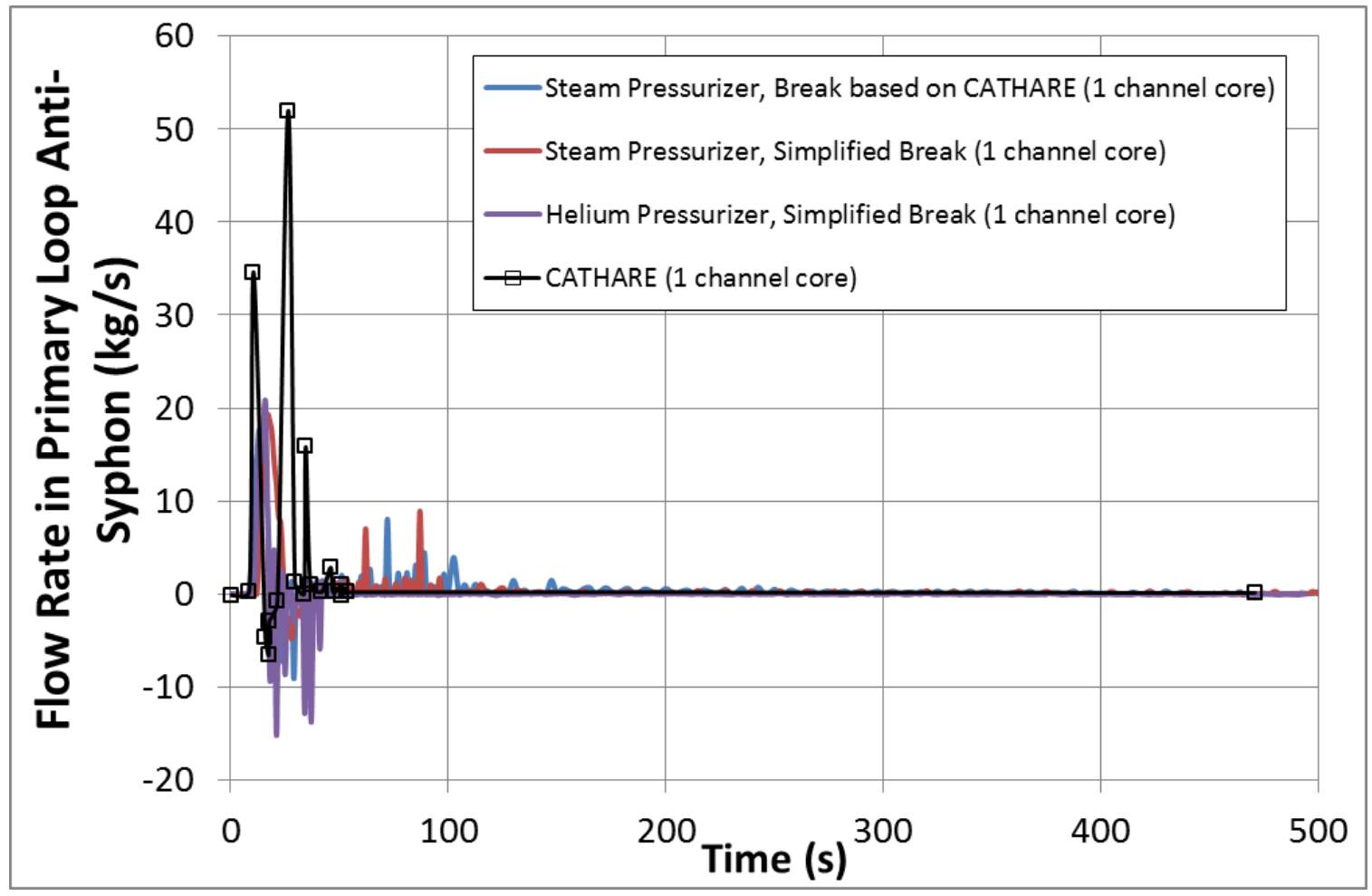

Figure 64 Flow rate in CRAB loop primary loop anti-syphon due to pressurizer gas and break model. RELAP5 junction 282

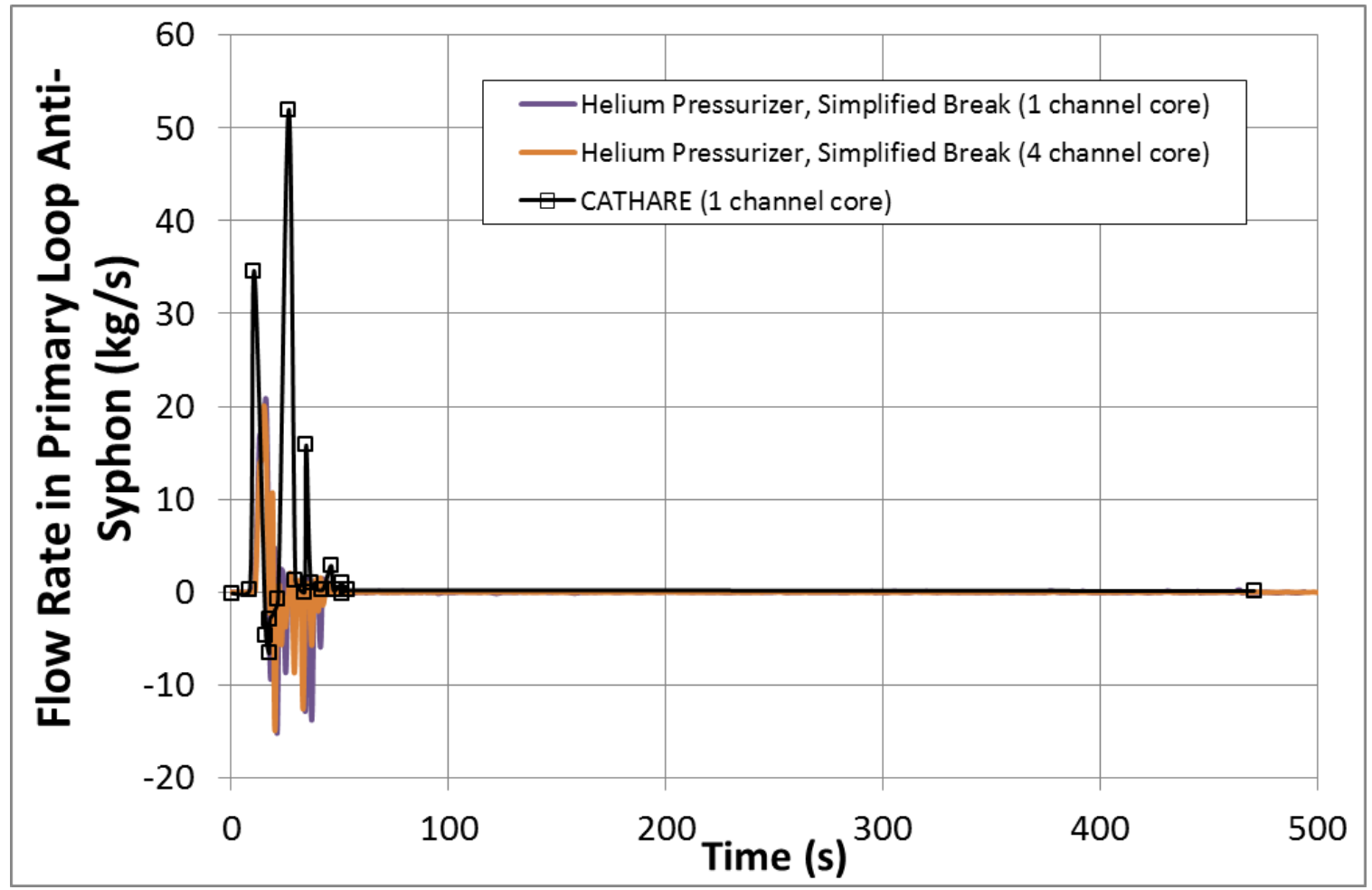

Figure 65 Flow rate in CRAB loop primary loop anti-syphon due to core model. RELAP5 junction 282

Verification of Historical System Transient Simulations for the RHF Research Reactor 


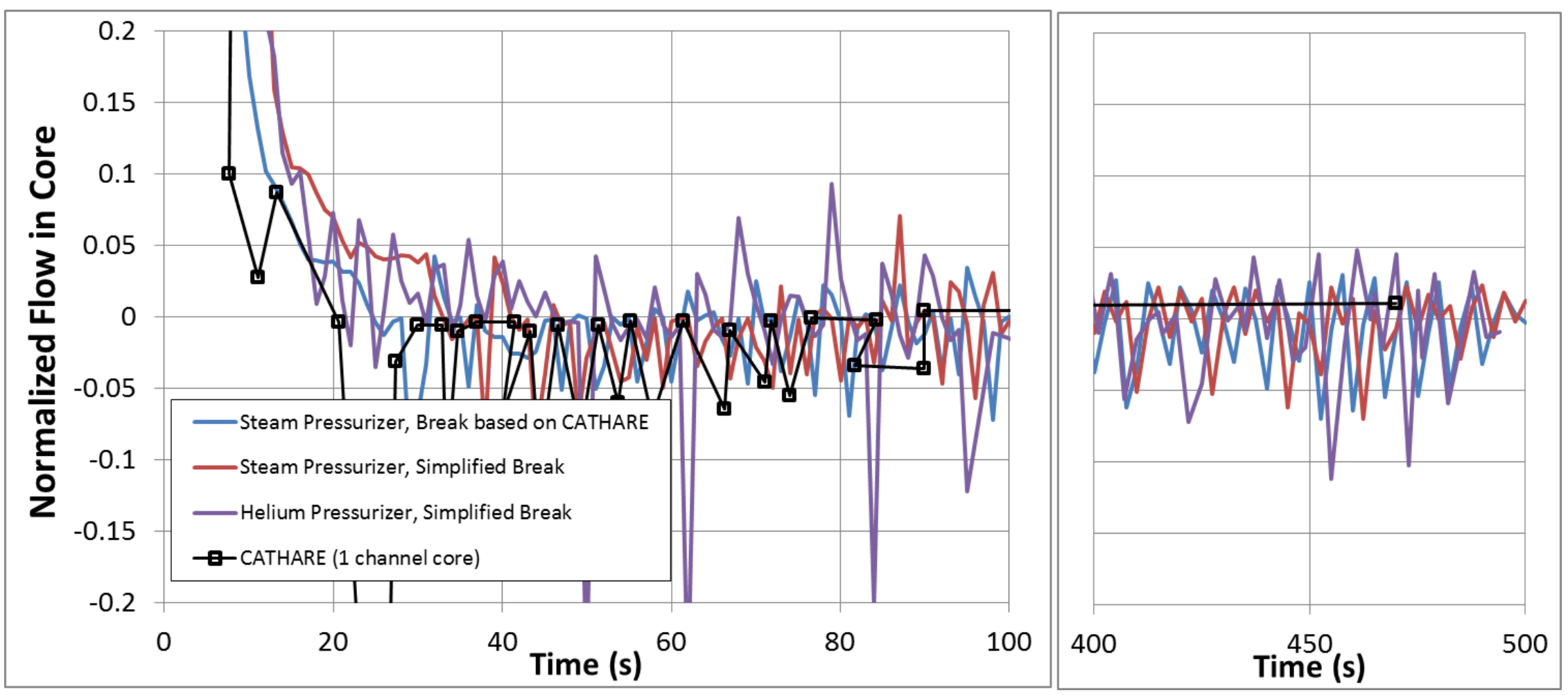

Figure 66 Normalized flow rate in core for single channel model due to pressurizer gas and break model. RELAP5 40(1) 

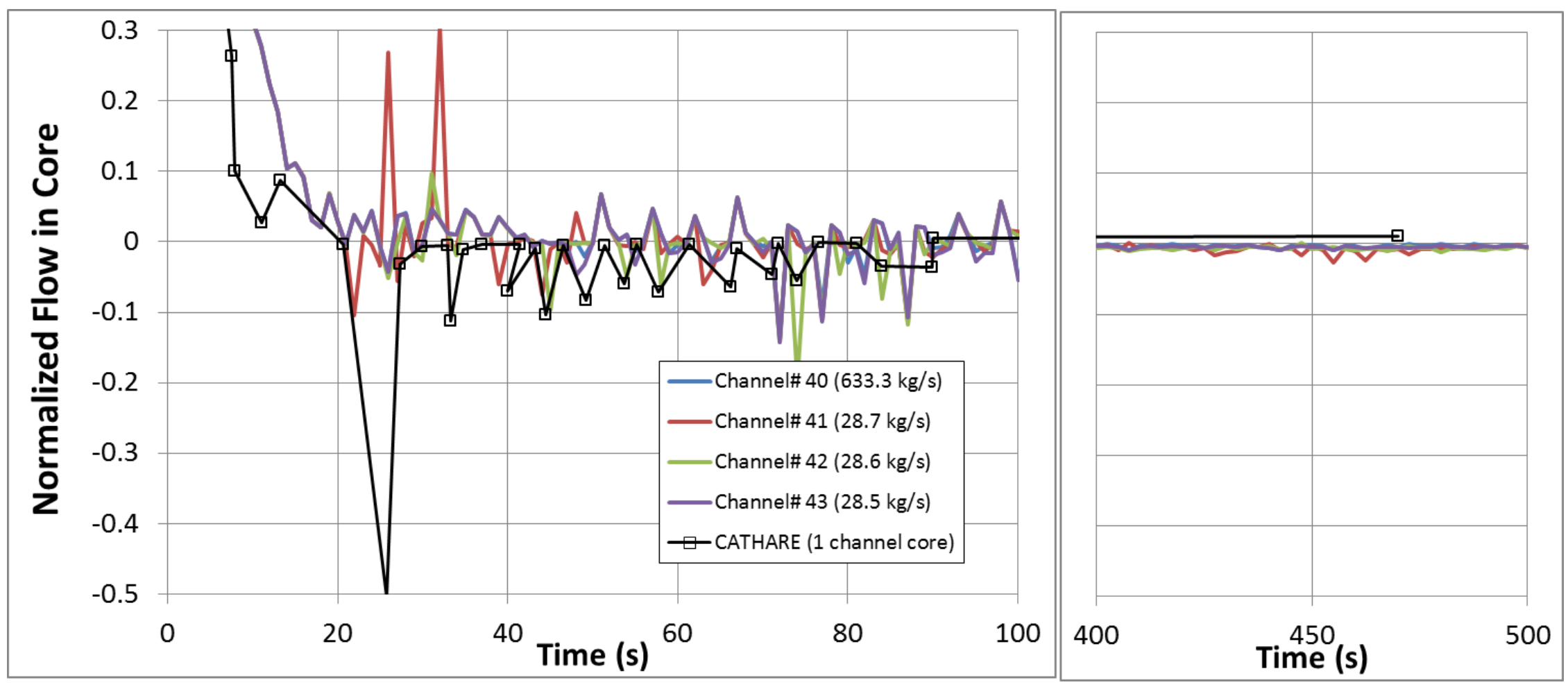

Figure 67 Normalized flow rate in core for four channel model. RELAP5 40(1) 


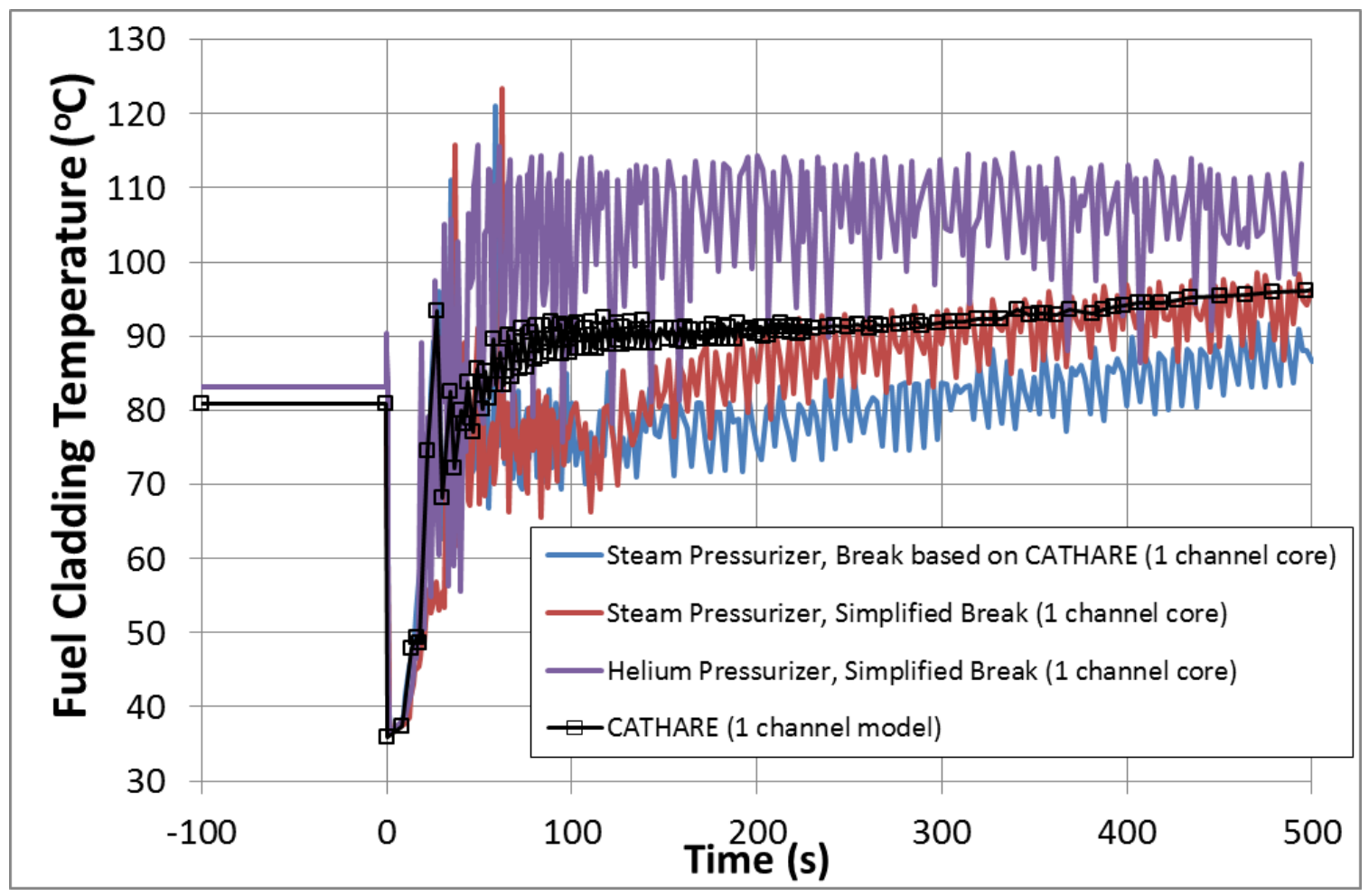

Figure 68 Fuel cladding temperature due to pressurizer gas and break model. RELAP5 41(3)

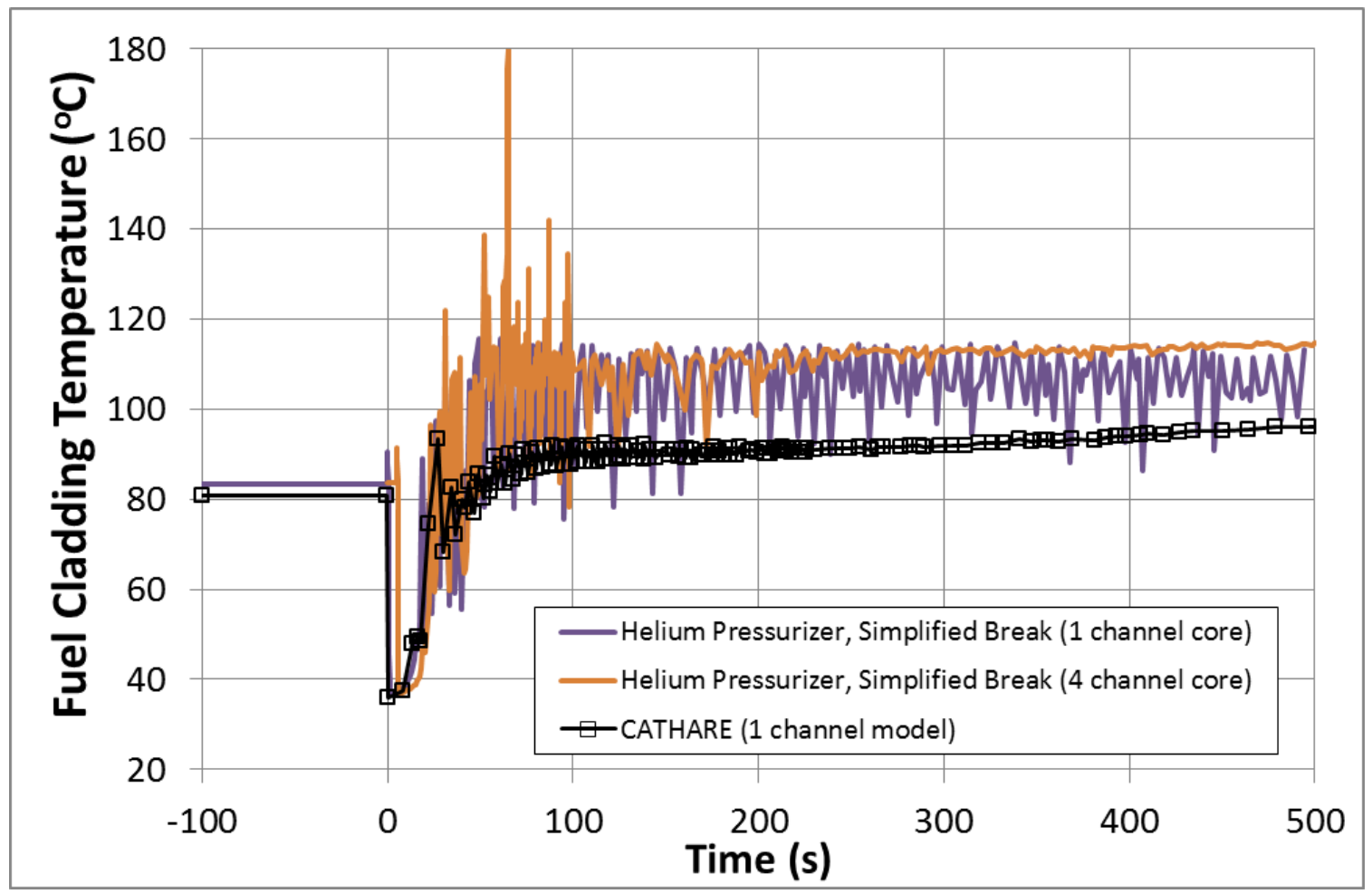

Figure 69 Fuel cladding temperature due to core model. RELAP5 40(3)

Verification of Historical System Transient Simulations for the RHF Research Reactor 


\section{Appendices}

\section{A. Tees}

The first section explicitly describes the Tee junction modeled at RELAP5 volume 134 as an example for how forward and reverse loss coefficients were determined. The second section summarizes information for all RELAP5 Tee junctions.

Figure A-1 illustrates the RELAP5 Tee for the pressurizer pipe (260) connection to the primary outlet pipe (132-136). In addition to the default setting, the y-crossflow has been activated for volume 134 . All ydirection friction has been disabled and the y-length has been specified as the diameter of volume 134.

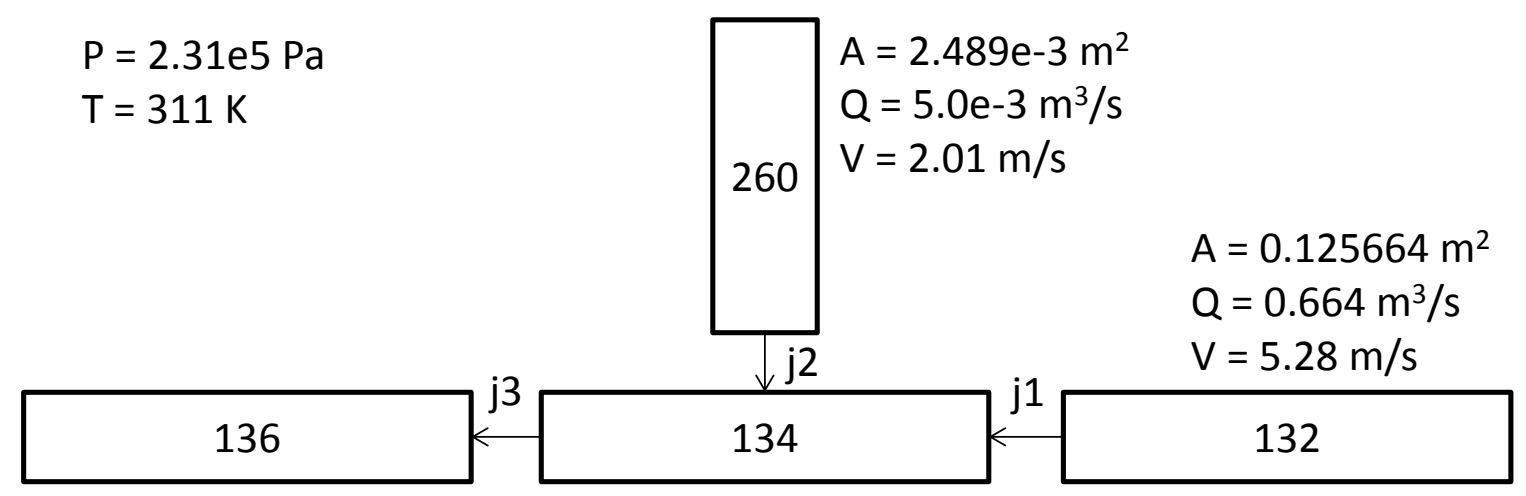

Figure A-1 Tee located at junction of pressurizer and primary piping.

The forward and reverse loss coefficients have been determined by evaluating the difference in predicted loss coefficient values (Idel'chik [11]) and that calculated by the RELAP5 crossflow model under typical normal operating conditions. Although the RELAP5 model utilizes a pressure boundary to replace the pressurizing effect of the pressurizer pumps, the loss coefficients were determined assuming the RHF specified pressurizer pump flow rate. Determining the RELAP5 calculated losses requires describing the momentum equations of the tee for the idealized case of steady-state, single-phase, no gravity, and no friction. The momentum equation at junction 2 is:

$$
P_{260}+\frac{1}{2} \rho\left(V_{260, x}^{2}+\operatorname{dif} v f x_{260, x}\right)=P_{134}+\frac{1}{2} \rho\left(V_{134, y}^{2}+\operatorname{difvfx_{134,y}}\right)+\frac{1}{2} \rho K_{j u n c t i o n} V_{j 2}^{2}
$$

The momentum equation at junction 3 is:

$$
P_{134}+\frac{1}{2} \rho\left(V_{134, x}^{2}+\operatorname{difvf} x_{134, x}\right)=P_{136}+\frac{1}{2} \rho\left(V_{136, x}^{2}+\operatorname{difvfx_{136,x}}\right)
$$

The pressure of volume 134 can be eliminated to obtain an equation resembling the Bernoulli equation:

$$
\begin{aligned}
& P_{260}+\frac{1}{2} \rho V_{260, x}^{2} \\
& =P_{136}+\frac{1}{2} \rho V_{136, x}^{2}+\frac{1}{2} \rho\left(\operatorname{difv} f x_{136, x}-\operatorname{difv} f x_{260, x}\right) \\
& +\frac{1}{2} \rho\left[\left(V_{134, y}^{2}+\operatorname{difvfx_{134,y}}\right)-\left(V_{134, x}^{2}+\operatorname{difvfx_{134,x}}\right)\right]+\frac{1}{2} \rho K_{j u n c t i o n} V_{j 2}^{2}
\end{aligned}
$$


In this form, the RELAP5 calculated loss coefficients can be defined as

$$
\begin{gathered}
K_{1}=\frac{\left(d i f v f x_{136, x}-d i f v f x_{260, x}\right)}{V_{j 2}^{2}} \\
K_{2}=\frac{\left[\left(V_{134, y}^{2}+d i f v f x_{134, y}\right)-\left(V_{134, x}^{2}+d i f v f x_{134, x}\right)\right]}{V_{j 2}^{2}}
\end{gathered}
$$

where they are related to the Idle'chik loss coefficient by:

$$
K_{\text {Idelchik }}=K_{1}+K_{2}+K_{\text {junction }}
$$

The difvf terms are an artificial viscosity defined by:

$$
\operatorname{difvf} x_{\#, x}=V_{\#, x}\left[\frac{1}{2}\left(V_{\text {in }, x}+V_{\text {out }, x}\right)-V_{\#, x}\right]+\frac{1}{2}\left|V_{\#, x}\right|\left(V_{\text {in }, x}-V_{\text {out }, x}\right)
$$

The difvf $x_{136, x}$, difvf $x_{260, x}$ and difv $f x_{134, y}$ terms are zero since the inlet, outlet and mean velocities are identical. Only the $\operatorname{dif} v f x_{134, x}$ representing the junction volume is non-zero. The mean velocity in the $y$-direction is determined by the RELAP5 definitions of length and area in the cross flow model. If the user does not select the cross flow model but makes a cross flow connection, the default values are used with the $y$-direction friction enabled. Thus, the user must activate the cross flow model and de-activate the $y$-direction friction. By default, the $y$-direction length is based on the $x$-direction diameter. This then fixes the $y$-direction area since the volume is conserved in both directions. The mean velocity in the $y$ direction is then determined by the branch velocity times the ratio of $y$-direction area and branch area (conservation of mass). For this example we find that:

$$
\begin{gathered}
K_{1}=\frac{\left(d i f v f x_{136, x}-d i f v f x_{260, x}\right)}{V_{j 2}^{2}}=0 \\
K_{2}=\frac{\left[\left(-7.96 e^{-2}\right)^{2}-\left((5.3)^{2}-0.106\right)\right]}{(2.01)^{2}}=-6.925
\end{gathered}
$$

The target loss term for a converging tee can be determined from Idelchik table 7-7:

$$
K_{\text {Idelchik }}=A\left[1+\left(\frac{V_{260}}{V_{136}}\right)^{2}-2\left(1-\frac{Q_{260}}{Q_{136}}\right)\right]=-0.842
$$

These results are then used to determine the addition loss factor ( $\left.K_{\text {junction }}\right)$ required to achieve the target Idel'chik loss value in the RELAP5 simulation:

$$
K_{\text {junction }}=K_{\text {Idelchik }}-K_{1}-K_{2}=-0.842-0+6.925=6.083
$$




\section{Tee 134 (reverse)}

The same procedure as described above can be used to determine the reverse loss coefficient for a diverging tee (the pressurizer flow rate has been reversed) with a few minor changes. The RELAP5 loss coefficients $K_{1}$ and $K_{2}$ are unchanged except for the terms 136 have been replaced with 132:

$$
\begin{gathered}
K_{1}=0 \\
K_{2}=\frac{\left[\left(\left(7.96 e^{-2}\right)^{2}-0\right)-\left(5.3^{2}+0.106\right)\right]}{2.01^{2}}=-6.977
\end{gathered}
$$

The loss term for a diverging tee was determined from Idel'chik Table 7-21:

$$
K_{\text {Idelchik }}=A^{\prime}\left[1+\left(\frac{V_{260}}{V_{132}}\right)^{2}-2 \frac{V_{260}}{V_{132}} \cos (\theta)\right]=1.145
$$

Combining the above terms the additional loss coefficient required in RELAP5 is:

$$
K_{\text {junction }}=K_{\text {Idelchik }}-K_{1}-K_{2}=1.145-0+6.977=8.122
$$

\section{$\underline{\text { RELAP5 tee's }}$}

Table A-1 summarizes the properties of each tee and the calculation results used to obtain the loss coefficients. The same process described in the previous section was used for determining the loss coefficients for the tee junction at volume 250 . The remaining tee junctions are only active when the natural circulation valves open. Because each of the branch and channel flows change with time and the Idle'chik loss coefficients are dependent on flow and velocity ratios, preliminary simulation results were reviewed to determine a representative flow rate distribution.

Tee 24 results indicated that the mass flow rate in the branch remained relatively close to one half the value in the strait both before and after flow reversal. The channel velocity remained less than $0.1 \mathrm{~m} / \mathrm{s}$ for prior to and following flow reversal in the core. These values result in quite a large pressure loss for both forward and reverse values. This is a diverging tee except for the brief period when flow reversal occurs.

Tee 462 is symmetrical tee in which the majority of the flow comes from the control rod from the first $400 \mathrm{~s}$ of the transient. The calculations were performed at the limit of all flow coming from one branch and results in a forward and reverse loss coefficient of 1.84 .

Tee 132 remains a converging tee throughout the transient with branch mass flow rate being 0.25 times the channel flow rate prior to flow reversal (240 s) and approximately this value for as long as 275 seconds. After this the ratio quickly approaches one. A ratio of 0.25 was used for the calculations. A velocity of $0.27 \mathrm{~m} / \mathrm{s}$ was chosen as the reference velocity of the channel.

Tee 248 behaved similar to tee 132 (within the same natural circulation piping). A velocity in the channel of $0.75 \mathrm{~m} / \mathrm{s}$ was chosen since this is the value just prior to flow reversal in the core. 
Table A-1 Tee parameters for RELAP5 model (NC = valves are activated in the case of natural circulation)

\begin{tabular}{|c|c|c|c|c|c|c|}
\hline Tee\# & 134 & 250 & $24(\mathrm{NC})$ & $462(\mathrm{NC})$ & $132(\mathrm{NC})$ & $248(\mathrm{NC})$ \\
\hline \multicolumn{7}{|l|}{ Connected cell parameters } \\
\hline Branch Area $\left(\mathrm{m}^{2}\right)$ & 2.49E-03 & $2.01 \mathrm{E}-04$ & $1.51 \mathrm{E}-02$ & 5.03E-03 & 0.015394 & 0.015394 \\
\hline $\mathrm{Y}$ velocity $(\mathrm{m} / \mathrm{s})$ & 2.01 & $-5.53 E+00$ & $\begin{array}{c}-7.02 \mathrm{E}- \\
01\end{array}$ & $-2.00 \mathrm{E}+0$ & $5.51 \mathrm{E}-01$ & $-2.04 \mathrm{E}+0$ \\
\hline \multicolumn{7}{|l|}{ Junction cell parameters } \\
\hline $\mathrm{X}$ length $(\mathrm{m})$ & 0.2 & 0.2 & 0.436 & 0.2 & 0.2 & 0.1545 \\
\hline $\mathrm{X}$ area $\left(\mathrm{m}^{2}\right)$ & 0.125664 & 0.125664 & 0.141196 & $5.03 E-03$ & 0.125664 & 0.125664 \\
\hline Volume $\left(\mathrm{m}^{3}\right)$ & 0.0251328 & 0.025133 & 0.061561 & 0.001005 & 0.025133 & 0.019415 \\
\hline$X$ diameter $(\mathrm{m})$ & 0.40000047 & 0.4 & 0.424 & 0.08 & 0.4 & 0.4 \\
\hline$X$ velocity in (small, $\mathrm{m} / \mathrm{s}$ ) & 5.28 & 5.311784 & 0.075 & 0 & 0.2025 & 1 \\
\hline$X$ velocity out (large, $\mathrm{m} / \mathrm{s}$ ) & 5.32 & 5.320626 & 0.15 & $2.00 \mathrm{E}+00$ & $2.70 \mathrm{E}-01$ & $7.50 \mathrm{E}-01$ \\
\hline Y length $(\mathrm{m})$ & 0.40000047 & 0.4 & 0.424 & 0.08 & 0.4 & 0.4 \\
\hline Y Area $\left(\mathrm{m}^{2}\right)$ & 0.06283193 & 0.062832 & 0.145192 & 0.012566 & 0.062832 & 0.048538 \\
\hline $\mathrm{X}$ mean velocity $(\mathrm{m} / \mathrm{s})$ & 5.3 & 5.316205 & 0.1125 & 1 & 0.23625 & 0.875 \\
\hline \multicolumn{7}{|l|}{ Converging Tee Results } \\
\hline$X$ DIFVFX $\left(\mathrm{m}^{2} / \mathrm{s}^{2}\right)$ & -0.106 & -0.0235 & -0.00422 & -1 & -0.00797 & 0.109375 \\
\hline Y MEAN VELOCITY $(\mathrm{m} / \mathrm{s})$ & $-7.96 \mathrm{E}-02$ & $1.77 \mathrm{E}-02$ & $7.29 E-02$ & 8.00E-01 & $-1.35 \mathrm{E}-01$ & $6.47 \mathrm{E}-01$ \\
\hline K2 & -6.925 & -0.924 & -0.006 & & -0.098 & -0.110 \\
\hline K_Idel'chik (7-7) & -0.842 & 0.076 & 19.917 & & 3.665 & 5.738 \\
\hline K_Junction & 6.083 & 1.000 & 19.923 & & 3.762 & 5.847 \\
\hline \multicolumn{7}{|l|}{ Diverging Tee Results } \\
\hline X DIFVFX $\left(\mathrm{m}^{2} / \mathrm{s}^{2}\right)$ & 0.106 & 0.023503 & 0.004219 & 1 & 0.007973 & -0.10938 \\
\hline Y MEAN VELOCITY $(\mathrm{m} / \mathrm{s})$ & 0.07962337 & -0.01768 & -0.07294 & -0.8 & 0.135 & -0.64725 \\
\hline $\mathrm{K} 2$ & -6.977 & -0.926 & -0.023 & & -0.150 & -0.057 \\
\hline K_Idel'chik (7-21) & 1.143 & 2.079 & 22.917 & & 5.165 & 8.404 \\
\hline K_Junction & 8.120 & 3.005 & 22.94 & & 5.315 & 8.461 \\
\hline \multicolumn{7}{|l|}{ Symmetric Tee Results } \\
\hline K2 & & & & 0.160 & & \\
\hline K_Idel'chik (7-29) & & & & 2.000 & & \\
\hline K_Junction & & & & 1.840 & & \\
\hline
\end{tabular}


(This page intentionally left blank) 


\section{Argonne}

\section{Nuclear Engineering Division}

Argonne National Laboratory

9700 South Cass Avenue, Bldg. 208

Argonne, IL 60439-4842

www.anl.gov

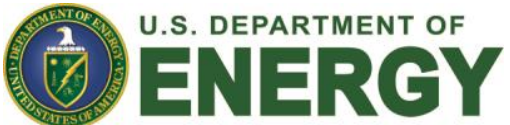

Argonne National Laboratory is a U.S. Department of Energy laboratory managed by UChicago Argonne, LLC 